\title{
Geología del yacimiento de Fe-Pb-Ag de la Mina Rica de Pulpí (Almería, España)
}

\author{
Fernando J. Palero(1), Àngels Canals ${ }^{(2)}$, Alexander van Driessche ${ }^{(3)}$ y Juan Manuel García-Ruiz ${ }^{(1)}$ \\ (1) Laboratorio de Estudios Cristalográficos, Instituto Andaluz de Ciencias de la Tierra, \\ Consejo Superior de Investigaciones Científicas-Universidad de Granada, E-18100 Armilla, Granada, España. \\ (2) Departamento de Mineralogía, Petrología y Geología Aplicada, Facultad de Ciencias de la Tierra \\ Universidad de Barcelona, 08028 Barcelona, España. \\ (3) Université Grenoble Alpes, Université Savoie Mont Blanc, CNRS, IRD, IFSTTAR, ISTerre, 38000 Grenoble, France.
}

\begin{abstract}
RESUMEN
La Mina Rica, situada en la pedanía del Pilar de Jaravía, en el municipio de Pulpi (Almería, España), es hoy internacionalmente conocida por la gran geoda de yeso selenítico descubierta en su interior. El yacimiento explotado en ella para el beneficio del $\mathrm{Fe}, \mathrm{Pb}$ y Ag se localiza en una banda de cizalla NE-SW dextral, afectada por un sistema de fallas NNESSW, de componente sinestral. El yacimiento lo forman dos bloques hectométricos de roca poco deformada con forma lenticular (lentejones tectónicos), constituidos por una alternancia replegada y fallada de calizas y dolomías, y en menor cantidad yesos y filitas, todo ello con orientación general NNE-SSW y fuerte buzamiento al W. En la secuencia temporal de las fases minerales presentes en la Mina Rica se distingue una primera mineralización estratoligada de carbonatos de hierro que fosiliza la deformación de edad Serravaliense. A los rejuegos Tortonienses se asocia una mineralización de barita y a los Messinienses de celestina. El yeso cristalizado a temperatura por debajo de los $25^{\circ} \mathrm{C}$, es la última fase sulfatada en formarse y lo hace con posterioridad a los rejuegos verticales Pliocenos. Este estudio-cuyo soporte cartográfico ha servido como base para los trabajos de recuperación y musealización de la mina- nos ha permitido descubrir las enormes posibilidades de la Mina Rica como centro de interpretación geológica y geominera, más allá del indudable aliciente de su gran geoda. Los resultados presentados en este trabajo pueden servir como base de una utilización de la Mina Rica como herramienta didáctica para la formación de futuras generaciones de geólogos e ingenieros de mina.
\end{abstract}

Palabras clave: Cordilleras Béticas, Geoda de Pulpí,Yacimientos de plomo-plata, Yacimientos de hierro, Yeso.

\section{Geology of the Fe-Pb-Ag "Mina Rica" deposit, Pulpí (Almería, Spain)}

\begin{abstract}
The "Mina Rica" (the Rich Mine), located in the district of Pilar de Jaravía, in the municipality of Pulpi (Almería province, Spain), has become internationally renowned for the great geode of selenite gypsum discovered in its interior. The ore deposit is located in a NE-SW dextral shear band, affected by a system of NNE-SSW sinistral faults. The deposit is composed of two hectometric blocks of weakly deformed rocks with a pod shape, which are constituted by a folded and faulted alternation of limestone and dolomites, and to a lesser amount, gypsum and phyllites, all with a general NNESSW orientation and strong dipping to the W. In the time sequence of the mineral phases present in the "Mina Rica" we can distinguish a first stratabound, mineralization of iron carbonates that fossilizes the Serravallian age deformation. Baryte mineralization is associated with the Tortonian movements and celestine mineralization with the Messinian ones. Gypsum, which crystallized at a temperature of below $25^{\circ} \mathrm{C}$, was the last major sulphated mineral phase to be formed, and this took place after the Pliocene vertical replays. Moreover, this study - the cartographic underpinning of which has served as the basis for the recovery and musealization of the mine-has enabled us to discover the enormous potential that the "Mina Rica" has as a centre for geological and geo-mining practical teaching, beyond the indisputable lure of its Great Geode. We foresee that the results presented in this study will be the basis for the use of the "Mina Rica" as an educational tool to help train future generations of geologists and mining engineers.
\end{abstract}

Keywords: Betic mountain ranges, Geode of Pulpí, Lead-silver ore, Iron ore, Gypsum. 


\section{Introducción}

La Mina Rica se halla en el municipio de Pulpí, en el extremo NE de la provincia de Almería, al pie de la ladera oriental de la Sierra del Aguilón y junto a la pedanía del Pilar de Jaravía (Fig.1). Este yacimiento fue una de las explotaciones de mineral de hierro del SE de la Península Ibérica que estuvieron activas a finales del siglo XIX y principios del XX. Estas mineralizaciones ferruginosas aparecen ampliamente distribuidas por las provincias de Granada, Almería y Murcia, pero esta mina almeriense presentaba algunas peculiaridades mineralógicas, entre ellas una mineralización de sulfuros, que le otorgaron nuevas posibilidades productivas beneficiando en la segunda mitad del siglo $\mathrm{XX}$ el plomo argentífero.

Fundamentalmente, el yacimiento corresponde a un reemplazamiento por carbonatos de hierro de las rocas carbonatadas triásicas de la Cordillera Bética que, al quedar expuestos a la atmósfera, se meteorizaron. Las monteras de óxidos de hierro fueron el objeto de la primera explotación minera a gran escala. La situación superficial de estos minerales, muchas veces ligados a crestones rocosos que dan lugar a relieves positivos, facilitaron su explotación a cielo abierto mediante cortas de formas irregulares que intentaban ceñirse a las masas de mineral oxidado. Al profundizar estas labores se encontraba la mineralización primaria de carbonatos de hierro (ankerita y/o siderita) obligando a cambiar a una minería subterránea. El beneficio de los carbonatos suponía una notable merma en el contenido en hierro, lo que exigía practicar una calcinación para poder obtener un producto oxidado con un contenido de metal aceptable por las plantas siderúrgicas. En el caso de la Mina Rica esta práctica facilitaba además la eliminación de muchas de las impurezas que llevaba el mineral crudo. Hoy día aún se conservan a pie de mina un par de hornos destinados a aquella función. Después de años de inactividad, la instalación de un lavadero de flotación a principios de los 60 del siglo XX, permitió el aprovechamiento de los dispersos minerales de $\mathrm{Pb}$ y Ag que había en yacimiento.

En el conjunto paragenético de este yacimiento, además de las mineralizaciones de hierro y sulfuros de plomo y plata, hay otra abundante mineralización sulfatada con barita, celestina y yeso selenítico, que aparece principalmente en oquedades tanto dentro de los cuerpos de carbonatos de hierro como en estructuras independientes que los cortan. Estas mineralizaciones presentan un elevado grado de cristalinidad, lo que supuso en la década de los años 90 un atractivo para aficionados a la mineralogía que volvieron a resucitar el interés por la mina, prácticamente olvidada desde su cierre a finales de la década de 1960. Esta actividad dio lugar al descubrimiento en diciembre de 1999 de una geoda de yeso selenítico de once metros cúbicos de volumen con cristales de hasta dos metros de tamaño que atrajo también la atención de la comunidad científica y geominera (Palero et al., 2000; García-Guinea et al., 2002; García-Ruiz et al., 2008).

El interés del Laboratorio de Estudios Cristalográficos en el estudio de la formación de cristales gigantes (García-Ruiz et al., 2007; García-Ruiz 2007; Van Driessche et al., 2011; Otálora y García-Ruiz, 2013) nos llevó a interesarnos pronto por el origen de esos megacristales de yeso. Tras varios años de trabajo, la investigación culminó en un estudio exhaustivo del contexto geológico en el que se formaron las geodas y los grandes cristales de yeso de la Mina Rica. Los resultados de esa investigación, que incluye también estudios geoquímicos, isotópicos, medidas de inclusiones fluidas, y un modelo cristalogenético, ha sido publicado recientemente (Canals et al., 2019). Sin embargo, durante estos diez años de investigación hemos descubierto que, más allá del indudable interés mineralógico y geoturístico de la justamente llamada "Gran Geoda de Pulpí," el yacimiento en sí mismo tiene unas peculiaridades geológicas y geomineras que lo hacen de gran interés, pudiendo ser considerado como un compendio de la metalogenia del SE peninsular. Por esta razón creemos que era conveniente hacer público los trabajos adicionales de topografía, cartografía geológica, geología estructural y mineralogía que hemos realizado durante estos años. Estos estudios, que han sido utilizados como la base de la reciente rehabilitación y musealización de la Mina, pueden servir también para promover visitas especializadas para profesionales e instituciones educativas superiores.

\section{Descripción de la mina}

La explotación de la Mina Rica se llevó a cabo en dos sectores que coinciden básicamente con las concesiones mineras 'Quien Tal Pensara' (OTP), en la parte nororiental, $y$ 'Por Si Acaso' (PSA), en la suroccidental (Fig. 2). Estas dos concesiones cubrían prácticamente la casi totalidad del yacimiento, que se halla en una serie de crestones carbonatados discontinuos orientados NE-SW. La explotación inicial a cielo abierto se hizo mediante zanjones irregulares, reconociéndose actualmente tres grandes excavaciones situadas dos de ellas sobre QTP y otra en PSA (Fig. 2).

Para el desarrollo de la minería subterránea se excavó un socavón en crucero de $100 \mathrm{~m}$ de longitud que al alcanzar las zonas mineralizadas se abría en dos galerías en dirección que iban hacia el NE y SW. De estas 


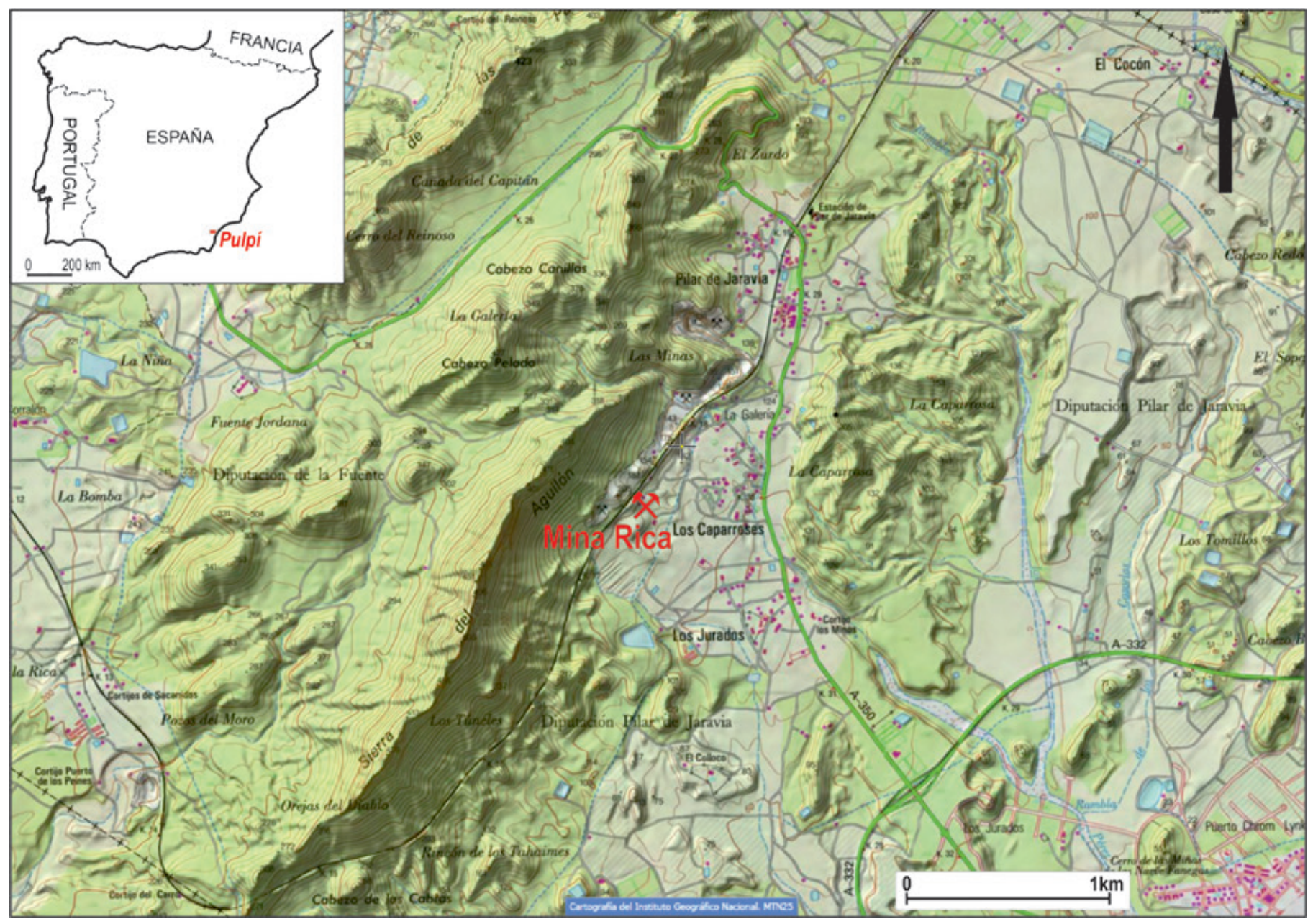

Figura 1. Localización de la Mina Rica en el mapa topográfico del Instituto Geográfico Nacional (I.G.N.) a escala 1:25.000.

Figure 1. Location of the "Mina Rica" on the Instituto Geográfico Nacional (IGN) topographical map scale 1:25.000.

galerías salían otras en crucero dirigidas a reconocer los cuerpos mineralizados. Durante nuestro estudio, la galería dirigida al NE estaba impracticable mientras que la galería del SW era accesible hasta alcanzar las principales explotaciones de PSA.

En sus comienzos los principales trabajos mineros se realizaron en el sector NE (QTP), y para profundizar las labores mineras se construyó un Pozo Maestro que alcanzó una profundidad de $100 \mathrm{~m}$ con $4 \mathrm{ni}-$ veles de explotación. Todas las referencias de nivel de la mina se establecen considerando al emboquille del Pozo Maestro como nivel 0. Este Pozo comunica con el socavón de acceso a los $15 \mathrm{~m}$ de profundidad mediante una galería de $24 \mathrm{~m}$, considerándose a este nivel como la $1^{\text {a }}$ Planta de la mina (nivel-15). En este sector, para acceder a las labores mineras por debajo del nivel del socavón, hay también un contrapozo de escalas que llega al nivel-68 m (Fig. 3).
Los principales trabajos en el sector SW (zona de 'Por Si Acaso') se realizaron durante el periodo de aprovechamiento de los sulfuros. Este sector tiene 5 niveles cuyo acceso directo se realiza por el contrapozo denominado Carrasco, que da servicio desde la primera planta de la mina (Fig. 3). Estos niveles son $2^{\mathrm{a}}$ Planta $(-29,5), 3^{a}$ planta $(-45), 4^{a}$ planta $(-57)$, y $5^{a}$ planta $(-71)$. Además, en la parte más occidental hay un subnivel desde la $3^{a}$ planta que llega a la cota -59 , equivalente a la $4^{a}$ planta pero que no está conectado con ella. Es aquí donde se halla la conocida como la "Gran Geoda de Pulpí." A esta explotación se accedía por un contrapozo llamado Clemente. Otros accesos entre estos niveles se realizan por una rampa que comunica la $1^{\mathrm{a}} \mathrm{con}$ la $2^{a}$ planta en el extremo SW, así como por antiguas cámaras de explotación hasta la $4^{\mathrm{a}}$ planta. Finalmente, otro contrapozo en la parte oriental de esa planta da acceso al nivel de $5^{\text {a }}$ planta (Fig. 3 ). 


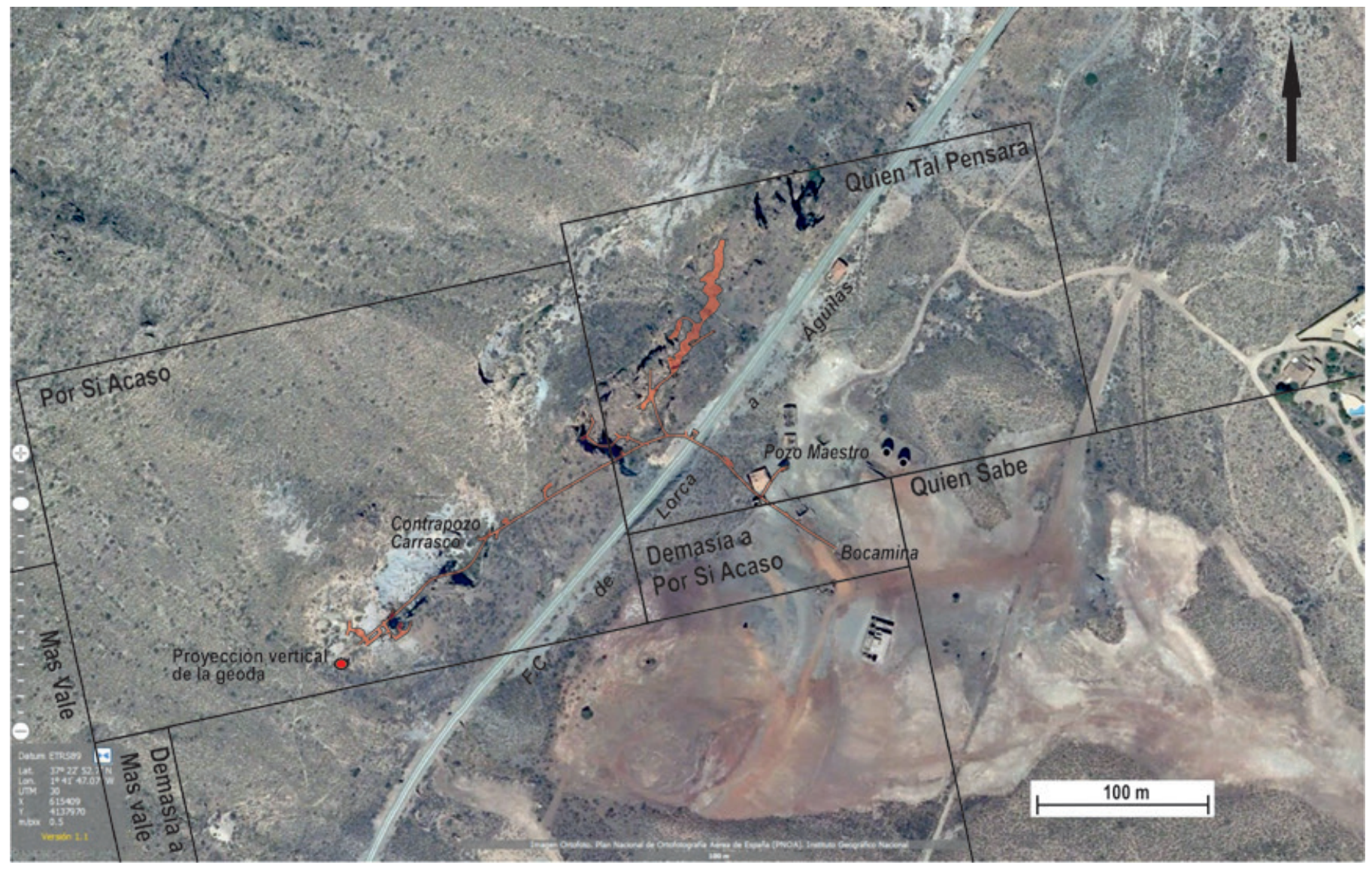

Figura 2. Proyección sobre la ortoimagen aérea del I.G.N de la primera planta (nivel-15) de la Mina Rica y las antiguas concesiones mineras que cubrían el yacimiento. Se indica la posición en la vertical de la 'Gran Geoda' de yeso selenítico.

Figure 2. Projection on the IGN aerial orthoimage of the first level (level-15) of the "Mina Rica" and the old mining tenements that covered the deposit. The location of the large selenite gypsum geode is indicated on the map.

La explotación se realizó mediante grandes cámaras que iban desarrollándose sin un orden preconcebido, arrancando las masas de mineral mediante un burdo banqueo realizado normalmente en realce. La altura de las cámaras es muy variable y se llevaba en principio hasta el piso del nivel superior. La conexión de varios huecos superpuestos puede alcanzar los 50 $\mathrm{m}$ de altura. La estabilidad de los hastiales, un predominio de discontinuidades subverticales y una alta cohesión del macizo rocoso, permitieron la excavación de grandes cavidades sin sostenimientos especiales. Se dejaban pilares corona en los pisos de las plantas y pilares horizontales a modo de grandes llaves en puntos estratégicos. Los tramos estériles entre cámaras quedaron como pilares barrera y, en lugares de gran anchura del hueco, se dejaron algunos verticales para apoyar los techos. Si bien no hay una distribución regularizada de estos pilares tan solo se produjo un hundimiento de parte del pilar corona entre $2^{\mathrm{a}}$ y $3^{\mathrm{a}}$ plantas.
Cuando se trabajaron cuerpos tabulares estrechos, se explotaron en realce sin utilizar rellenos y dejando solo algunas llaves para dar estabilidad al hueco. Estos pilares posiblemente servían también para facilitar el apoyo de los perforistas durante su trabajo. Solo se han encontrado rellenos en la galería de transporte de la $1^{\text {a }}$ planta, seguramente para protegerla e individualizarla de las labores de producción de los minerales situados sobre ella.

El mineral arrancado por voladura se dejaba caer al piso de la cámara de explotación, donde era cargado en vagones. Los vagones eran empujados hasta los contrapozos, en donde se elevaban por el Pozo Carrasco hasta la galería de transporte de $1^{a}$ Planta. En esta planta eran conducidos hasta el Pozo Maestro, por donde se sacaban a la superficie para ser descargados en la alimentación del lavadero de concentración. En la Figura 4 se indican los lugares, cuarteles y los elementos reseñables de la explotación para su 


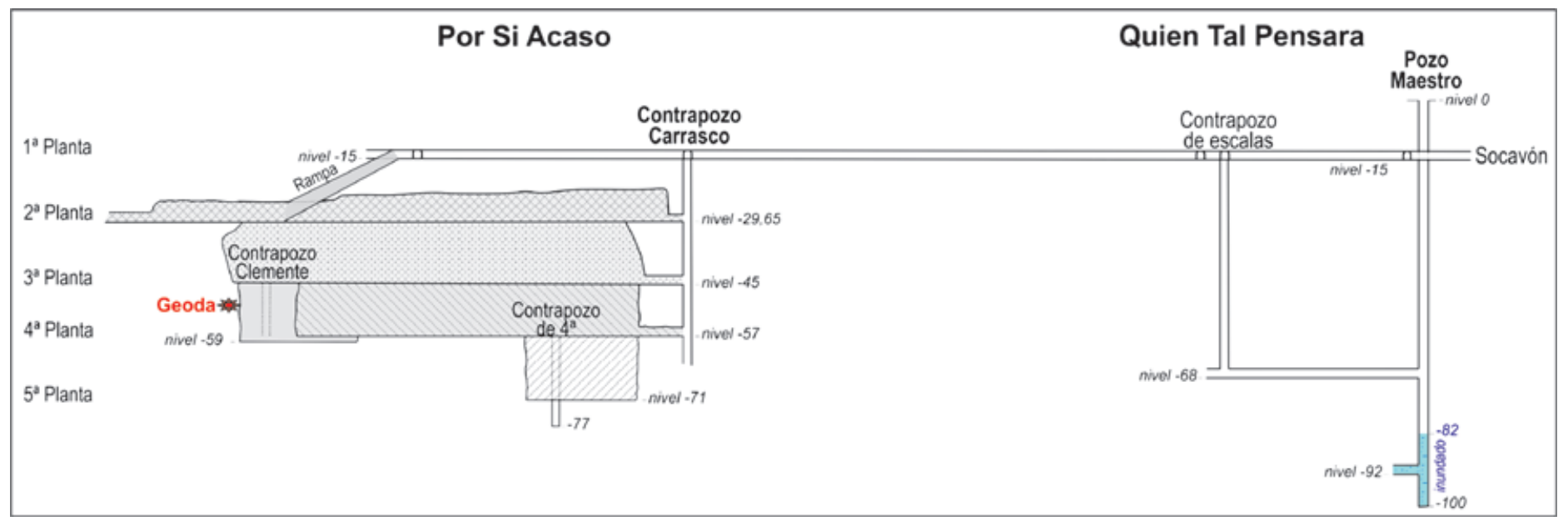

Figura 3. Sección longitudinal esquemática de la Mina Rica basado el Plan de Labores de 1966, presentado en la antigua Jefatura Provincial de Minas. Archivo Histórico de Almería.

Figure 3. Schematic cross-section of the "Mina Rica" based on the 1966 Work Plan presented in the old Provincial Mine Administration. Historic Archive of Almería.

localización a lo largo de este artículo. En lo posible se han mantenido las denominaciones encontradas en los documentos antiguos.

\section{Metodología}

Para poder acometer el estudio detallado del yacimiento fue necesario realizar un levantamiento topográfico de las labores mineras accesibles, ya que no existía un plano de suficiente resolución entre la documentación antigua recopilada en el Archivo Histórico de Almería. Con los planos de las diferentes plantas se realizó la cartografía geológica a escala 1:250, tomándose a la vez las muestras que se creyeron convenientes para los posteriores estudios de laboratorio. La caracterización mineralógica y textural de láminas delgadas se llevó a cabo con un microscopio petrográfico Nikon Eclipse LV100POL, con cámara Nikon Digital Camera DX M 1200F. Cuando se necesitó una caracterización textural y química de mayor resolución espacial se utilizó un microscopio de barrido de emisión de campo Zeiss Supra 40VP equipado con un analizador de energía dispersiva de rayos $X$ Oxford (Spain) en el Centro de Instrumentación Científica (CIC) de la Universidad de Granada. La determinación de fases cristalinas se realizó por medio de difracción X de polvo en el Laboratorio de Estudios Cristalográficos (Granada), en un difractómetro de alta resolución Bruker D8 Advance con radiación monocromática $\mathrm{Cu} \mathrm{Ka} 1$, monocromador primario de $\mathrm{Ge}(111)$ y un detector PSD Lynxeye. Los difractogramas se analizaron con el programa Malvern HighScore Plus (PANalytical) usando la Crystallographic Open Database.

\section{El contexto geológico regional}

El yacimiento de la Mina Rica se halla en una alineación NE-SW de afloramientos de rocas carbonatadas entre filitas, que se extiende por la ladera oriental de la Sierra del Aguilón. Esta sierra corresponde a un relieve orientado NNE-SSW formado por rocas carbonatadas de edad triásica con un rumbo $\mathrm{N} 30^{\circ} \mathrm{E}$ y $60^{\circ}-70^{\circ}$ de buzamiento al WNW. Esta orientación es inusual en el dominio de las Cordilleras Béticas, localizándose en el borde occidental del denominado "Arco de Águilas" (Alvarez, 1987), estructura limitada por 2 accidentes regionales, la falla de Las Moreras por el Norte y la Banda de Cizalla de la Béticas Orientales (ESBZ de su acrónimo en inglés) por el Oeste (Torres Roldán, 1979). Ambas estructuras actúan como bandas de cizalla conjugadas, dando lugar a que las unidades geológicas describan en la zona una forma arqueada característica del extremo SE penínsular.

La ESBZ es un gran accidente de rumbo NNE-SSW (aproximadamente $\mathrm{N} 20^{\circ} \mathrm{E}$ ) que se comporta como una banda de cizallamiento sinestral (Montrenant et al. 1987). Afecta al apilamiento de mantos, normalmente orientados $\mathrm{E}-\mathrm{W}$, haciéndoles rotar a posiciones cercanas a N-S. Queda definida por dos grandes faIlas paralelas, Palomares al Oeste, y Cocón-Terreros al Este (Silva et al., 1993). Esta última falla es la que limita al "Arco de Águilas" por el Oeste y junto a ella se halla el yacimiento de la Mina Rica (Fig. 5).

En la ladera oriental de la Sierra del Aguilón afloran filitas con algunos lentejones de carbonatos que se extienden hacia el Este, es decir hacia la costa, y hacia el NE. Álvarez y Aldaya (1985) consideran a estas rocas como parte de la unidad estructural "Las 


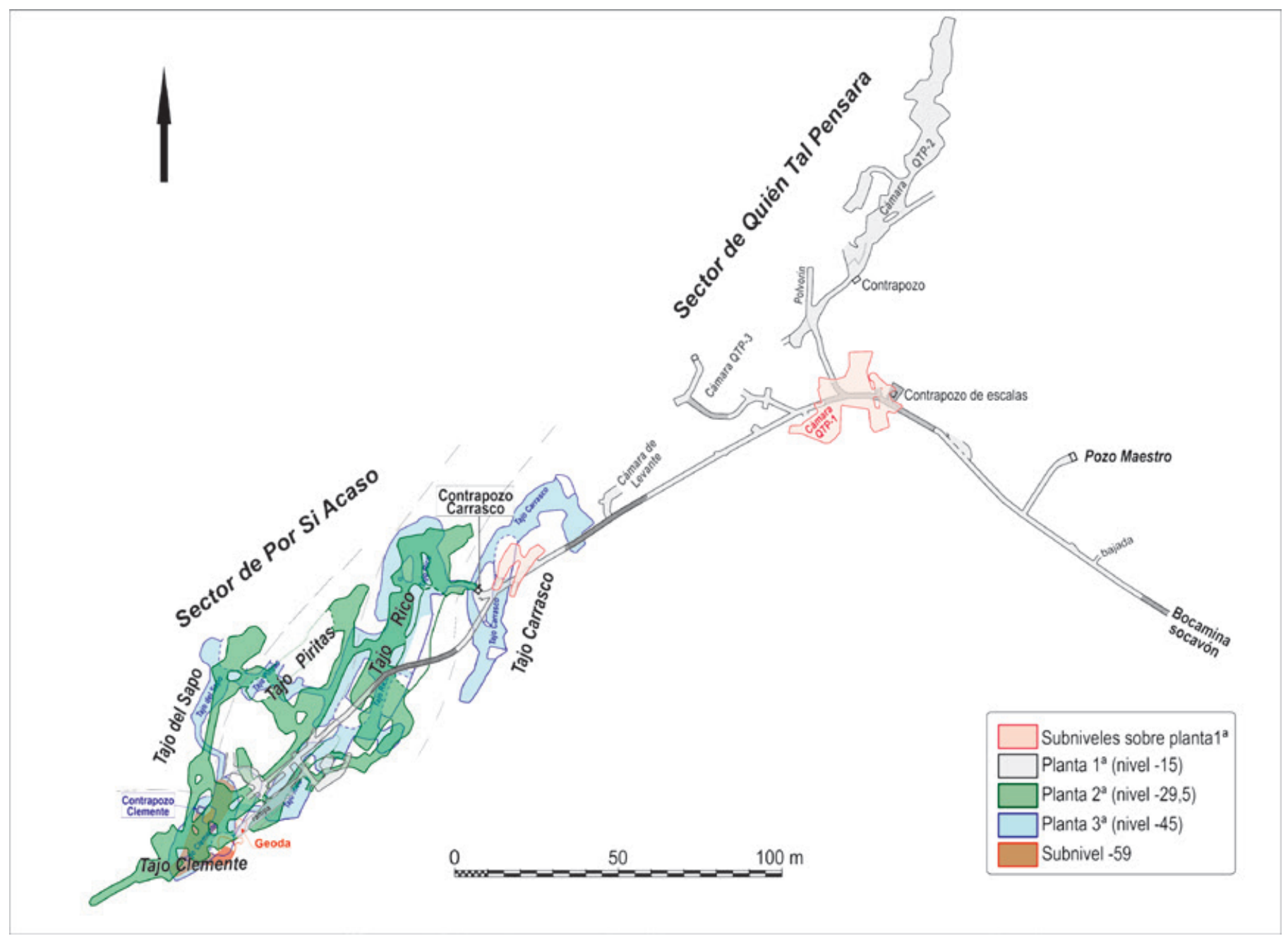

Figura 4. Plano de labores mineras de la Mina Rica indicando los tajos de explotación y lugares singulares de la mina sobre base topográfica propia.

Figure 4. Mining map of the "Mina Rica", indicating the mine stopes and singular sites. Topography made by the authors.

Palomas", que comprende dos de las formaciones que ellos definen, la de "micaesquistos y cuarcitas" que atribuyen al Paleozoico Superior, y la "carbonatada" considerada como Triásico Medio-Superior. Para Coppier et al. (1989) las filitas serían equivalentes a la unidad de Lomo de Bas y, por tanto, tendrían una edad Devónico Medio. Más recientemente Martin-Rojas et al. (2014) establecen una columna sintética de la plataforma Triásica en el Complejo Alpujárride, en la que incluyen ambas unidades en ese periodo. La Unidad de Las Palomas ocupa la mayor parte del domino meridional del Arco de Águilas siendo el encajante del yacimiento.

Los trabajos de Sanz de Galdeano (1983, 1987 y 1990) sobre la evolución de las Cordilleras Béticas después del emplazamiento de los mantos, señalan una variación continua del campo de esfuerzos des- de WNW-ESE en el Serravalliense a NNW-SSE en el Messiniense. En los primeros momentos se formarían grandes desgarres de rumbo NE-SW a ENE-WSW con componente dextral (sistemas $\mathrm{C}$ y $\mathrm{P}$ siguiendo la nomenclatura de Harding, 1974; o de Logan et al., 1979), a los que se unirían los conjugados E-W correspondientes al sistema Riedel sintético $(R)$ con la misma componente de desplazamiento (Fig. 5). Estas estructuras de cizalla provocarían el desplazamiento de la zona interna de las Béticas hacia el Oeste y la compartimentación de las grandes unidades de la cordillera (Sanz de Galdeano, 1990). Su movimiento podría haberse iniciado ya durante el apilamiento de mantos al final del Oligoceno y comienzos del Mioceno (Aquitaniense) y ser reactivados posteriormente como fallas directas en un periodo intermedio extensional en el Burdigaliense o Langhiense (Álvarez et 


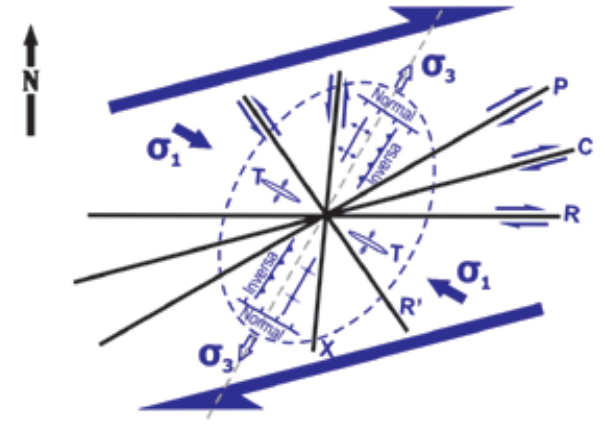

SERRAVALLIENSE

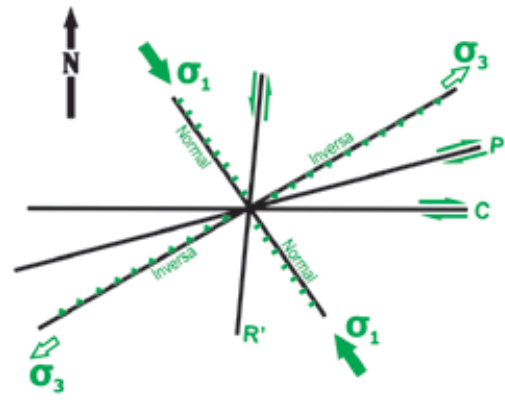

TORTONIENSE

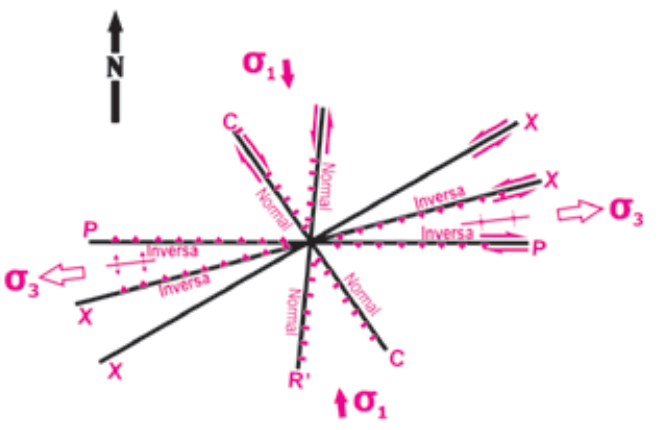

MESSINIENSE
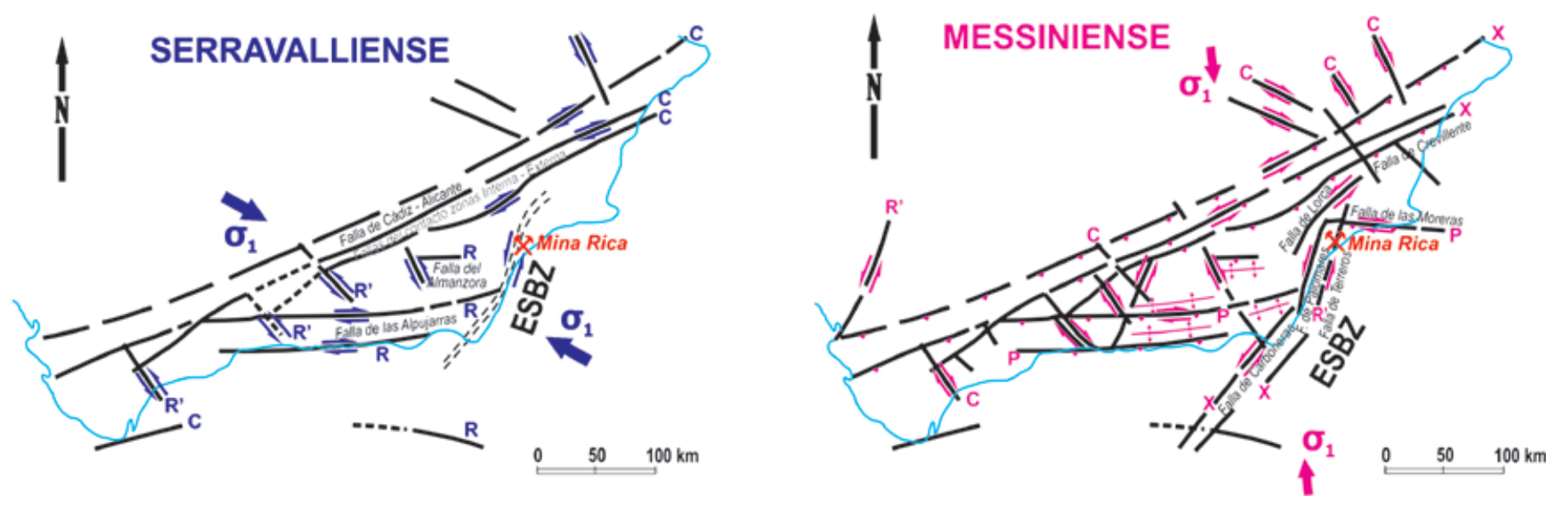

Figura 5. Abajo: Esquemas estructurales de la Cordillera Bética con representación de las principales fracturas y su comportamiento cinemático durante el Serravalliense y Messiniense (basado en los modelos de Sanz de Galdeano, 1990). Arriba: Patrones de fracturación y reactivaciones de fracturas generados en los diferentes campos de esfuerzos activos durante el Mioceno Medio y Superior en el contexto de la Cordillera Bética.

Figure 5. Bottom: Structural outlines of the Cordillera Bética with representation of the main fractures and their kinematic behaviour during the Serravallian and the Messinian (based on the models by Sanz de Galdeano, 1990). Top: patterns of fracturation and reactivations of fractures generated in the different stress fields active in the Middle and Late Miocene in the Cordillera Bética.

al., 1989). Durante el Serravalliense se habrían formado también pliegues, que dentro de las bandas de cizalla presentan planos axiales NNE-SSW.

Dentro de este contexto, en sus inicios la EBSZ podrían asimilarse a la respuesta dúctil de una banda sinestral Riedel simétrica antitética $(X)$, de rumbo cercano a N-S, que sería conjugada con las cizallas principales dextrales (C, P, R) (Fig. 5). Su nucleación estaría condicionada y activada por el inicio de la indentación de un bloque de zócalo de menor viscosidad sobre otro más rígido desplazándose hacia el Norte, comenzando con ello la formación del Arco de Águilas en el Serravalliense (Coppier et al., 1989). Los movimientos tangenciales de bloques se habrían producido sobre una superficie de deslizamiento a niveles de corteza media. Según progresa la dinámica de la banda de cizalla, el movimiento del bloque de zócalo va a tener una componente rotacional hacia el NW, lo que va a favorecer la formación de las cuencas transtensivas al sur y transpresivas al Norte (Silva et al., 1993). Por esa razón, aparecen en las cuencas meridionales las primeras manifestaciones volcánicas del Cabo de Gata en este periodo (Fernández-Soler, 1992). En este campo de esfuerzos con compresión WNW-ESE, la dirección de extensión es la complementaria NNE-SSW, por lo que las estructuras de rumbo cercano a E-W, como las dextrales Riedel sintéticas $(R)$, tendrán una cierta componente extensional (ver Fig. 5). El movimiento de la banda se habría prolongado hasta el Messiniense (Coppier et al., op cit.), pero sus efectos más notables sobre el paisaje se harían notar a partir del Messiniense (Silva et al., op. cit.), habiéndose registrado incluso actividad reciente (Giménez et al., 2000). 
Banda y Ansorge (1980) muestran que la EBSZ separa una corteza de espesor 30 a $40 \mathrm{~km}$ al Oeste de otra adelgazada de 22 a $24 \mathrm{~km}$ al Este. Esta última quedaría restringida al SE de la península, y estaría delimitada por los accidentes corticales cuyo reflejo superficial es la ESBZ y las fallas NE-SW de Lorca y Crevillente. El adelgazamiento se puede relacionar con la extensión en el Burdigaliense-Tortoniense que dio lugar a la cuenca Argelino-Provenzal (Sanz de Galdeano, 1990), o bien a un colapso gravitacional pre-Messiniense según el modelo de indentación de Coppier et al. (1989).

Con el cambio a una compresión NW-SE en elTortoniense (Sanz de Galdeano, 1990; Huibregtse et al., 1998), Ilegando a NNE-SSW durante el Tortoniense Superior (Coppier et al., 1989), se produce una componente extensional sobre las estructuras de rumbo entre NW-SE y N-S. La extensión favoreció el volcanismo del final del Tortoniense, con ejemplos incluso en la zona de afección de ESBZ como los apuntamientos volcánicos de Vera y los cuerpos riodacíticos de Los Lobos (Bellido y Brändle, 2008). En el Messiniense el acortamiento cambia a NNW-SSE, reactivándose las fallas previas NE-SW, ahora como desgarres sinestrales con componente inversa (Fig. 5). La EBSZ acentúa su desplazamiento sinestral y las fallas E-W combinan su desplazamiento dextral con una componente inversa. Durante este periodo se forman los pliegues abiertos de rumbo axial cercano a E-W que afectan especialmente a las cuencas neógenas de la zona.

A finales delTerciario se producen movimientos de elevación que van dejando las cuencas Tortonientes, Messinienses y Pliocenas cada vez más restringidas, con diferentes ratios de elevación, especialmente rápidos en el Messiniense (Martín et al., 2003). Estos autores describen además que la actual línea de costa habría quedado ya perfilada después del comienzo del Plioceno, aunque los movimientos de elevación han continuado hasta el Cuaternario. Estos últimos movimientos responderían a un acortamiento NNW-SSE en el Plioceno (Montenat et al., 1987).

En el Arco de Águilas, durante el Plioceno se da una sedimentación detrítica en las laderas de la Sierra del Aguilón y sobre las superficies de erosión marina desarrolladas en las filitas que se extienden hacia la costa. Se producen movimientos en la vertical post-Pliocenos con compartimentación en bloques limitados por accidentes de rumbo norteado que han sido reconocidos con sísmica de reflexión (Coppier et al., 1989). Giménez et al. (2000) calculan un movimiento en vertical de $0,9 \mathrm{~mm} / \mathrm{año} \mathrm{en} \mathrm{la} \mathrm{falla} \mathrm{de} \mathrm{Cocón-Terreros,} \mathrm{re-}$ sultado de movimientos coetáneos de hundimiento a favor de ella misma y ascensionales producidos por otras fallas inversas asociadas de rumbo E-W.

\section{El contexto metalogénico}

EI SE de la Península Ibérica ha sido una región con amplia actividad minera y con importantes yacimientos de diversas sustancias repartidos por las provincias de Murcia, Almería y Granada. Los más extendidos e importantes han sido los de hierro y los de $\mathrm{Pb}-\mathrm{Zn}-\mathrm{Ag}$, pero también se trabajaron otros depósitos de $\mathrm{Sr}, \mathrm{Ba}, \mathrm{Au}, \mathrm{Hg}$, Co-Cu, Fluorita y azufre, sin contar las explotaciones que ha habido, y aun hay, de rocas industriales, como yesos, mármoles, bentonita, diatomeas, alunita, etc. (Fernández-Leyva et al., 2011; Sánchez Valverde et al., 2011; Manteca et al., 2005). En la figura 6 se muestran la situación de los depósitos minerales más relevantes en esa parte de España.

En la Mina Rica aparecen superpuestas varias de estas mineralizaciones, concretamente la de $\mathrm{Fe}$, la de $\mathrm{Pb}-\mathrm{Ag}$, la de $\mathrm{Ba}$ y la de $\mathrm{Sr}$, habiendo sido las 2 primeras las que han tenido un beneficio industrial. Desde el punto de vista metalogénico se pueden englobar al yacimiento en el grupo de mineralizaciones en mantos y filones de $\mathrm{Pb}-\mathrm{Zn}$-Fe-Ag-(Ba-Cu-Sn-Sb) encajados en rocas dolomitizadas de edadTriásica de Arribas yTosdal (1994), autores que las considera de edad miocena y las relacionan con la actividad volcánica de la región.

La mineralización volumétricamente más importante en la Mina Rica ha sido la de hierro, integrada por carbonatos de $\mathrm{Fe}$ (ankerita principalmente) en cuerpos de reemplamiento, formados claramente en condiciones post-cinemáticas respecto a la etapa orogénica principal de la cordillera. Como se describe más adelante se trata de cuerpos estratoides que en general van siguiendo la estratificación, aunque también los hay que son discordantes. Morfológicamente la mineralización podría corresponder a los cuerpos de reemplazamiento por metasomatismo ferruginoso en calizas triásicas controladas por fracturas extensionales sinsedimentarias, según el modelo propuesto por Torres Ruiz (2006). Sin embargo, las condiciones claramente post-deformacionales de los cuerpos de la Mina Rica descartan este origen.

Considerando la paragénesis del yacimiento, la Mina Rica también encajaría en el grupo de yacimientos filonianos de Fe-Ba-Pb-Zn-Ag que aparecen en la parte oriental del complejo Nevado-Filábride (Molina y Ruiz-Montes, 1993), aunque en ese grupo falta la de $\mathrm{Sr}$, ampliamente presente en Pulpí. Hay similitudes con los yacimientos cercanos que son clásicos de ese tipo, como los de Sierra Almagrera (Morales et al., 1993). Equivalencias en cuanto a morfología y mineralización se encuentran con los de Fe-Mn-Ba-Ag de Herrerías (Martínez Frías, 1993). De esta forma, dentro de las peculiaridades que hay entre unos y otros, la Mina Rica ofrece una metalogenia que puede considerarse 


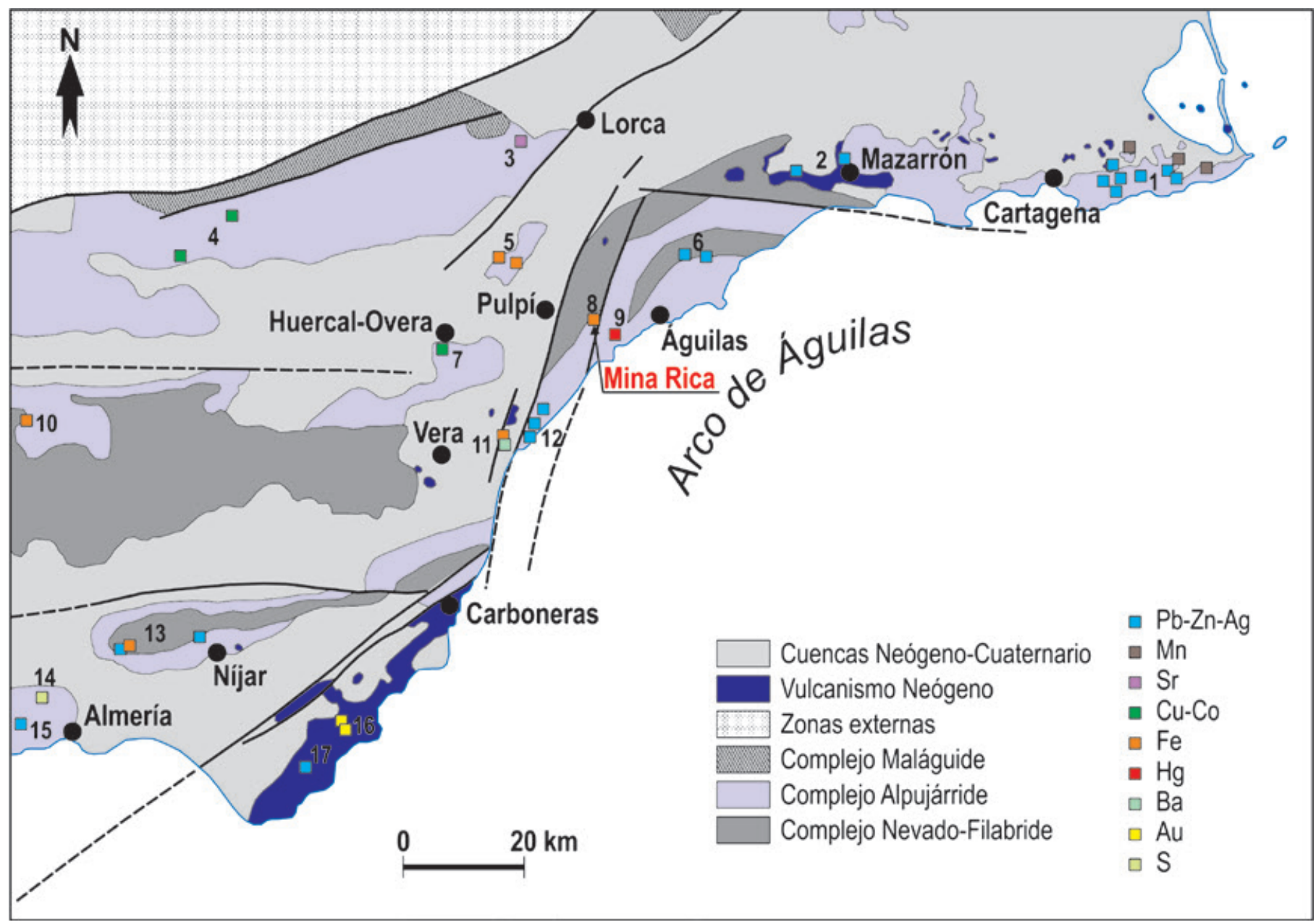

Figura 6. Esquema geológico del SE de la Península Ibérica con situación de los yacimientos minerales más relevantes. 1 Sierra de Cartagena-La Unión (Pb-Zn-Ag-Mn), 2 Campo de Mazarrón (Pb-Zn-Ag), 3 El Saltador (Sr), 4 Sierra de Las Estancias (Cu), 5 Sierra Enmedio (Fe), $6 \mathrm{Lomo}$ de Bas (Pb-Ag), 7 Huercal-Overa $(\mathrm{Cu}-\mathrm{Co}), 8$ Sierra del Aguilón (Fe-Pb-Ag-Ba-Sr), 9 Valle del Azogue (Hg), 10 Serón (Fe), $11 \mathrm{Herrerías}$ (Fe-Ba-Ag), 12 Sierra Almagrera (Pb-Ag), 13 Sierra Alhamilla (Pb-Ag-Fe), 14 Las Balsas-Benahadux (S), 15 Sierra de Gádor (Pb-F), 16 Rodalquilar (Au), 17 Cabo de Gata (Pb-Cu-Au).

Figure 6. Geological sketch of the SE part of Iberian Peninsula including the location of the main ore deposits. 1 Cartagena-La Unión Range (Pb-Zn-Ag-Mn), 2 Mazarrón District (Pb-Zn-Ag), 3 El Saltador (Sr), 4 Las Estancias Range (Cu), 5 Sierra Enmedio (Fe), 6 Lomo de Bas (Pb-Ag), 7 Huercal-Overa (Cu-Co), 8 Aguilón Range (Fe-Pb-Ag-Ba-Sr), 9 Azogue Valley (Hg), 10 Serón (Fe), 11 Herrerías (Fe-Ba-Ag), 12 Almagrera Range (Pb-Ag), 13 Alhamilla Range (Pb-Ag-Fe), 14 Las Balsas-Benahadux (S), 15 Gádor Range (Pb-F), 16 Rodalquilar (Au), 17 Gata Cape (Pb-Cu-Au).

un compendio de aquellos, a la que hay que añadir las mineralizaciones de estroncio y yeso, ausente en los otros casos. Con este conjunto de mineralizaciones reconocibles en la Mina Rica, se puede decir que en ella está presente tanto las que son propias de los yacimientos encajados en el complejo Nevado-Filábride, como la de aquellos que se sitúan en el complejo Alpujárride y cuencas Neógenas.

Hay un cierto consenso en la idea de relacionar estas mineralizaciones con el vulcánismo neógeno de la región como propusieron Arribas y Tosdal (1994). En el entorno de Mina Rica, el vulcanismo de Mazarrón y Vera, Lustrino et al. (2011) lo sitúan en el Tortoniense o inicio del Messiniense. La mineralización de la Mina
Rica sería por tanto compatible con un momento de gradiente geotérmico elevado en la región a causa de dicha actividad volcánica, al igual que ocurriría con otras mineralizaciones del entorno (Morales Ruano et al., 1995; Dyja et al., 2015).

\section{Estructura geológica del yacimiento}

Las mineralizaciones de la Mina Rica aparecen en dos grandes lentejones tectónicos de rocas carbonatadas entre filitas, que coinciden aproximadamente con los dos sectores de la mina 'Quien Tal Pensara' y 'Por Si Acaso'. Estos lentejones están limitados por importantes cizallas frágiles-dúctiles de traza arqueada de NNE- 


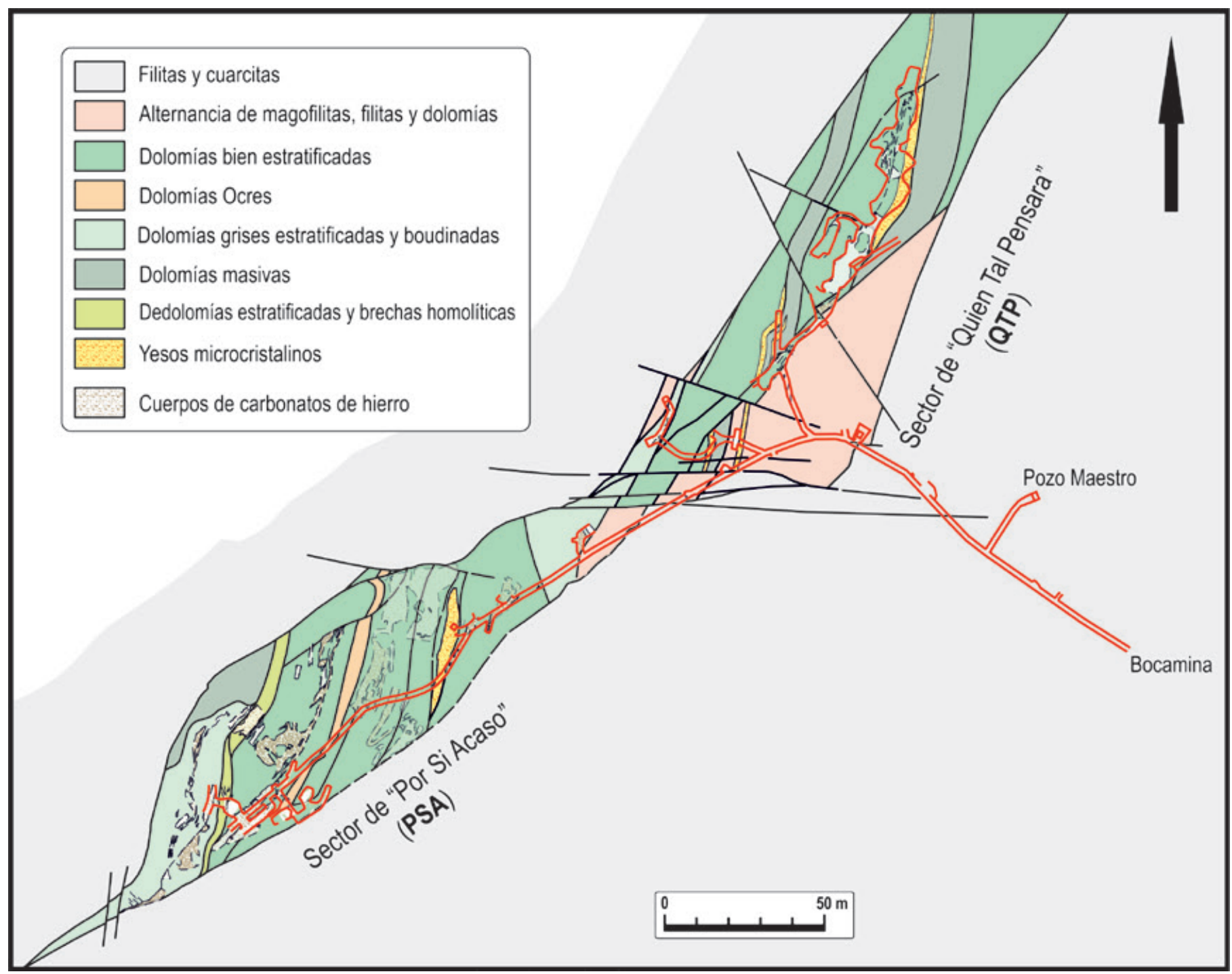

Figura 7. Mapa geológico de la $1^{\mathrm{a}}$ planta de la Mina Rica (nivel-15).

Figure 7. Geological map of the first level of the "Mina Rica" (level -15).

SSW a ENE-WSW, subverticales, y con componente de desplazamiento dextral. Dentro de ellos las rocas encajantes de la mineralización forman alternancias replegadas y falladas de calizas y dolomías con una orientación general NNE-SSW y fuerte buzamiento al Oeste. Hay algunos sectores con buzamientos suaves que coinciden con zonas de charnela.

Los trabajos de explotación en la mina siguieron los cuerpos mineralizados de geometría estratoligada, lo que conlleva una orientación principal de los huecos de explotación también NNE-SSW. Esta orientación forma un ángulo con la estructura general del criadero NE-SW de la banda de cizalla en la que se ubica, dirección principal que siguen las galerías de transporte y servicios (ver Fig. 4). El encajante principal de las mineralizacio- nes es una alternancia de paquetes de carbonatos con finas intercalaciones de filitas. A escala del yacimiento se han diferenciado varias unidades litológicas en base al grosor de los estratos, su textura y la mayor o menor presencia de intercalaciones filíticas. Además, se han reconocido otras unidades formadas por yesos, brechas de distintas litologías y filitas, siendo estas últimas las que están bordeando a los lentejones tectónicos de carbonatos. En total se han considerado diez unidades, ocho de las cuales están representadas en la cartografía geológica del yacimiento (Fig. 7). Dada la deformación que afecta a estas unidades y siendo la mayoría de los contactos entre ellas por falla, se hace imposible establecer la secuencia estratigráfica por lo que el orden expresado no tiene implicaciones cronológicas. 


\section{Filitas grises}

Esta unidad actúa de encajante de lo que propiamente es el depósito, aunque ha habido algunas labores sobre pequeñas vetas encajadas en ellas. Se trata de alternancias centimétricas de micaesquistos y filitas sensu stricto, con filitas carbonosas e intercalaciones de capas cuarcíticas de espesor entre los 5 y $25 \mathrm{~cm}$, normalmente boudinadas (Fig. 8A). Presentan una foliación muy marcada sub-paralela a la estratificación, con rumbo de NE-SW a E-W con fuertes buzamientos hacia el SE y S. Superpuesta a la esquistosidad se aprecia una crenulación dando una lineación con un cabeceo (plunge) de $70^{\circ}$ al SW.

\section{Calizas y dolomías claras bien estratificadas}

Se trata de una alternancia de paquetes de espesor centi y decimétrico de calizas y dolomías grises claras, separadas por finas intercalaciones de filitas. Es la litología dominante en el yacimiento y principal encajante de los cuerpos mineralizados.

Las intercalaciones filíticas son muy delgadas, no más de unos milímetros, pero son netas y continuas, lo que confiere a la alternancia un aspecto tableado (Fig. 8, B), con continuidad de las capas solo alterada por cuñas tectónicas y boudinamientos. En ciertos tramos las filitas están casi ausentes, presentando entonces las capas de carbonatos una laminación bien marcada. Los carbonatos presentan un aspecto microgranular (esparítico) con señales de dedolomitización visibles al microscopio (Fig. 9A y 9B). También son frecuentes las estructuras estilolíticas si bien no muestran incisiones muy marcadas. La alternancia aparece replegada y cizallada, con pliegues en "chevron" con charnelas apretadas y rotas, aunque también hay charnelas cilíndricas y festoneadas, pero nunca con engrosamientos. Los flancos tienen buzamientos fuertes Ilegando a estar invertidos. En general se reconoce una estratificación orientada de NE-SW a NNE-SSW, con vergencia hacia el Este. Los repliegues y repeticiones por falla dan anchuras de varias decenas de metros para esta unidad. Los cuerpos mineralizados de carbonatos de hierro aparecen remplazando a estas alternancias siguiendo la estratificación, pero con desigual espesor y geometría (Fig. $8, \mathrm{C})$.

\section{Calizas y dolomías grises estratificadas y boudinadas}

Esta unidad aparece formada por una alternancia de calizas, dolomías y dedolomías de color gris oscuro en paquetes de espesor decimétrico y métrico sepa- rados por finas intercalaciones de filitas. Se dispone formando una banda alargada en el borde occidental del sector PSA, donde contiene buena parte de la mineralización del Ilamado 'Tajo del Sapo'. También se encuentran carbonatos de aspecto similar en la parte más oriental de los trabajos del 'Tajo Carrasco'. Las capas aparecen en general con rumbos N-S que rotan a NE-SW en los extremos del lentejón tectónico por efecto de cizallamiento. Los buzamientos son fuertes hacia el Oeste y NW. La potencia es métrica a decamétrica. Están en contacto con las filitas grises mediante una gran cizalla dúctil-frágil con fuerte buzamiento al Oeste. Los paquetes de carbonatos aparecen boudinados, siendo muy patente en la zona del 'Tajo del Sapo', donde la proximidad a la cizalla que limita el bloque por el Oeste los ha afectado de forma más intensa. El cizallamiento produce también acuñamientos por deslizamientos a favor de las intercalaciones filíticas, que actúan como planos de despegue. El aspecto de la roca en muestra de mano es masivo-microgranudo, con evidencias de recristalización. Al microscopio presentan frentes estilolíticos que separan zonas con diferentes tamaño de granos cristalinos, llegando algunos a varios $\mathrm{mm}$ con evidencias de dedolomitización y disolución. Hay además cristales de moscovita, entre 100 y $200 \mu \mathrm{m}$, orientados marcando las sinuosidades de los boudines.

\section{Dolomías masivas craqueladas}

En el extremo norte de las labores del 'Tajo del Sapo' aparece un cuerpo masivo de dolomías grises y marronáceas, compactas y fracturadas, lo que les da un aspecto craquelado. Están en contacto con las calizas y dolomías boudinadas mediante una cizalla frágil de trazado sinuoso y componente dextral. En el otro extremo está en contacto con las filitas que rodean el lentejón tectónico mediante la cizalla que lo limita (Fig. 7). Estas rocas presentan un aspecto masivo con textura microgranuda (dolesparítica) sin estructura interna excepto una tenue estratificación. Es muy característico el craquelado, con fisuras rellenas de dolomita y algunos sulfuros. Una red de fracturación posterior, generalmente controlada por grietas de componente tensional, contiene barita y granos dispersos de sulfuros (Fig. 8D). Al microscopio se trata de una roca dolomítica heterométrica y heterogénea, brechificada y masiva, con dolomita, cuarzo, sulfuros (galena, pirita y en menor proporción esfalerita) y moscovita. A partir de la cartografía geológica se define un cuerpo estirado con forma elipsoidal, de unos $10 \mathrm{~m}$ de anchura máxima, unos $40 \mathrm{~m}$ de largo y amplia continuidad en la vertical. 

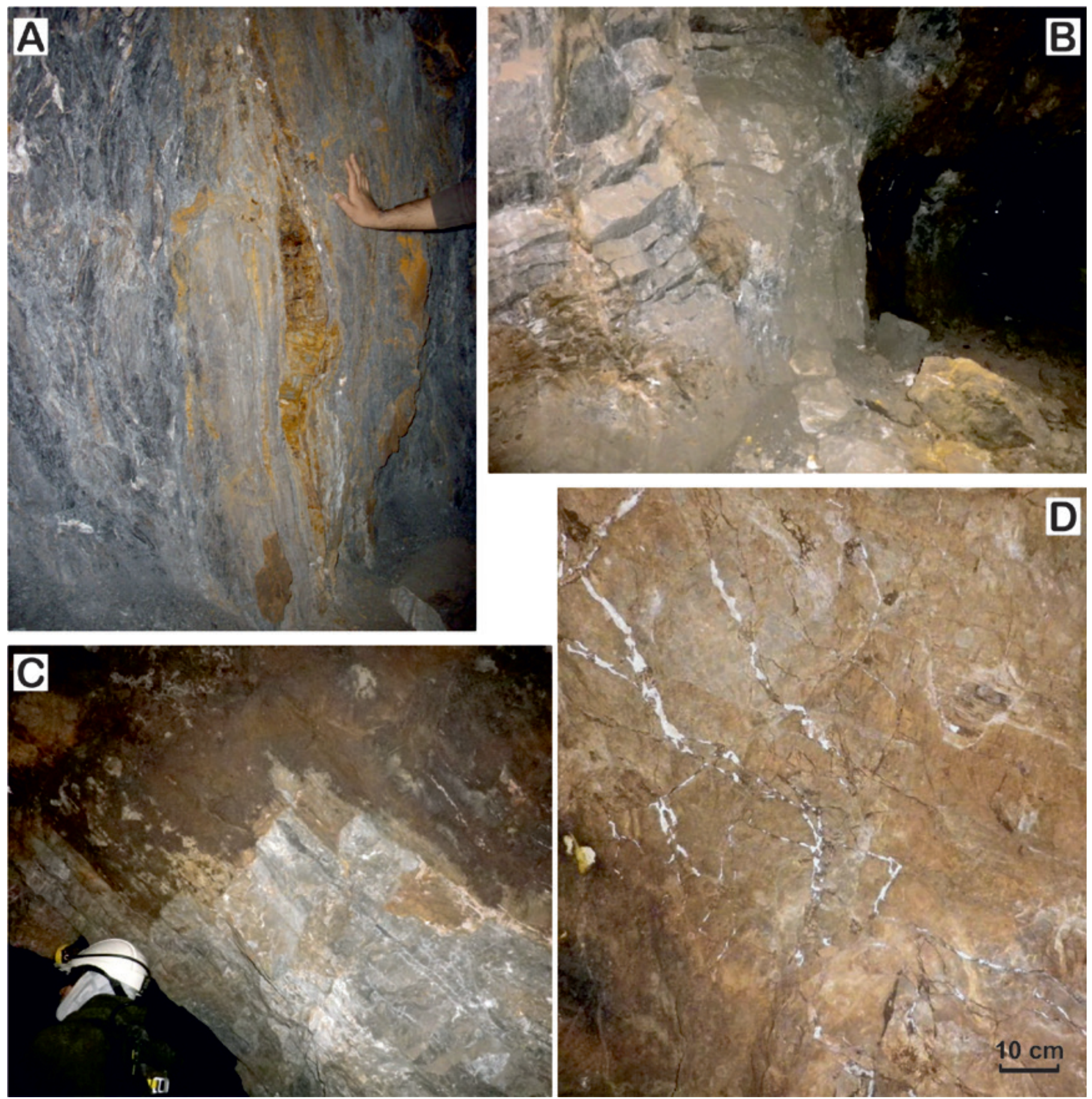

Figura 8. A: Unidad de filitas grises. Capa de cuarcita estirada y boudinada entre filitas grises carbonosas. Socavón transversal de acceso a la mina (nivel-15). B: Unidad de calizas y dolomías claras bien estratificadas. Exposiciones de las calizas y dolomías de aspecto tableado que aparecen replegadas en una galería lateral del 'Tajo Rico', planta ${ }^{2}$, sector PSA. C: Unidad de calizas y dolomías claras bien estratificadas. Calizas y dolomías con laminación marcada y con frente de reemplazamiento por metasomatismo ferroso. 'Tajo Rico', planta $2^{\mathrm{a}}$, sector de PSA. D: Unidad de dolomías masivas craqueladas. Aspecto de las dolomías en el techo de la cámara del 'Tajo del Sapo' en la planta $2^{\text {a }}$ de PSA. Las vetas de tonos blanquecino son de barita.

Figure 8. A: Unit of grey phyllites. Layer of stretched and boudinated quartzite between carbonaceous grey phyllites. Cross-cut adit (level -15). B: Unit of light colour and well stratified limestone and dolostones. Outcrops of the folded limestone and dolostones with a layered appearance in a lateral tunnel of the 'Tajo Rico' exploitation, $2^{\text {nd }}$ level, PSA sector. C: Unit of light colour and well stratified limestones and dolostones. Limestone and dolostones beds with marked lamination and a replacement front by ferrous metasomatism. 'Tajo Rico', $2^{\text {nd }}$ level, PSA sector. D: Unit of massive craquelated dolostones. Aspect of the rock in the ceiling of the 'Tajo del Sapo' stope on the PSA sector, $2^{\text {nd }}$ level. The veins of whitish colour are baryte. 

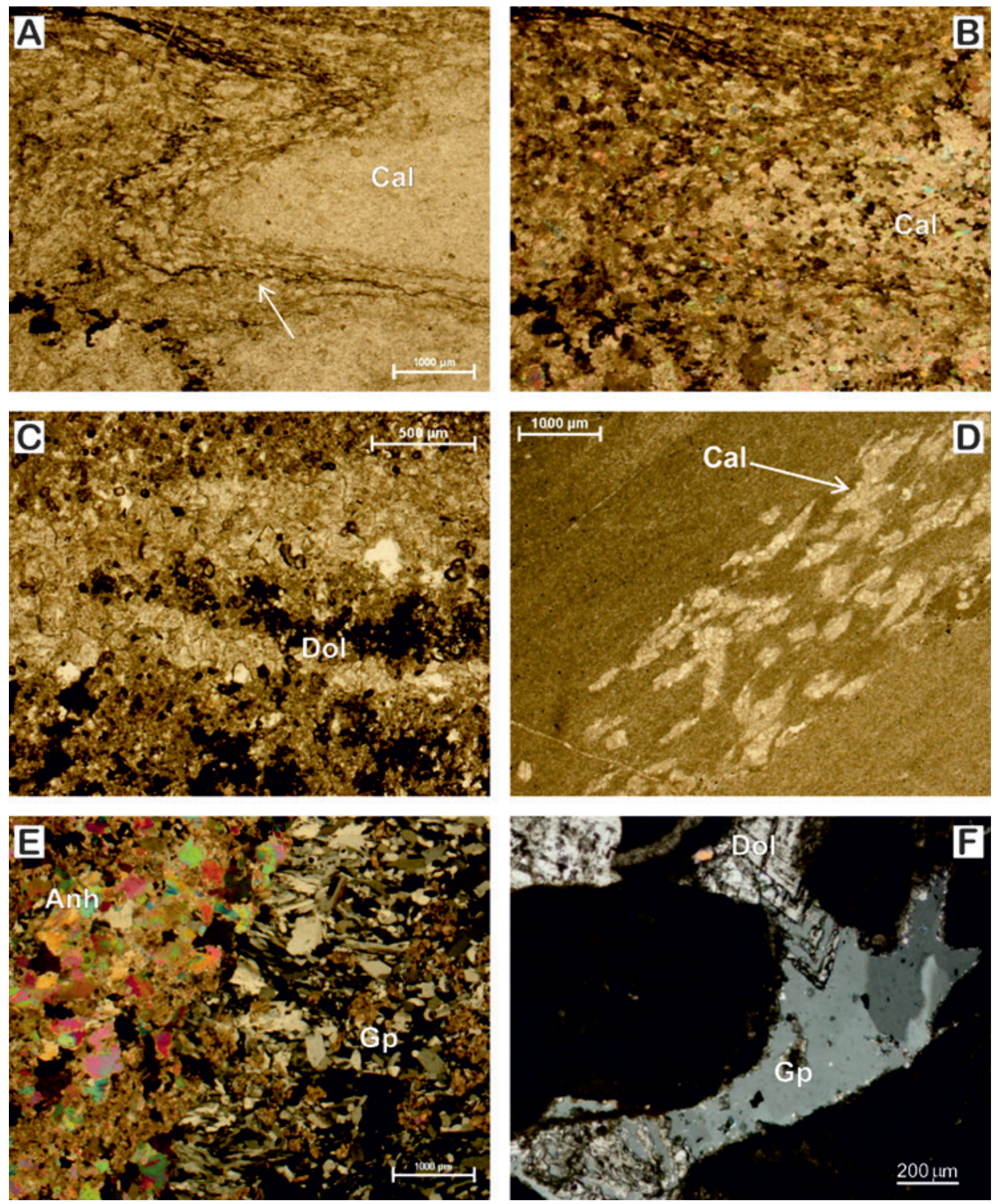

Figura 9. A: Calcita (Cal) de dedolomitización de la unidad de calizas y dolomías claras bien estratificada NP. La flecha indica una zona con restos de las intercalaciones finas, NP. B: La misma zona que A en NC. C: Aspecto heterométrico y alta porosidad de la unidad dolomías ocres, NP. Dol: dolomita. D: Dolomías crema y dolomías oscuras donde se señala una banda con pseudomorfos de minerales lenticulares (¿yeso?), ahora calcita (Cal), NP. E: Contacto entre el yeso microscristalino (Gp) y la anhidrita (Anh), NC. F: Yeso microcristalinos (Gp) reemplazando cristales de dolomita (Dol). Las zonas oscuras corresponden a la unidad de dolomía crema y oscura, NC. (Las abreviaturas de minerales están de acuerdo con Whitney and Evans (2010). NP: Polarizadores paralelos; NC: Polarizadores cruzados).

Figure 9. A: Calcite (Call from dedolomitization of the unit of light colour and well stratified limestone and dolostones NP. The arrow indicates a zone of remnants of the fine-grain interbeddings, NP. B: The same zone as A in NC. C: Heterometric appearance and high porosity of the ochre dolostone unit, NP. Dol: dolomite. D: Cream dolostones and dark dolostones with a band of lenticular-shape mineral pseudomorphs (gypsum?), now calcite (Cal), NP. E: Anhydrite (Anh)-microcrystalline gypsum (Gp) contact, NC. F: Microcrystalline gypsum (Gp) replacing dolomite (Dol) crystals. The dark zones correspond to the unit of cream and dark dolostones, NC. (The abbreviations of minerals after Whitney and Evans (2010). NP: Parallel polarizers; NC: Crossed polarizers). 


\section{Brechas y dedolomías tableadas}

Esta unidad aparece formando una alternancia de paquetes centimétricos de carbonatos de color blanquecino y aspecto microcristalino (sacaroide), separados por finas intercalaciones de filitas y margo-filitas. Se presenta formando una continua banda en el sector occidental de PSA con rumbo NE-SW a NNE-SSW y fuerte buzamiento en los extremos norte y sur, pero con una flexión por plegamiento en la parte central con inclinaciones de $25^{\circ}$ a $30^{\circ}$ en la parte central. Dentro de esta banda se hallan las explotaciones del 'Tajo Piritas' en su parte centro-septentrional y en el 'Tajo Clemente' en su parte meridional. La potencia de la banda es de unos 5 a $8 \mathrm{~m}$, si bien la zona tendida da una anchura cartográfica mayor debido a su menor buzamiento.

Litológicamente la unidad es una alternancia multicapa deformada, donde los estratos pierden su continuidad por boudinamientos y acuñamientos. La alternancia lateralmente deriva a una estructura brechoide en el 'Tajo Clemente', con bloques que, por su aspecto, composición y relación con su encajante, se puede interpretar como una brecha intraformacional. La zona de brecha se extiende unos $30 \mathrm{~m}$, en forma de lentejón y con una anchura que llega hasta $5 \mathrm{~m}$. En la vertical se reconoce desde la $1^{\mathrm{a}}$ a la $3^{\mathrm{a}}$ planta y seguramente continúa hacia abajo. La brecha presenta una alteración compleja con la que, aunque visualmente la roca mantiene la estructura, pierde su consistencia y adquiere un aspecto terroso y un color gris verdoso (Fig. 9A). El color verdoso puede ser debido a una fina diseminación de sulfuros, esencialmente pirita, lo que explica el nombre de la explotación de este material: 'Tajo Piritas'. Además del sulfuro de hierro la roca tiene dolomita, calcita, cuarzo, moscovita, yeso, galena, y epsomita. Si bien esta alteración afecta especialmente a la brecha de rocas dedolimitizadas descrita más arriba, también hay zonas alteradas entre los tramos estratificados, dándose en estos casos oquedades rellenas parcialmente del material terroso suelto y cristales de yeso (selenita) que incluyen partículas de ese material. Otras alteraciones verdosas equivalentes se han encontrado ocasionalmente en las dolomías claras bien estratificadas, concentrándose en el contacto occidental con las calizas y dolomías ocres que se describen a continuación. Asimismo, en la cámara QTP-2 (ver fig. 4) se han visto algunas alteraciones puntuales de este tipo.

\section{Calizas y Dolomías ocres}

Se trata de una unidad formada por paquetes centi y decimétricos de calizas y dolomías, sin apenas inter- calaciones de filitas. Presentan un color gris claro con un tono ocre característico que pasa a marrón pálido en ciertas partes de la mina. Litológicamente son dolomías de grano fino, muy homogéneas a visu y heterométricas al microscopio (Fig. 9C), frecuentemente brechificadas por tectonización con evidencias de dedolomitización y disolución. En el sector de 'Por $\mathrm{Si}$ Acaso' forma una banda continua de unos $5 \mathrm{~m}$ espesor con rumbo NNE-SSW, que cruza completamente el lentejón tectónico. En ella encaja la gran geoda de selenita en su extremo SW, muy cerca del contacto con la cizalla que sirve de contacto meridional con las filitas. Presenta un buzamiento general de $60^{\circ}$ a $70^{\circ}$ al NW, y contactos mecánico netos con las dolomías claras bien estratificadas entre las que se sitúan (Fig. 9B). Al ser una unidad prácticamente estéril, solo se reconoce completamente en galerías transversales de acceso entre las cámaras de explotación, con buenas exposiciones en las que comunican el 'Tajo Rico' con los otros cuerpos situados más a poniente. El contacto de techo de esta unidad se comporta como una fractura que da lugar a cuerpos de brechas tectónicas de carácter tensional, con fragmentos angulosos de rocas carbonatadas y rellenos de celestina, sulfuros y placas y geodas de yeso selenítico. Resulta muy espectacular esta brecha en los techos de la planta $2^{\mathrm{a}}$ y en las paredes del 'Tajo Piritas' de la 4 .

\section{Margofilitas y dolomías laminadas}

Esta unidad está formada por una alternancia centimétrica de margofilitas de color blanquecino o gris claro y marcada laminación sedimentaria, con paquetes intercalados de dolomías con tonos marrones con grosores desde unos centímetros y casi un metro (Fig. 9C). Las margofilitas aparecen como un agregado fino de tacto untuoso con abundante sericita. El color blanquecino se lo aporta la componente carbonatada. La laminación viene marcada por la foliación tectónica, que parece superponerse a una original sedimentaria. Las intercalaciones de dolomías microcristalina con laminación sedimentaria son frecuentes, pero aparecen irregularmente repartidas en la alternancia.

Esta unidad aparece en la zona de 'Quien Tal Pensara' y está bien expuesta en la galería de acceso a la cámara principal QTP-2 y en la galería general de transporte hacia el pozo Carrasco (nivel -15). Forma una banda de unos $20 \mathrm{~m}$ de anchura y orientación NNE-SSW con buzamiento de $45^{\circ}$ a $70^{\circ}$ al Oeste. También aparece en el hastial meridional de esa cámara de explotación. En general se comporta como roca estéril, pero hay cuerpos de reemplazamiento de 

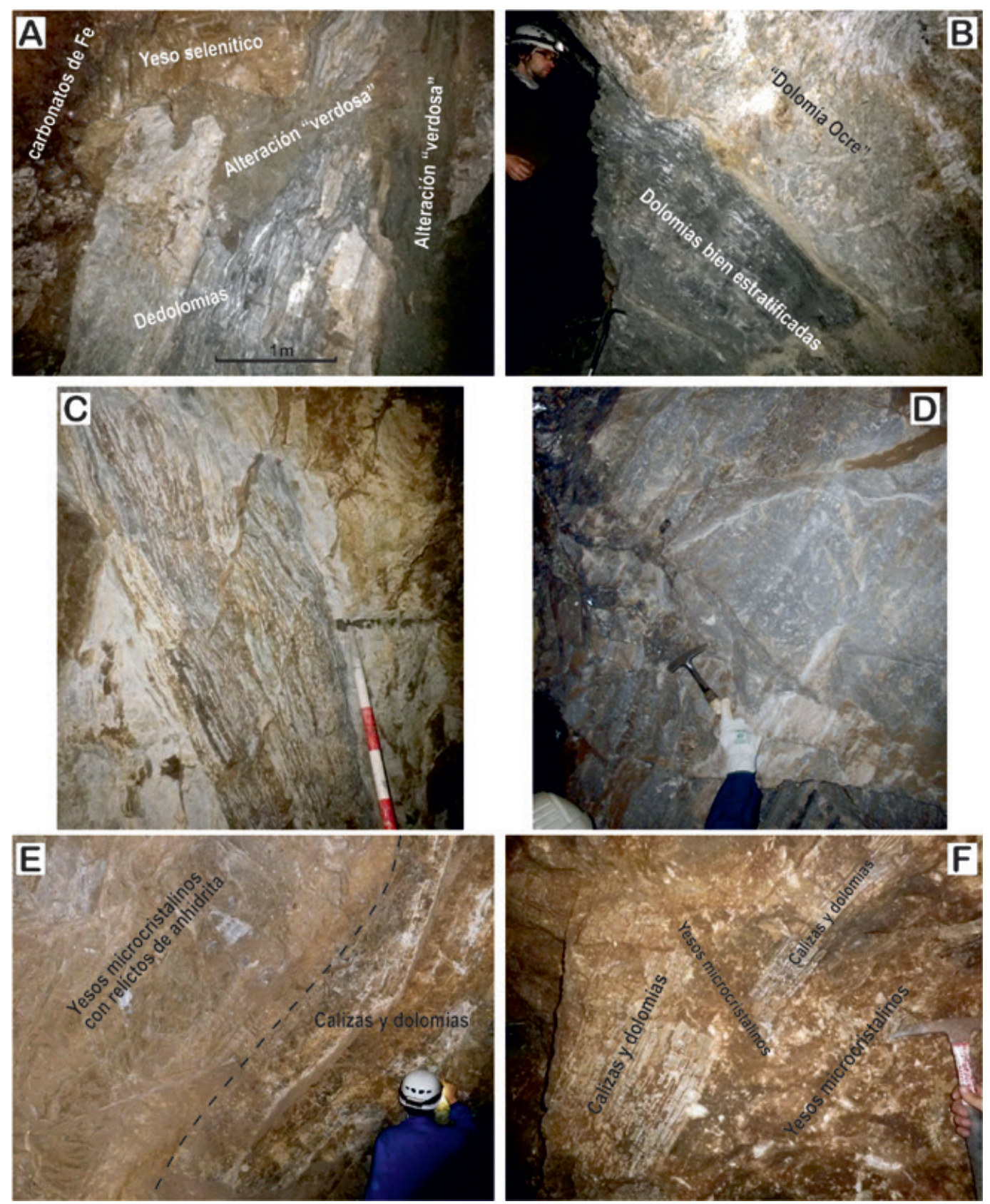

Figura 10. A: Unidad de brechas y dedolomías tableadas con tramos brechificados y con alteración verdosa superpuesta. Se puede apreciar un agregado macro-cristalino de yeso selenítico en la parte superior izquierda. 'Tajo Piritas', $1^{\mathrm{a}}$ planta, Sector PSA. B: Unidad de calizas y dolomías ocres. Contacto de muro de las calizas y dolomías ocres con las calizas y dolomías bien estratificadas en el crucero de acceso al 'Tajo Rico' en la Planta $2^{\mathrm{a}}$ del sector de PSA. C: Afloramiento característico de la unidad de margofilitas y dolomías laminadas en la pared de la galería general de transporte (nivel-15). D: Unidad de yesos microcristalinos en un pilar de la cámara principal de 'Quien Tal Pensara' (QTP-2). Se aprecia una laminación grosera y el contacto irregular con un cuerpo de carbonatos de hierro a la izquierda. E: Unidad de yesos microcristalinos junto al Pozo Carrasco en la $2^{a}$ planta. Se aprecia el bandeado grosero y el contacto de muro concordante con los carbonatos en la derecha de la imagen. F: Contacto de techo de un paquete de yesos microcristalinos en la galería de acceso a la cámara OTP-3. Los yesos se sitúan entre los planos de estratificación y fracturas de la capa de carbonatos produciendo su disgregación. Observar el bloque de la parte superior desplazado respecto a su continuación en la parte inferior.

Figure 10. A: Unit of breccias and layered dedolostones with brecciated intervals and greenish alteration superimposed. Macro-crystalline aggregate of selenite gypsum in the upper left side. 'Tajo Piritas', 1st level, PSA Sector. B: Unit of limestone and ochre dolostones. Footwall contact of limestone and ochre dolostones with the well bedded limestone and dolostones in the cross-cut tunnel to 'Tajo Rico' on the $2^{\text {nd }}$ level of the PSA sector. C: Characteristic outcrop of the unit of laminated marl-phyllites and dolostones in the wall of the general transport tunnel (level -15). D: Unit of microcrystalline gypsum in a pillar of the main stope of 'Quien Tal Pensara' (QTP-2). A roughly lamination can be seen in the gypsum seam. Irregular contact with an iron carbonate body to the left. E: Unit of microcrystalline gypsum next to the Carrasco Shaft on the $2^{n d}$ level. Rough layering and concordant footwall contact with carbonates beds on the right of the image. F: Hanging wall contact of a microcrystalline gypsum seam in the tunnel to access to OTP-3 stope. The gypsums are set between the stratification and fractures of the carbonate beds disaggregating the rocks. Observe the block in the upper part that has shifted with regard to its continuation in the lower part. 

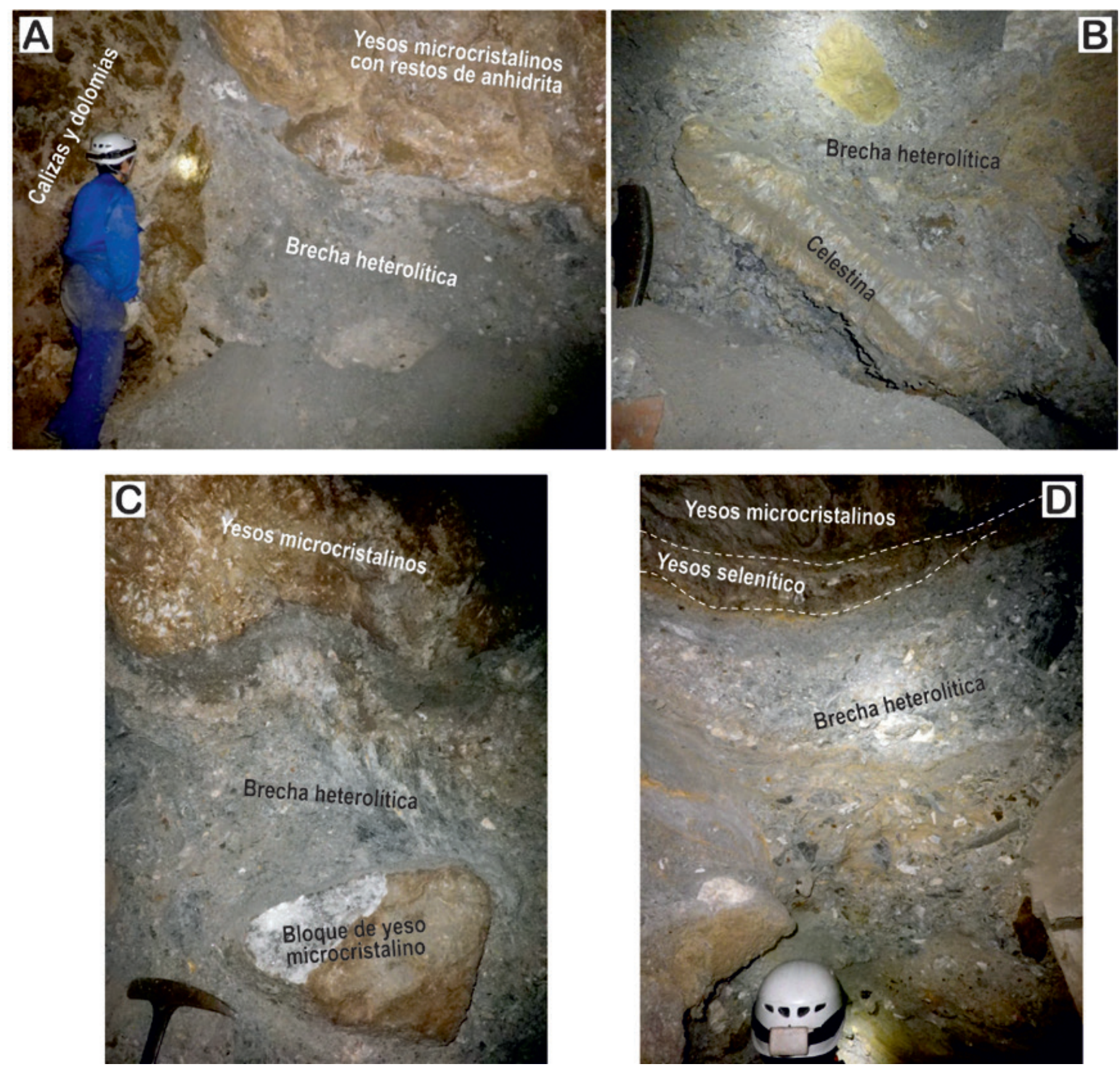

Figura 11. A: Cuerpo de brechas heterolíticas en yesos microcristalinos (parte superior de la imagen). Apreciar el contacto neto con una superficie lisa, sin aristas, del paquete yesífero. Planta $2^{\mathrm{a}}$ junto al Pozo Carrasco. B: Fragmento de la mineralización de celestina con estructura en escarapela, que ha quedado incorporado como un bloque en la brecha heterolítica. Afloramiento en la cabecera del Pozo Carrasco. C: Bloque redondeado de yeso microcristalino incorporado en la brecha heterolítica del afloramiento de la imagen A, junto al Pozo Carrasco. D: Cuerpo de brechas heterolíticas en la cabecera del Pozo Carrasco en la $1^{\mathrm{a}}$ planta. Apreciar una cierta ordenación interna de la brecha, propia de estructuras de colapso, y el lentejón de yeso selenítico que hay entre los yesos microcristalinos y la brecha.

Figure 11: A: Body of heterolithic breccia in microcrystalline gypsum unit (upper part of the image). Note the clear contact with a smooth surface, without edges, of the gypsum package. $2^{\text {nd }}$ level next to the Carrasco Shaft. B: Fragment of the celestine mineralization with cockade structure, which has been incorporated as a block in the heterolithic breccia. Outcrop at the head of the Carrasco Shaft. C: Rounded block of microcrystalline gypsum incorporated into the heterolithic breccia of the outcrop in image A, next to the Carrasco Shaft. D: Body of heterolithic breccia at the head of the Carrasco Shaft on the 1st level. Note a certain internal classification of the breccia, typical of collapse structures, and the lenticular body of selenite gypsum that is between the microcrystalline gypsums and the breccia. 
carbonatos ferrosos que quedan limitados a algunos paquetes de dolomía, así como en pequeñas vetas con siderita. También se han visto algunas grietas de tensión rellenas de yeso selenítico, especialmente en zonas cizalladas.

\section{Dolomías crema y dolomías oscuras}

En una galería lateral de la cámara QTP-2 se observan unos carbonatos crema bien estratificados en paquetes de más de 1 metro. Estos carbonatos parecen ser propios de este sector del yacimiento, donde se presentan orientados con direcciones NNE-SSW y buzamientos fuertes al Oeste. Son rocas de aspecto masivo ligeramente recristalizadas que aparecen en contacto aparentemente concordante con tramos de yesos microcristalinos o a modo de intercalaciones entre ellos, produciéndose en estos casos una brechificación de la roca. En los niveles carbonatados al microscopio se reconocen posibles bandas milimétricas que fueron ricas en sulfatos (Fig. 9D). En el polvorín interior (ver Fig. 4) y en la galería de base de la cámara QTP-3 se han encontrado unas dolomías oscuras, casi negras, en contacto con las dolomías crema. Se presentan bien estratificadas en paquetes de espesor decimétrico y tienen un aspecto masivo microgranular.

\section{Yesos microcristalinos de aspecto sacaroideo}

En ambos sectores de la mina se encuentran cuerpos masivos de yeso microscritalino en los que se reconoce una burda laminación sedimentaria (Fig. 9D). Destacan dos paquetes por su potencia y continuidad lateral y vertical, que son el de la cámara principal de 'Quien Tal Pensara' (QTP-2) y el del Pozo Carrasco en el sector de 'Por Si Acaso'. El primero de ellos corresponde a una banda que se inicia en forma de cuña entre las alternancias de calizas y dolomías bien estratificadas y las dolomías crema, formando un afloramiento continuo de unos 4 a $5 \mathrm{~m}$ de espesor y más de $50 \mathrm{~m}$ de longitud. Se extiende también en vertical y llega hasta la superficie. La banda está en contacto neto con un cuerpo mineralizado de carbonatos de hierro, llevando un rumbo NNE-SSW con buzamiento bastante constante de unos $65^{\circ}$ al Oeste. El paquete del sector PSA se reconoce en las tres plantas cartografiadas, encontrándose parte del Pozo Carrasco excavado en los yesos. En la sección de la $2^{\text {a }}$ planta tiene unos $5 \mathrm{~m}$ de espesor con rumbo $\mathrm{N} 20^{\circ} \mathrm{E}$ y $50^{\circ}$ de buzamiento al W (Fig. 9E). Presenta un bandeado grosero y el aspecto sacaroideo característico, pero intercalados hay parches de anhidrita con tono azulado, más duros y grano más fino (Fig. 9E). Los contactos de muro y techo parecen concordantes con las calizas y dolomías que los rodean (Fig. 9E), pero también hay algunos paquetes de carbonatos intercalados, que están brechificados y disgregados mecánicamente entre la masa de sulfato. Este proceso parece conllevar un cierto reemplazamiento de los carbonatos por yeso. Estos yesos se extienden hacia en SSW en más de $75 \mathrm{~m}$, como demuestran sus exposiciones en puntos apartados del Pozo Carrasco, tanto en la $1^{\text {a }}$ como en la $3^{\mathrm{a}}$ planta. Aparentemente el paquete va perdiendo espesor hacia el SW. Este paquete de yeso incluye una brecha heterolítica y caótica que será descrita más adelante.

Otros afloramientos reseñables de yesos microcristalinos sacaroides en la mina son los siguientes (ver figs. 4 y 6 ):

El del polvorín localizado en 'Quien Tal Pensara'. Allí se aprecia que los yesos tienen un contacto discordante con las capas de dolomías cremas y oscuras, con contactos netos y soldados. Igualmente se ven fragmentos de carbonato aislados entre la masa de yeso microcristalino. Al microscopio se observa como los yesos microcristalinos llegan a reemplazar a los cristales de dolomita (Fig. 9F).

En la galería de acceso a la cámara QTP-3, donde hay un paquete de $2 \mathrm{~m}$ de espesor que se extiende hacia el SSW cortándose también en la galería de transporte. Se presenta concordante entre las margofilitas y dolomías laminadas, aunque se ve como el yeso se introduce entre los estratos de carbonatos siguiendo los planos de rotura y de estratificación, produciendo la disgregación mecánica de la capa de carbonato (Fig. 9, F).

En la misma galería de acceso a la cámara QTP-3 hay otro paquete de yeso entre dolomías crema que está parcialmente disuelto y sustituido en gran parte por brechas heterolíticas.

También se encuentran lentejones a modo de pequeños lentejones tectónicos en una banda de cizaIla que va siguiendo la galería de acceso a la cámara QTP-2, entremezclados con mineralización y otras litologías.

En la fractura que sirve de límite meridional al lentejón de 'Por Si Acaso', en la que está excavada la rampa de bajada de $1^{\mathrm{a}}$ a $2^{\mathrm{a}}$ planta, hay otro lentejón de yeso estirado por efecto del cizallamiento. Pese a la fuerte deformación de la estructura, los microcristales de yeso no muestran señales deformativas, lo que sirve de criterio para afirmar que la recristalización del sulfato de calcio se realiza en condiciones post-cinemáticas.

Finalmente, en superficie se encuentran afloramientos de estos yesos en una pequeña cantera al 
norte de la corta de 'Por Si Acaso', así como en la pared meridional de una de las cortas de 'Quien Tal Pensara'. Este último es, seguramente, el mismo que aparece en el interior de la mina en esa zona.

\section{Brechas heterolíticas}

Ocupando los huecos de disolución en algunos paquetes deyesos microscristalinos, especialmente en el que hay junto al Pozo Carrasco, aparece una brecha de aspecto caótico con fragmentos de tamaños variables y todas las litologías del yacimiento. Los fragmentos, de tamaño irregular y formas angulosas, aparecen envueltos por abundante matriz terrosa dando al material un aspecto deleznable (Fig. 11A). Esta matriz es argílico-arenosa formada por moscovita, cuarzo, epsomita, goethita, hematites y yeso, siendo este el que confiere cierta cohesión. Las formas angulosas de los fragmentos, con aristas marcadas y superficies de rotura, indican un mínimo transporte. Los que son de la mineralización llegan a mantener texturas cristalinas frágiles propias de su formación, como algún bloque con celestina fibrosa que, pese a la fragilidad del material, no están muy disgregadas (Fig. 11B). Los únicos bloques que tienen formas redondeadas son los de yeso microcristalino (Fig. 11C).

La brecha presenta una cierta ordenación en capas inclinadas y forma cóncava hacia el centro del cuerpo, características propias de brechas gravitacionales de colapso (Fig. 11D). Los contactos con los yesos encajantes son netos, con superficies lisas, sin aristas, compatibles con procesos de disolución (Fig. 11B), al igual que los bloques redondeados de yesos incorporados en la brecha.

En la cabecera del Pozo Carrasco, en la $1^{\text {a }}$ planta, entre la brecha y el yeso microcristalino encajante hay una banda de yeso selenítico de forma lenticular, de unos $25 \mathrm{~cm}$ de anchura, (Fig. 11D). Estas placas de yeso, que pueden llegar a tener algunos huecos geódicos, se han encontrado en otras exposiciones de estas brechas ( $3^{\mathrm{a}}$ planta, o en la galería a QTP-3), situándose siempre hacia los bordes.

A lo largo de la pared SE de la cámara del nivel-59, justo bajo la cavidad de la "Gran Geoda", hay también un cuerpo de brechas de este tipo, aunque de pequeñas dimensiones y no relacionado con yesos microcristalinos. Su forma es lentejonar tumbada, con menos de $1 \mathrm{~m}$ de espesor y unos $5 \mathrm{~m}$ de largo. Está formada principalmente por fragmentos de filitas y algunos de mineralización de carbonatos de hierro, en una matriz terrosa y arcillosa. Estas brechas se encuentran entre la dolomía ocre brechificada en el muro y una delgada banda de carbonatos de hierro

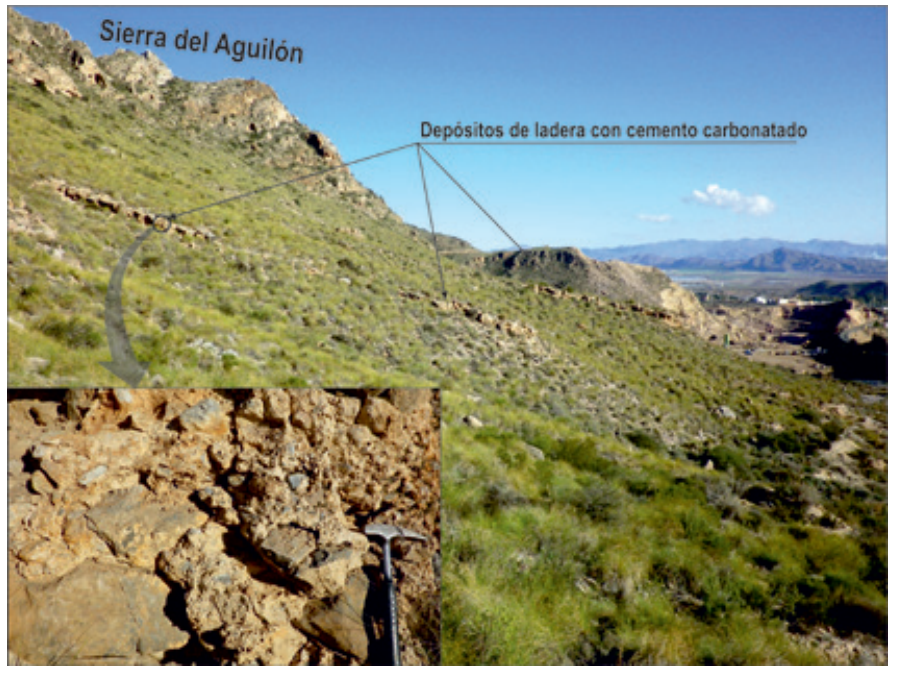

Figura 12. Afloramientos de las brechas de pie de monte consolidadas con cemento carbonatado, en la ladera oriental de la Sierra del Aguilón. Abajo izquierda, un detalle del afloramiento de la brecha, donde predominan bloques de caliza subangulosos a subredondeados y con señales de disolución.

Figure 12. Outcrops of consolidated-piedmont breccia deposit with carbonate cement, on the east slope of the Sierra del Aguilón. Below left, a detail of the breccia outcrop, where sub-angular to sub-rounded blocks of limestone predominate, with signs of dissolution.

en el techo, encontrándose inmediatamente encima de ella la selenita de uno de los extremos de la "Gran Geoda". Por la forma del cuerpo y su localización, esta brecha se sitúa muy cerca y paralela al contacto por falla con las filitas, que son las que aportan la mayor parte del material que la forma.

\section{Recubrimientos}

En las laderas de la Sierra del Aguilón hay unos depósitos de pie de monte que recubren parcialmente la superficie del yacimiento de la Mina Rica y su entorno. Estos depósitos aparecen consolidados y marcan una paleoladera, actualmente en parte desmantelada por la erosión de cursos de agua pluviales (Fig. 12). Se trata de brechas polimícticas con bloques de diferentes carbonatos y cuarzo, matriz escasa y abundante cemento carbonatado, las cuales enlazan con materiales arenosos gruesos que cubren la parte alta de la plana de San Juan de Terreros, formando un paquete de 3 a $5 \mathrm{~m}$ de potencia. Estos materiales marcan una superficie de arrasamiento que ha sido posteriormente elevada y en parte erosionada, indicando una clara reactivación del relieve en tiempos muy recientes. Se consideran, como muy antiguos, del techo del Plioceno Inferior (Espinosa Godoy et al. 1974), lo que concuerda con lo expresado por Martín et al (2003) y se puede suponer que la configuración del paisaje era ya parecida a la actual en esos 
tiempos. Su situación actual elevada sobre la línea de costa indica que ha habido una nueva elevación y aumento de las condiciones erosivas seguramente a comienzos del Cuaternario.

\section{Geología estructural del yacimiento}

La estructura general del yacimiento viene definida por la banda de afloramientos carbonatados de rumbo general NE-SW, que discurre por la ladera oriental de la Sierra del Aguilón, con cuya línea de cumbres describe un rumbo ligeramente divergente hacia el NE (Fig. 13). Los afloramientos de carbonatos están rodeados de filitas o micaesquistos con un grado de deformación importante. La banda termina en el extremo nororiental en una cantera de áridos calizos junto a la aldea del Pilar de Jaravía. En el lado opuesto se extiende hacia el SSW más allá de los dominios de la mina, donde los afloramientos quedan parcialmente cubiertos por depósitos de ladera.

La alineación de afloramientos carbonatados corresponde a una banda de cizalla de componente dextral, de rumbo general NE-SW, que van formando lentejones tectónicos de carbonatos entre las filitas. Esta estructura encaja en el modelo estructural de Sanz de Galdeano (1990) para el campo de esfuerzos durante el Serravalliense. La banda de cizalla de la Mina Rica correspondería a una estructura regional del sistema P (ver Fig. 5). Los bloques de carbonatos quedan limitados por cizallas frágiles-dúctiles de traza arqueada, de rumbos NNE-SSW a ENE-WSW, subverticales o con fuertes buzamientos hacia el SE, y componente de desplazamiento dextral (Fig. 14). Cortando a estas fallas principales hay otras de rumbo cercano a E-W, también dextrales y otras NW-SE, conjugadas, con componente sinestral. Dentro de los lentejones predominan las fallas NNE-SSW, también sinestrales, que forman estructuras en cuñas, metiendo las filitas entre los carbonatos. La banda de cizalla serravalliense se ve afectada por la reactivación producida por la falla regional de Cocón-Terreros de componente sinestral en el Tortoniense y Messiniense, haciendo jugar de nuevo a las fracturas existentes de rumbo parecido, especialmente a las fallas NNESSW, pero ahora en sentido a izquierdas. Estas fallas compartimentan a la banda de carbonatos en bloques, donde el occidental es desplazado hacia el Sur respecto al oriental.

Esta estructuración es la suma de los 2 episodios de cizallamiento y da lugar a la presente geometría interna de los lentejones tectónicos, encontrándose el yacimiento en uno de ellos. Este lentejón está a su vez cortado por una falla del sistema E-W dextral que

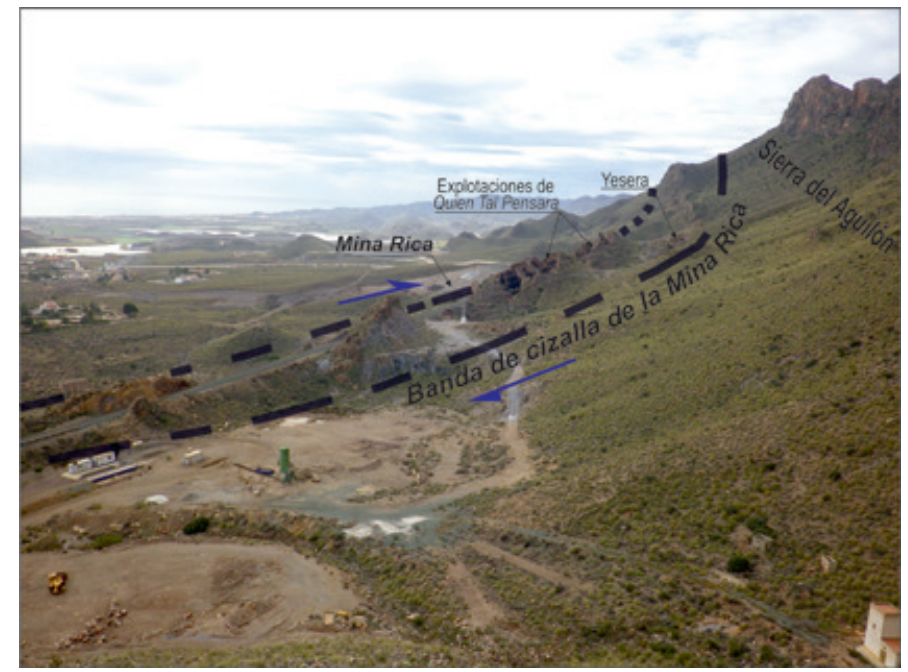

Figura 13. Alineación de afloramientos carbonatados de rumbo general NE-SW en la ladera oriental de la Sierra del Aguilón, que va marcando la banda de cizallamiento dextral en la que se encuentra el yacimiento. Vista hacia el Sur

Figure 13. Alignment of carbonate outcrops with NE-SW strike on the east slope of the Sierra del Aguilón, which marks the dextral shearing band in which the "Mina Rica" deposit is found. View towards the south.

lo individualiza en 2 bloques, los cuales corresponden a los 2 sectores de la mina: 'Quien Tal Pensara' al Norte y 'Por Si Acaso' al Sur (Fig. 14). Por todo ello la orientación interna de los bloques es NNE-SSW, haciendo ángulo con la de la banda de cizalla que es NE-SW. La estratificación se presenta con fuerte buzamiento al Oeste, con tendencia monoclinal, con los planos axiales de los pliegues inclinados unos $70^{\circ}$ al $W$, lo que da una vergencia general hacia el Este (Fig. 15A). Los tramos con buzamientos invertidos son difíciles de diferenciar de aquellos que se hallan en posición normal, ya que el ángulo entre flancos es muy agudo. Las charnelas están frecuentemente rotas y se realiza el paso de un flanco a otro mediante una fractura que suele estar reactivada como desgarre.

Los sistemas de fracturación que afectan a los lentejones tectónicos son, en su mayor parte, estructuras de fuerte buzamiento. En general se pueden agrupar en 3 sistemas: las fallas longitudinales que Ilevan la misma dirección que la estratificación NNE-SSW, y las transversales NW-SE y E-W; todas ellas compatibles con la dinámica del corredor de cizalla dextral NE-SW mencionado. Cortando a todas las estructuras aparece otro sistema formado por fracturas más tendidas con rumbo norteado y buzamientos entre $60^{\circ}$ y $40^{\circ}$ al Este y al Oeste, que suelen aparecer abiertas. Son pocas estas estructuras frágiles pero indican una clara extensión en la vertical posterior al cizallamiento.

Las estructuras reconocidas en la mina permiten establecer 3 episodios de deformación que encajan 


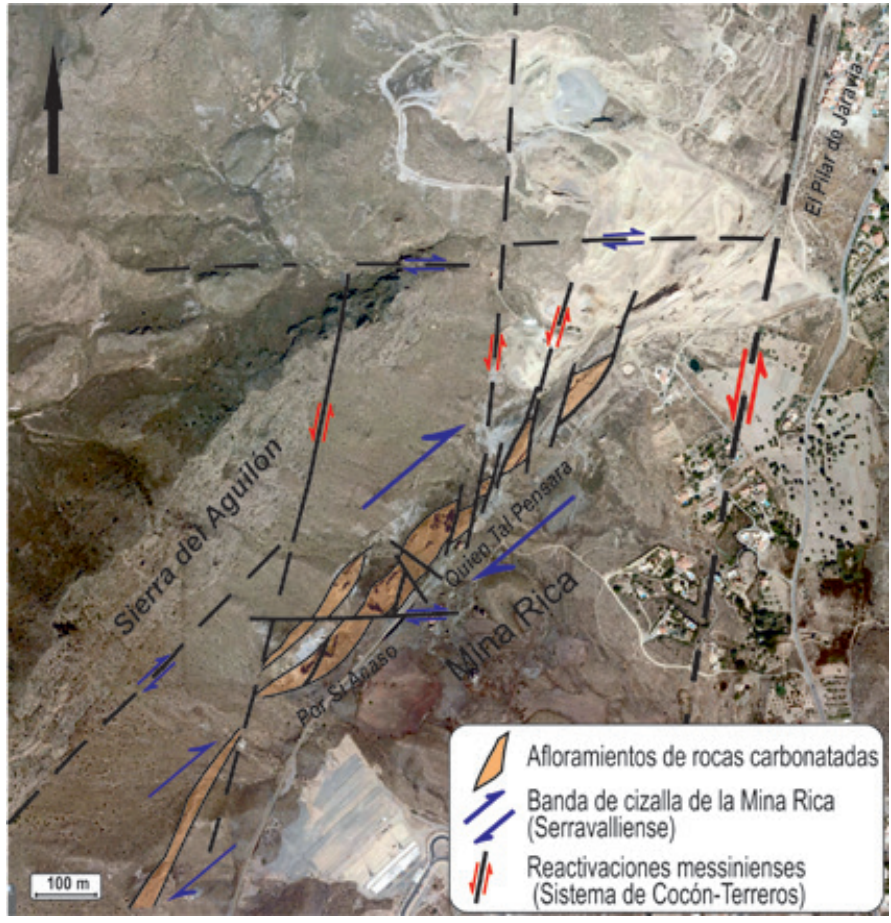

Figura 14. Esquema geológico-estructural del yacimiento de la Mina Rica. Figure 14. Geological-structural sketch of the "Mina Rica" deposit.

bien con la "evolución Neo-Bética" propuesta por Boccaletti et al. (1987), a saber:

a) Tectónica de cizallamiento y plegamiento, responsable de la formación de los lentejones tectónicos y su estructura interna.

b) Tectónica transcurrente frágil, principalmente representada por las reactivaciones de fallas.

c) Tectónica extensional, manifestada por nuevas reactivaciones de fallas en condiciones tensionales y la formación de nuevas estructuras frágiles.

\section{Tectónica de cizallamiento y plegamiento}

El cizallamiento representa una deformación heterogénea que dentro de los lentejones tectónicos se manifiesta mediante desgarres que actúan de contactos entre las unidades descritas anteriormente y rotaciones de la estratificación en los bordes. El plegamiento es compatible también con el acortamiento producido dentro de la cizalla dextral NE-SW, con trazas axiales NNE-SSW que reflejan una dirección de compresión WNW-ESE.

La roseta de direcciones de los planos de estratificación en las plantas $2^{\mathrm{a}}$ y $3^{\mathrm{a}}$ del sector de PSA muestran un rumbo predominante de NNE-SSW a NE-SW, con buzamientos concentrados en el rango de 60 a $70^{\circ}$ al Oeste (Fig. 16A y 16B). El estereograma de polos de es- tos planos muestra la concentración casi exclusiva en un único cuadrante, en este caso el $\mathrm{SE}$, propio de una serie monoclinal. En el sector de QTP la estratificación sigue el mismo patrón, si bien en esa parte de la mina no se han visto charnelas de pliegues (Fig. 16C). El cálculo de autovectores a partir de esos datos determina la orientación del campo de esfuerzos en diversos lugares de la mina como se indica en la Tabla 1:

Las orientaciones de los vectores calculados son muy semejantes en las plantas del sector PSA. Corresponden a un régimen de desgarre con una cierta componente inversa al presentar el vector intermedio $\left(\sigma_{2}\right)$ una inclinación de $57^{\circ}$ y $63^{\circ}$ al NW. En QTP el vector principal compresivo $\left(\sigma_{1}\right)$ es similar, pero el intermedio $\left(\sigma_{2}\right)$ y el tensional $\left(\sigma_{3}\right)$ muestran plunges de mediana inclinación, indicando que la componente inversa es más acusada y corresponden a un régimen mixto inverso-desgarre. La presencia de estrías con un pitch de $50^{\circ}$ al SW en los planos de estratificación es coherente con lo deducido en el cálculo de eigenvectores. Los eigenvalores relacionados a estos vectores (Fig. 16) muestran una componente esencialmente compresiva con magnitudes $>0,85$ para el vector principal $\left(\sigma_{1}\right)$, mientras que la componente tensional $\left(\sigma_{3}\right)$ es casi inapreciable, lo que justifica que no se encuentren fracturas tensionales relacionadas con los pliegues.

Los sistemas de fracturación encontrados en la mina son compatibles con los generados en este régimen de cizallamiento dextral del Serravalliense (Fig. 17). La roseta de direcciones de las fallas reconocidas en las plantas $2^{\mathrm{a}}$ y $3^{\mathrm{a}}$ del sector de PSA tienen un rumbo dominante entre $\mathrm{N} 20^{\circ} \mathrm{E}$ y $\mathrm{N} 40^{\circ} \mathrm{E}$ con buzamientos fuertes de 80 a $90^{\circ}$ al NW y SE (Fig. 17A y 17B). Estas fallas corresponderían a los desgarres dextrales de los sistemas C y $\mathrm{P}$ de la banda de cizalla, lo cual es lógico ante una componente esencialmente compresiva. Sin embargo Ilama la atención que apenas aparezcan fracturas del sistema $\mathrm{R}$, lo cual puede deberse a la acusada anisotropía de la roca, donde los planos de estratificación de la secuencia deformada facilitan el desarrollo de los sistemas $\mathrm{C}$ y $\mathrm{P}$ e inhiben el desarrollo de los $\mathrm{R}$.

Los autovectores calculados para la población de fallas es muy semejante en ambas plantas de 'Por $\mathrm{Si}$ Acaso', con posiciones del esfuerzo principal compresivo $\left(\sigma_{1}\right)$ en WNW-ESE y plunges casi horizontales, con el esfuerzo intermedio $\left(\sigma_{2}\right)$ subvertical y el esfuerzo tensional $\left(\sigma_{3}\right)$ con cabeceo casi horizontal (Tabla 2$)$.

Este régimen es de desgarre casi puro, que contrasta ligeramente con la componente mixta deducida para el plegamiento. Esto se puede explicar como consecuencia de una deformación progresiva en el caso de plegamiento, que debe iniciarse mediante un proceso de buckling al comienzo de la compresión, y terminar con charnelas rotas y festoneadas por aplastamiento 

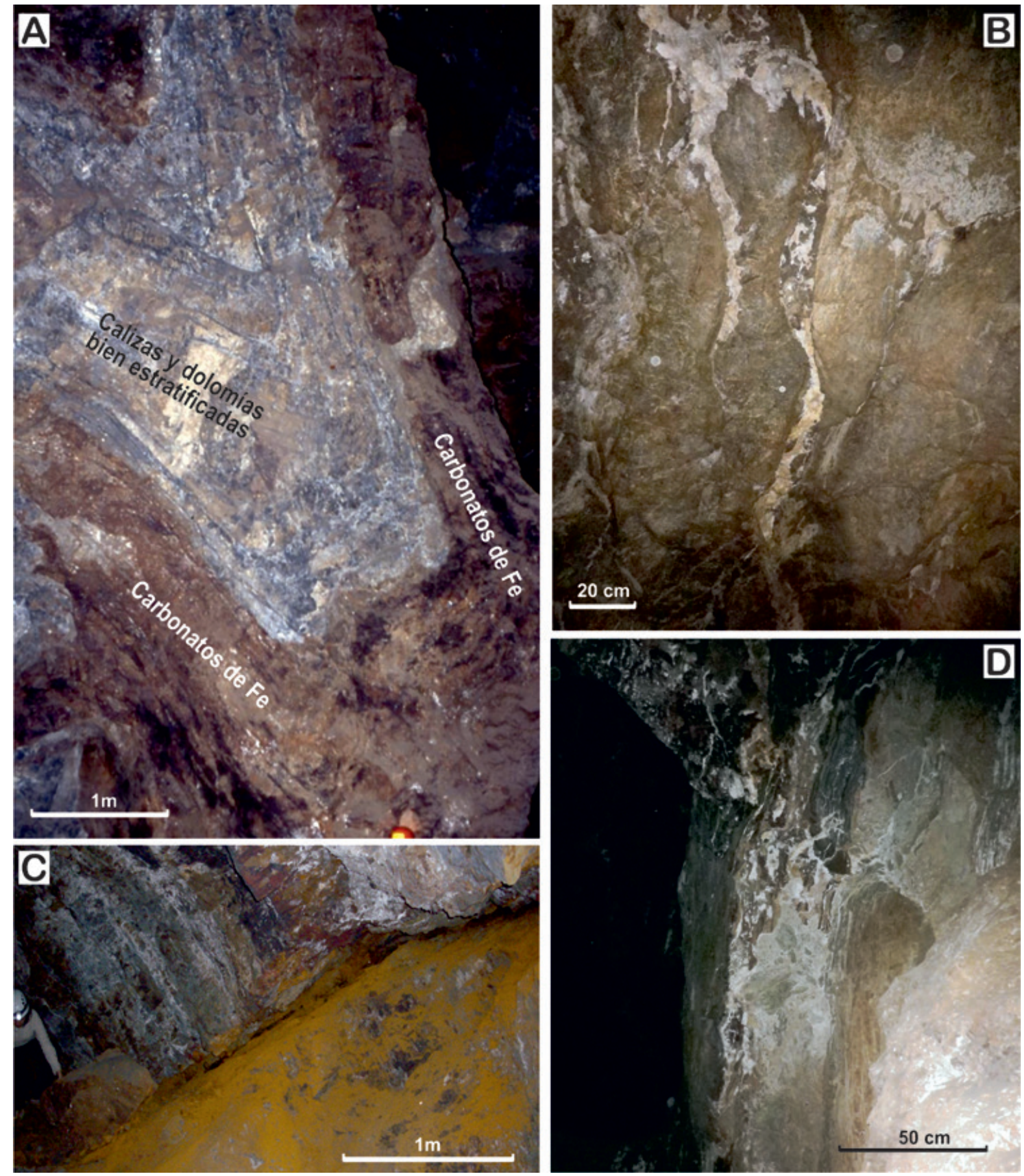

Figura 15. A: Pliegue en la pared sur de una cámara de explotación del 'Tajo Rico' en la $3^{\text {a }}$ Planta del sector PSA. El pliegue muestra la charnela apretada, rota y duplicada en la parte interna, resolviendo el acortamiento con acuñamientos y formación de doble charnela. B: Fractura de rumbo norteado con componente transtensiva en el techo de la cámara del 'Tajo del Sapo' en la planta $2^{\mathrm{a}}$ del sector PSA. EI reIleno es de barita. C: Brecha tectónica en el contacto de techo de las dolomías ocres con un cuerpo de carbonatos de hierro en las dolomías bien estratificadas. Se aprecia al menos 2 pulsos de brechificación. El primero brechifica y altera la roca, mientras que el segundo rompe de nuevo los fragmentos de brecha emplazándose los sulfatos (barita y celestina) en grietas. D: Fractura tensional de buzamiento tendido que corta casi ortogonalmente a la estratificación y fracturas verticales. Presenta relleno parcial de cristales de yeso selenítico y costras y agregados terrosos de limonitas.

Figure 15. A: Fold in the south wall of a stope of the 'Tajo Rico' exploitation on the $3^{\text {rd }}$ level of the PSA sector. The fold shows the hinge tightened, broken and duplicated on the internal part, resolving the shortening with wedging and double-hinge formation. B: Fracture northerly bearing with transtensional component in the ceiling of the 'Tajo del Sapo' stope on the $2^{\text {nd }}$ level, PSA sector. The infilling is baryte. C: Tectonic breccia in the hanging wall contact of the ochre dolostones with a body of iron carbonates hosted in the well stratified dolostones. At least two brecciation events can be seen. The first brecciates and alters the rock, whilst the second breaks the breccia fragments again, emplacing the sulphates (baryte and celestine) into the cracks. D: Low dip tensional fracture that cuts the stratification and vertical fractures almost orthogonally. It has a partial filling with crystals of selenite gypsum and crusts and earthy aggregates of limonites. 


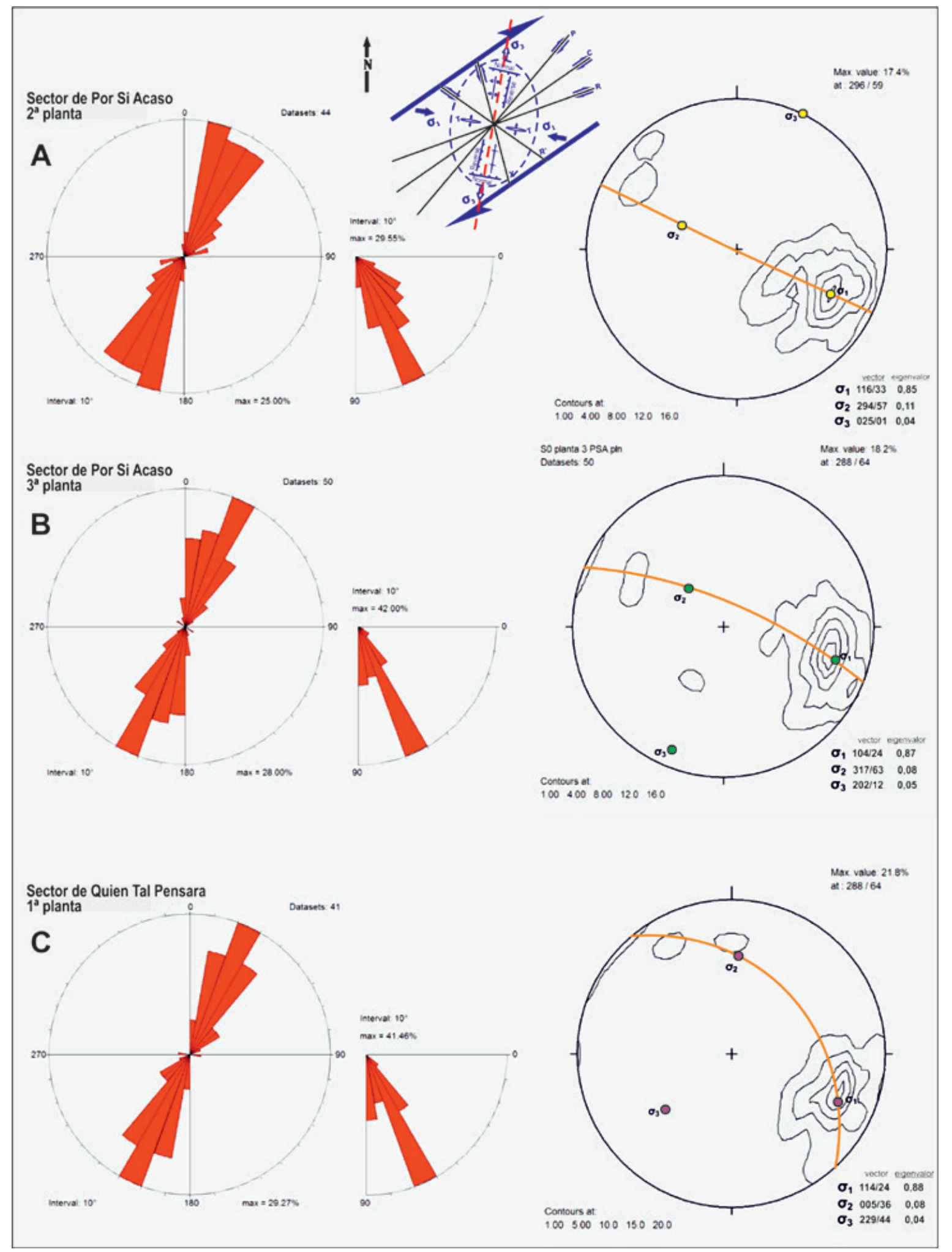

Figura 16. Rosetas de direcciones, estereogramas de polos de planos de estratificación y cálculo de eigenvectores representativos del campo de esfuerzos que ha deformado a la secuencia carbonatada de la Mina Rica. A: Planos de estratificación en la plantas $2^{\mathrm{a}}$ del sector PSA. B: Planos de estratificación en la planta $3^{a}$ del sector PSA. C: Planos de estratificación en el sector QTP.

Figure 16. Rose diagrams, stereograms of poles of stratification planes and calculation of eigenvectors representative of the stress field that has deformed the carbonate sequence of the Mina Rica. A: Bedding planes on the $2^{\text {nd }}$ level of the PSA sector. B: Bedding planes on the $3^{\text {rd }}$ level of the PSA sector. C: Bedding planes in the QTP sector. 
en un ambiente somero. La deformación progresiva supone una componente rotacional, lo que la suma de plegamiento, aplastamiento y cizallamiento conllevaría al regimen mixto dextral-inverso, aunque la banda de cizalla regional sea esencialmente de desgarre.

Los eigenvalores calculados para estos vectores (Fig. 17) muestran unas condiciones esencialmente compresivas (magnitudes de 0,70 para $\sigma_{1}$ ) pero con una componente tensional apreciable (magnitud de 0,25 y 0,22 para $\sigma_{3}$ ). Sin embargo, en la mina apenas se reconocen fracturas de tensión verticales de rumbo NW-SE. La componente tensional de la fracturación puede resolverse mediante fisuración de las capas de carbonatos así como por la apreciable componente frágil de las fallas longitudinales que afectan a la secuencia carbonatada. Además hay que tener en cuenta que en las filitas, debido a su poca competencia y abundancia de partículas planares, la componente va a ser esencialmente de aplastamiento, con desarrollo de fábricas tipo S/C. Dado que la mayor parte de las estructuras utilizadas para el cálculo corresponden a fallas de la zona de explotación en carbonatos, la componente frágil tensional de la macro-estructura completa del corredor de cizalla puede estar sobrevalorada.

En el sector de 'Quien Tal Pensara' la roseta de direcciones de fracturas muestra dos máximos en $\mathrm{N} 40^{\circ} \mathrm{E}$ a $\mathrm{N} 60^{\circ} \mathrm{E}$ y en $\mathrm{N} 160^{\circ} \mathrm{E}$ a $\mathrm{N} 180^{\circ} \mathrm{E}$ correspondientes a los sistemas $\mathrm{C}$ y $\mathrm{X}$, que son conjugados en la banda de cizalla dextral (Fig. 17C). Son también importantes los sistemas WNW-ESE (de N80 ${ }^{\circ}$ a N $120^{\circ}$ E) y NE-SW (de $\mathrm{N} 20^{\circ}$ a $\mathrm{N} 40^{\circ} \mathrm{E}$ ). Los buzamientos de las fracturas son en general fuertes, pero hay un grupo de fallas de rumbo
NNW-SSE con bajo buzamiento. Estas fallas tendidas no encajan en los sistemas de fallas generados por la banda de cizalla dextral siendo su formación posterior y deben ser consideradas de forma independiente. Los autovectores deducidos de la población global de fallas en QTP representan a un campo de esfuerzos algo diferente al de PSA (Tabla 2). La posición del vector principal de acortamiento $\left(\sigma_{1}\right)$ es más norteado y algo inclinado, más propio del modelo Tortoniense o Messiniense, aunque en origen la mayor parte de las fallas de este sector también se hubieran formado en el Serravalliense.

\section{Tectónica transcurrente frágil}

Aunque la mayor parte de la fracturación se generó durante el cizallamiento dextral del Serravalliense, muchas de las fracturas reconocidas en la mina muestran señales de reactivaciones frágiles dando lugar a brechas tectónicas que incorporan fragmentos con señales de la deformación precedente. Determinar el campo de esfuerzos en que se han generado estas reactivaciones es difícil, ya que son escasas las superficies estriadas expuestas y aún menos las que tienen estrías superpuestas. Las estructuras más comunes con señales de reactivación son las NW-SE a NNWSSE, compatibles con el acortamiento Tortoniense y Messiniense de Sanz de Galdeano (1990). Se reconocen nuevas fracturas del sistema NNW-SSE que son tensionales o con componente transtensiva, que cortan a fracturas más antiguas (Fig. 15B). También hay fracturas NNE-SSW que aparecen cortando a otras $\mathrm{E}-\mathrm{W}$ reflejando movimientos post-serravallienses. To-

\begin{tabular}{|c|c|c|c|c|c|c|}
\hline \multirow{2}{*}{ Planta de Mina } & \multicolumn{2}{|c|}{$\sigma_{1}$} & \multicolumn{2}{c|}{$\sigma_{2}$} & \multicolumn{2}{c|}{$\sigma_{3}$} \\
\cline { 2 - 7 } & Rumbo & Plunge & Rumbo & Plunge & Rumbo & Plunge \\
\hline $2^{\text {a }}$ planta PSA & $\mathrm{N} 116^{\circ} \mathrm{E}$ & $33^{\circ} \mathrm{SE}$ & $\mathrm{N} 294^{\circ} \mathrm{E}$ & $57^{\circ}$ al NW & $\mathrm{N} 025^{\circ} \mathrm{E}$ & $1^{\circ} \mathrm{NE}$ \\
\hline $3^{\mathrm{a}}$ planta PSA & $\mathrm{N} 104^{\circ} \mathrm{E}$ & $24^{\circ} \mathrm{SE}$ & $\mathrm{N} 317^{\circ} \mathrm{E}$ & $63^{\circ}$ al NW & $\mathrm{N} 202^{\circ} \mathrm{E}$ & $12^{\circ} \mathrm{SW}$ \\
\hline $1^{\mathrm{a}}$ planta OTP & $\mathrm{N} 114^{\circ} \mathrm{E}$ & $24^{\circ} \mathrm{SE}$ & $\mathrm{N} 005^{\circ} \mathrm{E}$ & $36^{\circ}$ al N & $\mathrm{N} 202^{\circ} \mathrm{E}$ & $44^{\circ} \mathrm{SW}$ \\
\hline
\end{tabular}

Tabla 1. Orientación de los autovectores del campo de esfuerzo deducidos a partir de los planos de estratificación en la Mina Rica.

Table 1. Orientation of the eigenvectors of the stress field obtained from the bedding planes in Mina Rica.

\begin{tabular}{|c|c|c|c|c|c|c|}
\hline \multirow{2}{*}{ Planta de Mina } & \multicolumn{2}{|c|}{$\boldsymbol{\sigma}_{1}$} & \multicolumn{2}{c|}{$\boldsymbol{\sigma}_{2}$} & \multicolumn{2}{c|}{$\sigma_{3}$} \\
\cline { 2 - 7 } & Rumbo & Plunge & Rumbo & Plunge & Rumbo & Plunge \\
\hline $2^{\text {a }}$ planta PSA & $\mathrm{N} 127^{\circ} \mathrm{E}$ & $8^{\circ} \mathrm{SE}$ & $\mathrm{N} 276^{\circ} \mathrm{E}$ & $80^{\circ}$ al NW & $\mathrm{N} 036^{\circ} \mathrm{E}$ & $5^{\circ} \mathrm{NE}$ \\
\hline $3^{\text {a }}$ planta PSA & $\mathrm{N} 127^{\circ} \mathrm{E}$ & $5^{\circ} \mathrm{SE}$ & $\mathrm{N} 238^{\circ} \mathrm{E}$ & $77^{\circ}$ al NW & $\mathrm{N} 036^{\circ} \mathrm{E}$ & $12^{\circ} \mathrm{NE}$ \\
\hline $1^{\text {a }}$ planta QTP & $\mathrm{N} 336^{\circ} \mathrm{E}$ & $26^{\circ} \mathrm{NW}$ & $\mathrm{N} 106^{\circ} \mathrm{E}$ & $52^{\circ}$ al SE & $\mathrm{N} 233^{\circ} \mathrm{E}$ & $25^{\circ} \mathrm{SW}$ \\
\hline
\end{tabular}

Tabla 2. Orientación de los autovectores del campo de esfuerzo deducidos a partir de los planos de fracturación en la Mina Rica. Table 2. Orientation of the eigenvectors of the stress field obtained from the fracture planes in Mina Rica. 


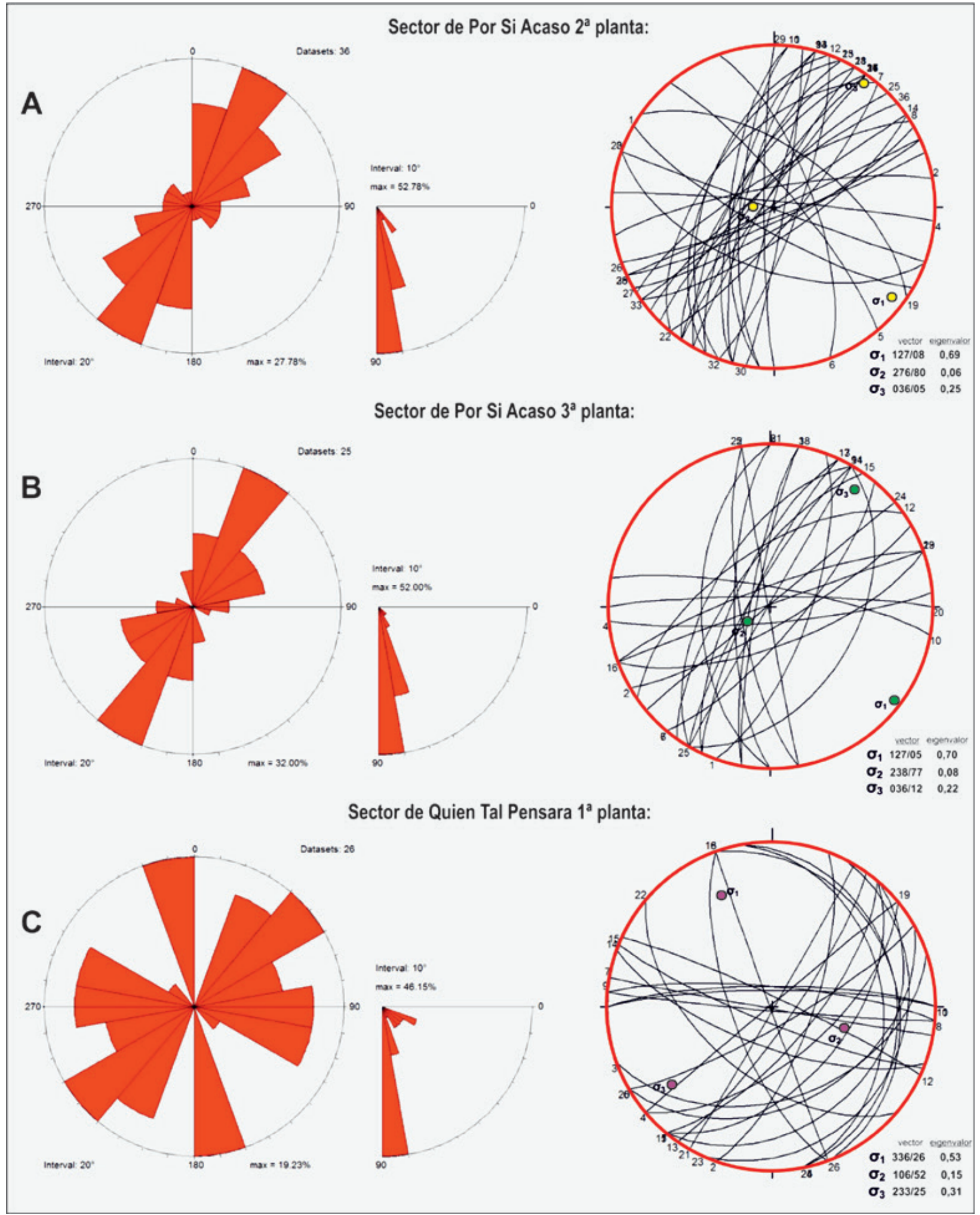

Figura 17. Rosetas de direcciones, estereogramas de planos de fracturas y cálculo de eigenvectores representativos del campo de esfuerzos que las ha formado en la Mina Rica. A: Planos de fracturas en la planta $2^{\mathrm{a}}$ del sector PSA. B: Planos de fracturas en la planta $3^{\mathrm{a}}$ del sector PSA. C: Planos de fracturas en el sector QTP.

Figure 17. Rose diagrams, stereograms of fracture planes and calculation of eigenvectors representative of the stress field that formed them in the Mina Rica. A: Fracture planes on the $2^{N D}$ level of the PSA sector. B: Fracture planes on the $3^{\text {rd }}$ level of the PSA sector. C: Fracture planes in the QTP sectors. 
das estas fallas presentan movimientos sinestrales, las cuales pertenecerían al sistema de fallas del corredor Cocón-Terreros, cuya actividad se hace más notable en elTortoniense (Coppier et al., 1989).

Analizando de forma separada los 2 conjuntos de fracturas que se reconocen en el sector de QTP (Tabla 3 ), en el conjunto de fuerte buzamiento los eigenvectores que se obtienen señalan al campo de esfuerzos Messiniense de Sáenz de Galdeano (1990), ya que el vector que representaría al esfuerzo compresivo principal $\left(\sigma_{1}\right)$ se sitúa cercano a N-S con plunge casi horizontal, el del esfuerzo intermedio $\left(\sigma_{2}\right)$ es casi vertical y el del tensional $\left(\sigma_{3}\right)$ es subhorizontal (Fig. 18A). Esto representa un sistema de desgarre casi puro, con componente principal de aplastamiento (magnitud 0,62 ), pero con una componente tensional importante (magnitud 0,34). Este modelo es compatible con la formación de fracturas tensionales verticalizadas NNW-SSE y reactivaciones frágiles de los sistemas de fallas precedentes con direcciones favorables.

Separar las reactivaciones que se producen en el Tortoniense y en el Messiniense resulta casi imposible, aunque parece clara su existencia puesto que quedan reflejadas en dos generaciones de brechas tectónicas. Huibregtse et al. (1998) encuentran un campo de esfuerzos muy semejante al aquí obtenido en las cuencas deformadas al Sur de Sierra Alhamilla y Sierra Cabrera, al Oeste de la zona de la Mina Rica, situándolo en el Messiniense.

Una especial atención merece la estructura de rumbo NNE-SSW que limita el contacto de techo de la unidad de dolomías ocres en la $2^{a}$ planta del sector PSA (Fig. 15C). Este contacto por falla contiene un cuerpo brechoide de más de un metro de potencia con dos episodios de brechificación así como geodas de yeso selenítico. Estas brechas indican unas condiciones tensionales claras, pero resultan incompatibles con las reactivaciones post-Serravalliense por la dirección que tiene, ya que debiera actuar como estructura compresiva. Sin embargo, las variaciones de buzamiento del contacto de las dolomías ocres con las alternancias de las dolomías bien estratificadas, inducen a la generación de espacios transtensi- vos en las partes más tumbadas, cuando se produce la reactivación como falla mixta inversa-desgarre. EI comportamiento como cuerpo rígido de las dolomías ocres facilita el desarrollo de las estructuras frágiles como esas brechas.

\section{Tectónica extensional}

Las mencionadas fracturas tensionales con buzamientos tendidos se encuentran en varios puntos de la mina pero las más importantes están en el sector de 'Quien Tal Pensara'. Aparecen vacías o parcialmente rellenas de cristales de yeso y costras de limonita (Fig. 15D). Presentan un desarrollo irregular, llegando a extensiones laterales decamétricas. Se trata de dos sistemas de fracturas conjugadas de dirección NE-SW y NNW-SSE que cortan a todas las estructuras precedentes, netamente tensionales pero con apenas desplazamientos en los labios. Los eigenvectores que se deducen de este grupo de fracturas (Fig. 18B) indican una dirección de acortamiento NE-SW casi horizontal, el vector intermedio $\left(\sigma_{2}\right)$ tiene un plunge inclinado $30^{\circ}$ al SE, y el tensional $\left(\sigma_{3}\right)$ lo tiene $58^{\circ}$ al NW. Los eigenvalores muestran una magnitud muy alta para el esfuerzo tensional $(0,80)$ y muy baja para el compresivo $(0,13)$, indicando todo ello unas condiciones claramente extensionales, con movimiento principal en la vertical, pero con una componente lateral añadida. El episodio extensional que genera estas fracturas es claramente tardío con respecto a todas las estructuras encontradas en la mina y habría que situarlo en momentos tardi-messinienses o pliocenos. Los depósitos de ladera con cemento carbonatado de la Sierra del Aguilón son del final del Plioceno Inferior (Espinosa Godoy et al., 1974; Aguirre 1998) y representan una elevación de la Sierra con la que se pueden relacionar. No obstante, el desmantelamiento erosivo de esos depósitos muestra nuevos movimientos verticales que Boccaletti et al, (1987) sitúan en el Pleistoceno y con los que también podrían estar relacionadas estas fracturas tensionales.

\begin{tabular}{|c|c|c|c|c|c|c|}
\hline \multirow{2}{*}{$\begin{array}{c}\text { Tipo de fracturas } \\
\text { en QTP }\end{array}$} & \multicolumn{2}{|c|}{$\sigma_{1}$} & \multicolumn{2}{c|}{$\sigma_{2}$} & \multicolumn{2}{c|}{$\sigma_{3}$} \\
\cline { 2 - 7 } & Rumbo & Plunge & Rumbo & Plunge & Rumbo & Plunge \\
\hline Fallas subverticales & $\mathrm{N} 353^{\circ} \mathrm{E}$ & $4^{\circ} \mathrm{N}$ & $\mathrm{N} 134^{\circ} \mathrm{E}$ & $85^{\circ}$ al SE & $\mathrm{N} 262^{\circ} \mathrm{E}$ & $3^{\circ} \mathrm{W}$ \\
\hline Fallas tendidas & $\mathrm{N} 207^{\circ} \mathrm{E}$ & $8^{\circ} \mathrm{SW}$ & $\mathrm{N} 113^{\circ} \mathrm{E}$ & $30^{\circ}$ al SE & $\mathrm{N} 310^{\circ} \mathrm{E}$ & $58^{\circ} \mathrm{NW}$ \\
\hline
\end{tabular}

Tabla 3. Orientación de los autovectores del campo de esfuerzo deducidos a partir de los planos de fracturación de la zona de ‘Quien Tal Pensara'.

Table 3. Orientation of the eigenvectors of the stress field obtained from the fractures planes in the "Quien Tal Pensara" zone. 


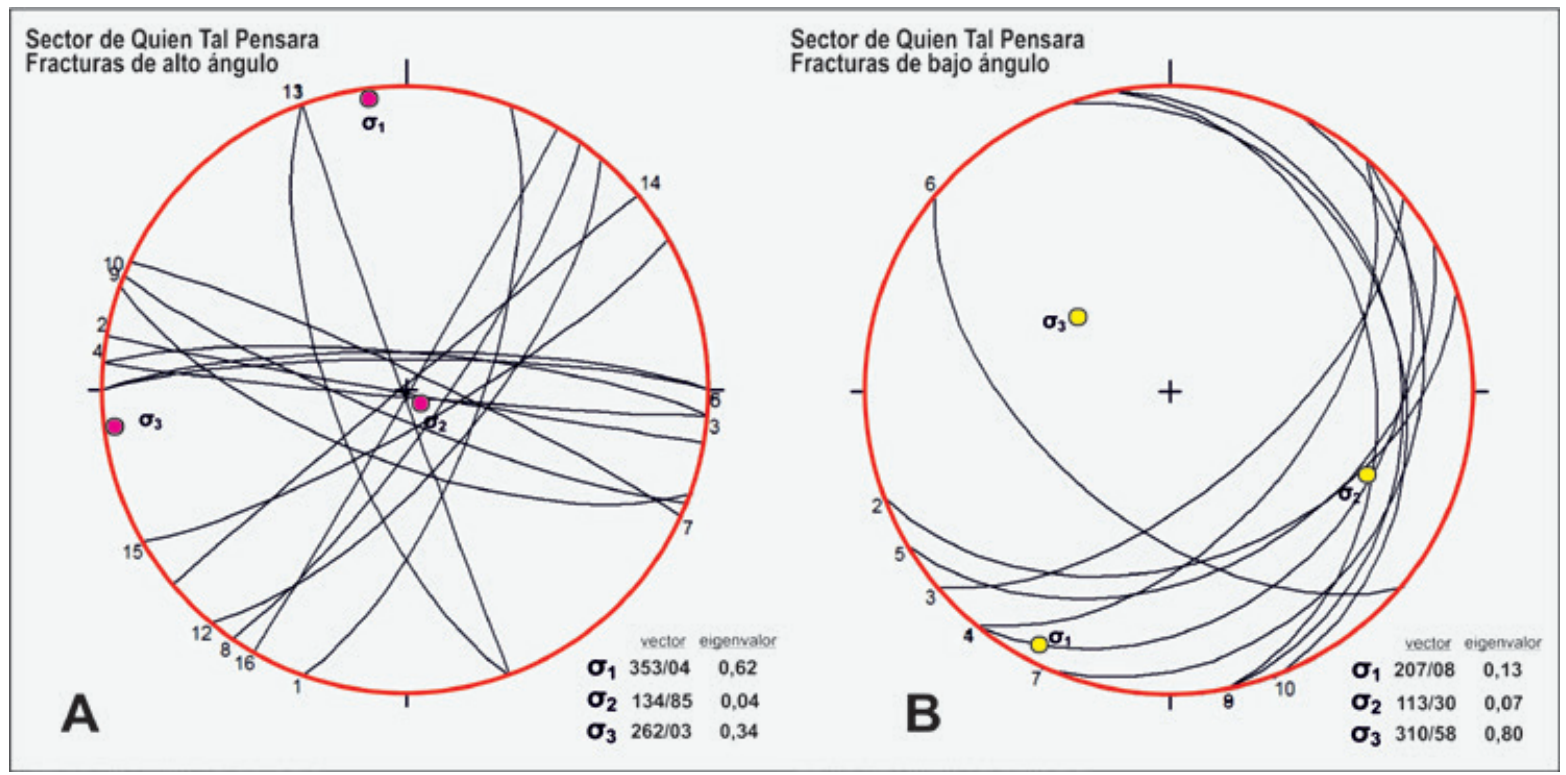

Figura 18. Proyección estereográfica y eigenvectores deducidos de los conjunto de fracturas observadas en el sector de QTP. A: Planos de fracturas con fuerte buzamiento. B: Planos de fracturas con buzamiento tendido.

Figure 18. Stereographic projection and eigenvectors deduced from the set of fractures observed in the QTP sector. A: Fractures with high dip. B: Fracture planes with low dip.

\section{La Mineralización}

\section{Distribución de la mineralización en el yacimiento}

La mineralización aparece en cuerpos estratoligados de carbonatos de hierro (ankerita y en menor proporción siderita) que siguen la estructura plegada y cizallada de los lentejones tectónicos. Cada uno o un conjunto de ellos forman los macizos mineralizados que fueron el objetivo de la explotación. En base a la documentación existente de la antigua Jefatura de Minas de Almería (actualmente en el Archivo Histórico de Almería), junto con lo observado en el interior de la mina se distinguen 3 macizos trabajados en el sector de 'Quien Tal Pensara' y 5 en el de 'Por Si Acaso', que se describen a continuación.

\section{Mineralizaciones en el Sector de' Quien Tal Pensara' (QTP)}

Los macizos del sector QTP, a falta de conocimiento de sus nombres originales, se han denominado QTP1, QTP-2 y QTP-3, todos con explotación subterránea y con cortas a cielo abierto sobre los dos últimos (ver Fig. 2). Además hay otra corta al NE en la que se explotó otro macizo que seguramente también tuvo labores de interior, que hoy día son inaccesibles.

El macizo de QTP-1 tiene unos $8 \mathrm{~m}$ de espesor $\mathrm{y}$ aparece como un cuerpo estratoligado de carbonatos de hierro en un sinclinal de lo que hemos llamado "calizas y dolomías bien estratificadas", quedando el limbo del pliegue justo por encima del nivel del socavón de la $1^{a}$ planta. Entre los carbonatos hay algunas zonas brechificadas con barita, celestina y sulfuros, y algunas grietas tensionales de poca inclinación con yeso selenítico.

En la cámara QTP-2 se trabajó un cuerpo continuo de carbonatos mineralizados de hasta $10 \mathrm{~m}$ de potencia, situado en "calizas y dolomías bien estratificadas" con fuerte buzamiento al W (Fig. 19). A poniente se haIla otro cuerpo más pequeño paralelo al principal. En el muro del cuerpo principal se localiza uno de los paquetes de yesos microcristalinos comentados anteriormente (Fig. 10D). Estos cuerpos de mineral terminan en su extremo SW en una falla NW-SE con claras reactivaciones, que localmente presentan mineralización de sulfatos y geodas con yeso selenítico. Algunas geodas incluyen un recubrimiento del yeso con espeleotemas de calcita. El límite suroriental del cuerpo ferruginoso es una estructura tabular a modo de filón subvertical de rumbo NNE-SSW con abundante celestina y placas y cristales idiomorfos de yeso de varios decímetros. Este filón termina al llegar al paquete de yesos microcristalinos, donde se incurva hacia el Norte y hace relevo con otra falla WNW-ESE con juego principal de desgarre. Cortando a todas las estructuras hay fracturas tensionales de buzamiento tendido (Fig. 15D) con rellenos parciales de yeso selenítico y limonitas. También aparecen pequeñas grietas tensionales subhorizontales con yeso muy transparente y sin limonitas. 


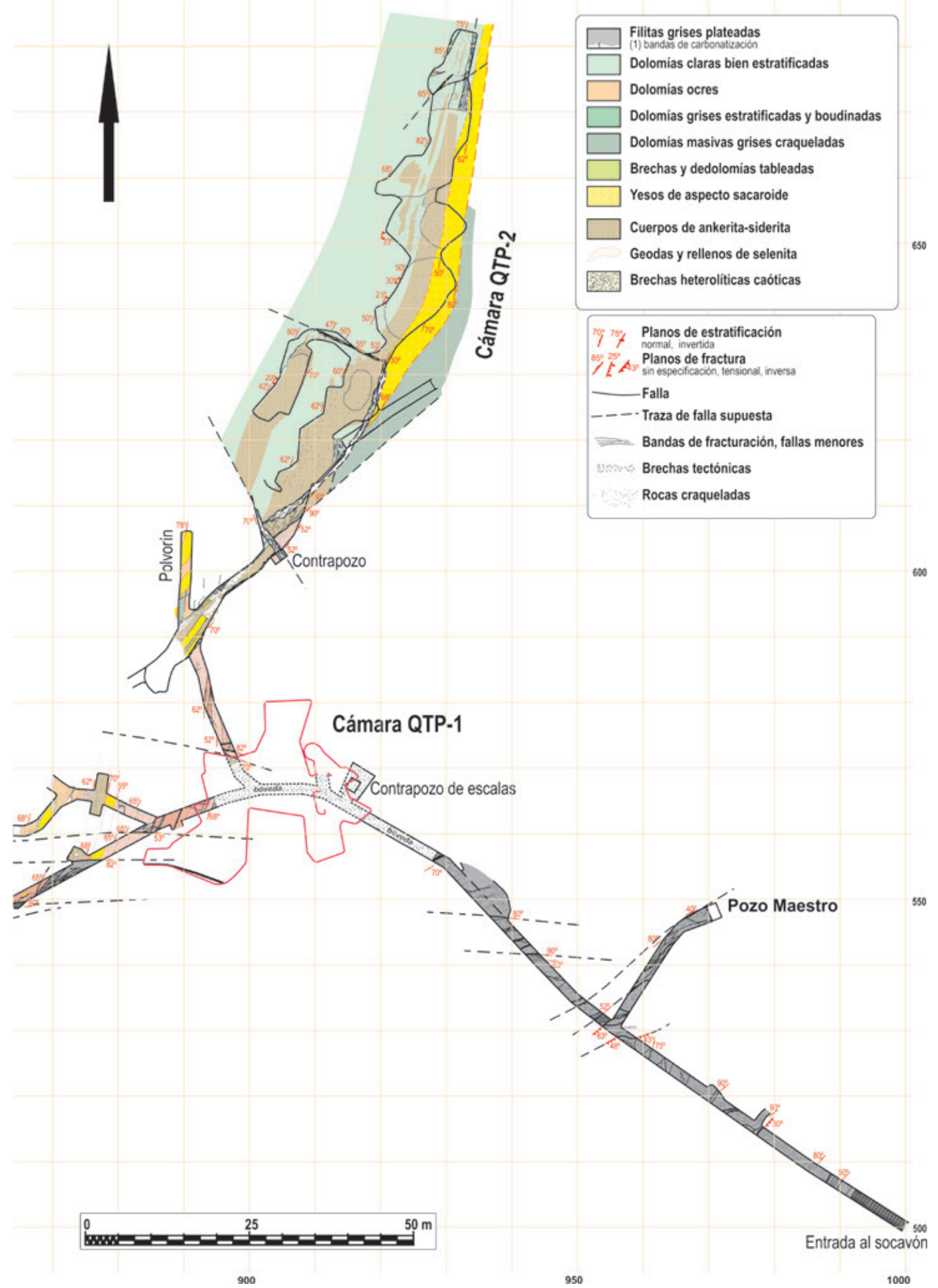

Figura 19. Mapa geológico del sector de 'Quien Tal Pensara' (OTP) a partir de las labores mineras reconocidas en la $1^{\mathrm{a}}$ planta de la mina. Figure 19. Geological map of the 'Quien Tal Pensara' (QTP) sector, from the mining works studied in the 1st level of the mine. 
Al SW del anterior macizo se encuentra la explotación de QTP-3 sobre un cuerpo mineralizado de entre 5 m y $7 \mathrm{~m}$ de espesor, orientado NNE-SSW y buzando $80^{\circ}$ al W. Encaja en "dolomías grises boudinadas". Los trabajos se extienden en $25 \mathrm{~m}$ de largo y hasta unos $15 \mathrm{~m}$ por encima del nivel de $1^{\text {a }}$ planta. El macizo de mineral queda limitado por una fractura WNW-ESE por su lado norte y por una red de fracturas E-W por el sur. También hay fracturas tensionales abiertas tendidas orientadas al NE y buzando al W, con selenita y costras de limonita.

\section{Mineralizaciones en el Sector de' Por Si Acaso'(PSA)}

En el sector PSA se han distinguido las siguientes zonas de explotación de levante a poniente (Fig. 20): 'Tajo Carrasco', 'Tajo Rico', 'Tajo Piritas', 'Tajo del Sapo' y 'Tajo Clemente'.

La galería de transporte de la $1^{\text {a }}$ planta llega al sector de PSA y cruza unas primeras explotaciones que son la prolongación hacia arriba del denominado 'Tajo Carrasco', cuyos trabajos se extienden hasta la $4^{a}$ planta. La explotación se centró en dos cuerpos estratoligados de carbonatos de hierro (Fig. 21A), de $1,5 \mathrm{~m}$ y $3 \mathrm{~m}$ de espesor orientados al NNE con buzamiento de $65^{\circ}$ al W, que convergen en sus extremos $\mathrm{N}$ y $\mathrm{S}$, extendiéndose en unos $70 \mathrm{~m}$ de corrida (Fig. 20). Encajan en las "calizas y dolomías bien estratificadas", pero en su parte septentrional, tras pasar una fractura NNW-SSE y una corta zona estéril, el cuerpo se extiende en las "dolomías grises boudinadas". En la primera planta se aprecia un cuerpo masivo de mineral con brechas tectónicas con barita, celestina y galena y sulfosales sin identificar (probablemente bournonita), así como vetas de rumbos norteados de barita, celestina y yeso. En la tercera planta la proporción de sulfatos es menor y se hallan diseminados entre las estructuras bandeadas rítmicas en los carbonatos de hierro (ritmitas o estructuras cebradas). Claramente relacionados con los carbonatos aparecen dispersos entre ellos galena y bournonita.

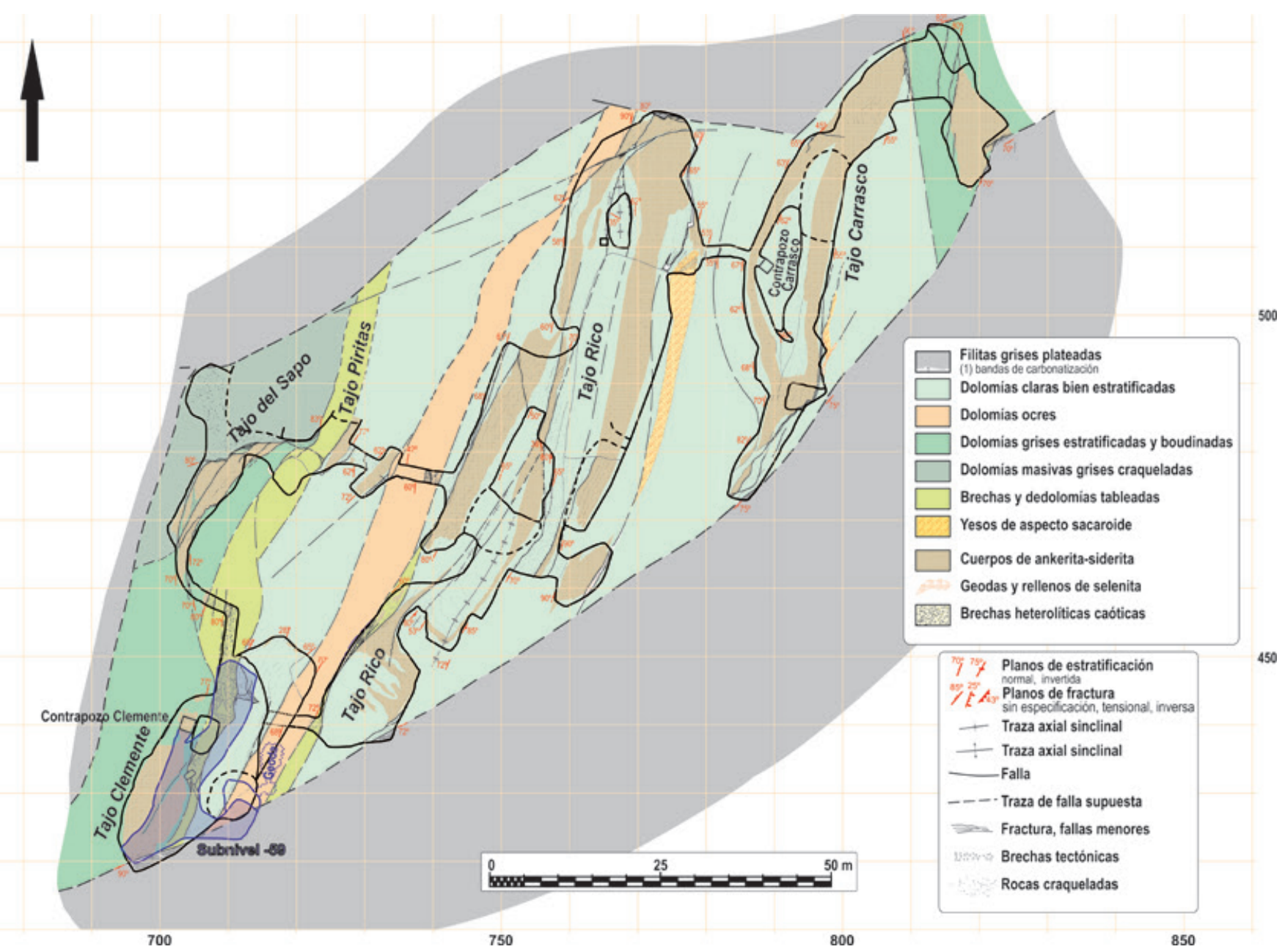

Figura 20. Mapa geológico del sector de 'Por Si Acaso' (PSA) a partir de las labores mineras reconocidas en la $3^{\text {a }}$ planta de la mina y subnivel-59.

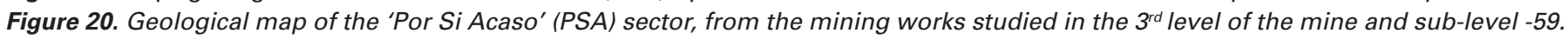


El 'Tajo Rico' constituye el principal cuerpo mineralizado en esta parte del yacimiento, con explotaciones en las cinco plantas de la mina y seguramente fue también el explotado en la corta de superficie. El macizo mineralizado está formado por un conjunto de cuerpos de carbonatos de hierro de desigual desarrollo, que siguen la estructuración de las "calizas y dolomías bien estratificadas" (Fig. 8C y 15A). Se definen 2 bandas de mineralización de entre 5 y $10 \mathrm{~m}$ de espesor, que quedan separadas por una de carbonatos estériles (Fig. 20). Las mineralizaciones del 'Tajo Rico' presentan comúnmente la estructura bandeada rítmica característica de este tipo de yacimientos (Fig. 21B). El contacto de muro (lado oriental) aparece normalmente fracturado, con desarrollo de brechas filonianas con barita y celestina.

La galería de transporte de la $1^{a}$ planta termina en el 'Tajo Piritas', cuya explotación llega hasta la $4^{a}$ planta. Este macizo de mineral encaja en "calizas y dedolomías tableadas" y en la brecha intraformacional alterada, formando la mineralización cuerpos irregulares y discontinuos de carbonatos de hierro y sulfuros diseminados en las zonas alteradas de aspecto terroso. También hay cuerpos irregulares de brechas con celestina abundante y yeso selenítico, así como cavidades con restos de un material terroso verdoso que pueden albergar grandes cristales de yeso. La difracción de rayos $\mathrm{X}$ del material terroso indica una mezcla de yeso, dolomita, moscovita, cuarzo, calcita, pirita y celestina.

En el borde occidental del lentejón tectónico de PSA se halla el 'Tajo del Sapo' que está formado por cuerpos irregulares de mineral y abundantes brechas, vetas y fisuras de orden centimétrico, conteniendo barita, bournonita y galena. Este macizo mineralizado arma en "dolomías masivas craqueladas" y en "dolomías grises boudinadas", extendiéndose estás hacia el Sur hasta alcanzar el denominado 'Tajo Clemente' (Fig. 20).

EITajo Clemente es realmente la confluencia de los cuerpos mineralizados del 'Tajo del Sapo', del 'Tajo Pi-

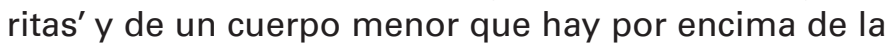
"dolomía ocre", este último en forma de brecha tectónica. Se trata de la brecha filoniana con celestina, barita y yeso comentada anteriormente. Se trabajó en $3^{\text {a }}$ planta y en el nivel-59, siendo en la pared de dicha cámara de explotación donde se halla la gran geoda, cuyo encajante es la "dolomía ocre" (Fig. 20).

\section{Tipología de los cuerpos mineralizados}

En base al estilo de mineralización, paragénesis, y relaciones geométricas y temporales, se establecen 5 tipos de mineralización: a) Cuerpos de reemplazamiento de carbonatos de hierro (ankerita principalmente).

b) Cuerpos filonianos de barita y celestina.

c) Cuerpos de reemplazamiento de celestina.

d) Cuerpos irregulares de aspecto terroso con sulfuros diseminados.

e) Geodas y rellenos de yeso selenítico.

A estos tipos de mineralización habría que añadir unos cuerpos vetiformes de siderita y barita encajados en las filitas que se trabajaron fuera de la banda de cizalla, hoy día inaccesibles. Según referencia de antiguos mineros eran vetas estrechas que contenían algunos sulfuros (galena y seguramente sulfosales).

\section{Cuerpos de reemplazamiento de carbonatos de hierro}

Los cuerpos de carbonatos de hierro son resultado de un reemplazamiento siguiendo principalmente la estructura estratificada dentro de los lentejones tectónicos. Corresponde a un metasomatismo ferruginoso de la roca carbonatada, produciendo una alteración que va desde dolomitización, a dolomita ferruginosa, a ankerita y siderita, siendo la ankerita el mineral más común. La siderita se encuentra solo como cristalizaciones en oquedades y en las salbandas de algunas fracturas. Las dimensiones de estos cuerpos varían desde unos centímetros hasta varias decenas de metros en extensión, llegando su potencia a los $10 \mathrm{~m}$. Los más importantes son los del 'Tajo Rico' en el sector de PSA y los de la cámara principal QTP-2 en ese sector nororiental (Figs. 19 y 20).

El reemplazamiento se realiza a favor de fracturas transversales (Fig. 21C) y longitudinales (Fig. 21D) a la estratificación, activas durante la deformación post-Serravalliense. La transformación progresa a favor de las capas de carbonatos, actuando las finas capas de filitas de forma refractaria, lo que provoca saltos repentinos de los frentes de reemplazamiento al ser sobrepasados esos tramos (Fig. 21E). Los frentes son bastante netos aunque se aprecia un halo de alteración de unos centímetros.

Sobre las filitas que rodean a los lentejones tectónicos se produce una intensa alteración producida por carbonatización. Esta se manifiesta en bandas decoloradas de tonos blanquecinos que alcanzan el medio metro de espesor (Fig. 22A) que se superponen a la fábrica milonítica de las cizallas que limitan a los lentejones tectónicos. Esto es indicativo de un proceso post-cinemático. Al microscopio la intensa decoloración de las filitas corresponde a una pérdida de filosilicatos y opacos, y a aumento de carbonatos que se superponen a la foliación (Fig. 22, B). 

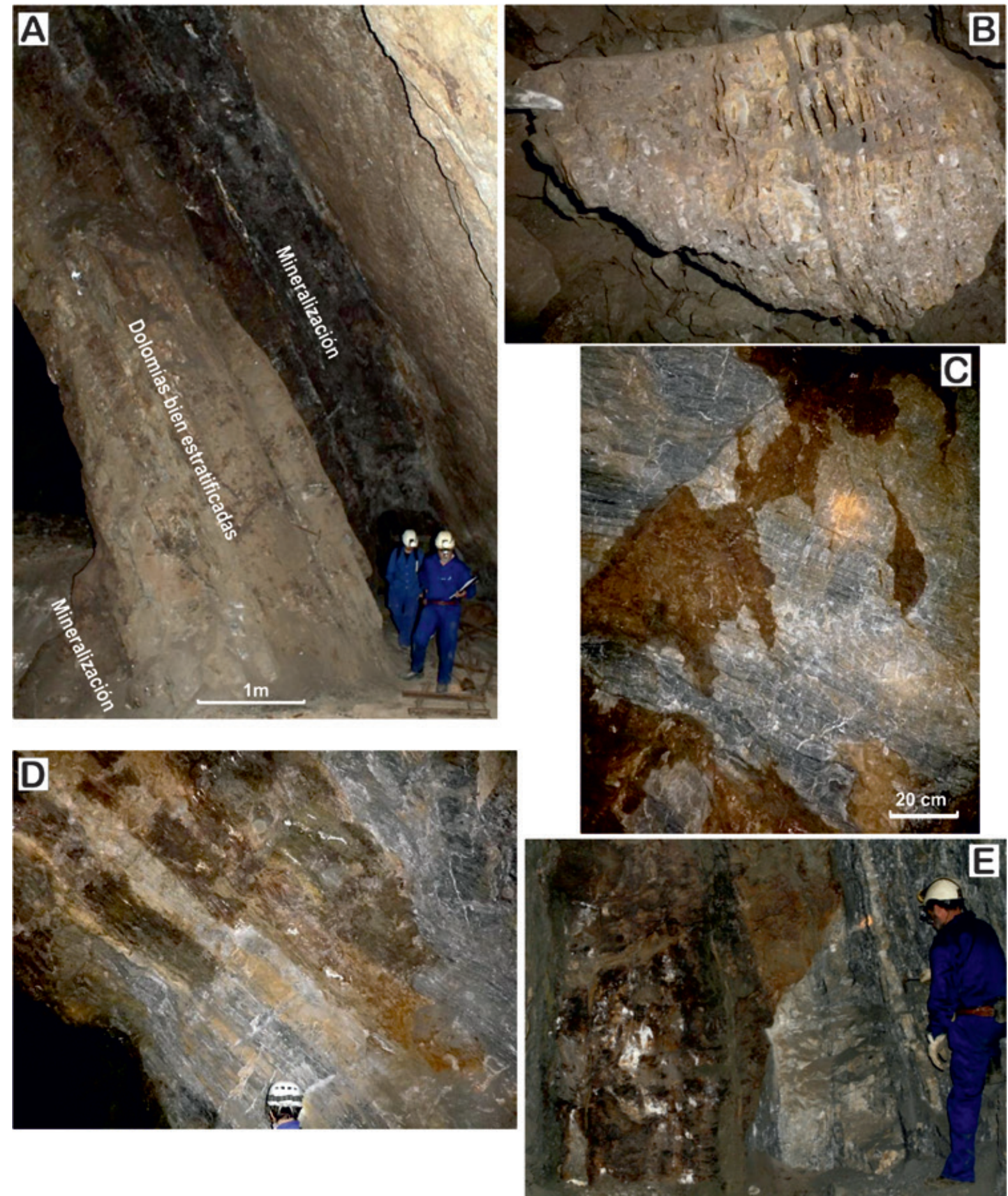

Figura 21. A: Explotación del 'Tajo Carrasco' sobre un cuerpo de carbonatos de hierro en aparente concordancia con la estratificación. $3^{\text {a }}$ Planta, sector PSA. B: Muestra característica del 'Tajo Rico' formada por un bandeado rítmico de carbonatos de hierro y abundantes oquedades donde aparecen cristales dispersos de barita y celestina. $2^{\mathrm{a}}$ Planta, sector PSA. C: Metasomatismo ferruginoso a favor de fracturas que cortan transversalmente a la estratificación. Extremo suroccidental del 'Tajo Rico', Planta $2^{\mathrm{a}}$, sector PSA. D: Frente de reemplazamiento ferruginoso escalonado siguiendo la estratificación. 'Tajo Rico', Planta $2^{\mathrm{a}}$, sector PSA. E: Frente de reemplazamiento ferruginoso escalonado condicionado por la presencia de lechos de filitas entre los estratos de dolomía. 'Tajo Piritas', Planta $3^{2}$, sector PSA.

Figure 21. A: Stope of the 'Tajo Carrasco' mining on an iron carbonate body in apparent conformity with the stratification, $3^{\text {rd }}$ level, PSA sector. B: Characteristic sample of the 'Tajo Rico' formed by a rhythmic banding of iron carbonates and abundant vugs with dispersed baryte and celestine crystals, $2^{\text {nd }}$ level, PSA sector. C: Ferruginous metasomatism controlled by fractures that cut transversally to the stratification.

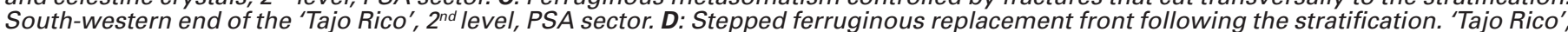
$2^{\text {nd }}$ level, PSA sector. E: Stepped ferruginous replacement front conditioned by the presence of layers of phyllites between the dolostone beds, $3^{\text {rd }}$ level 'Tajo Piritas', PSA sector. 

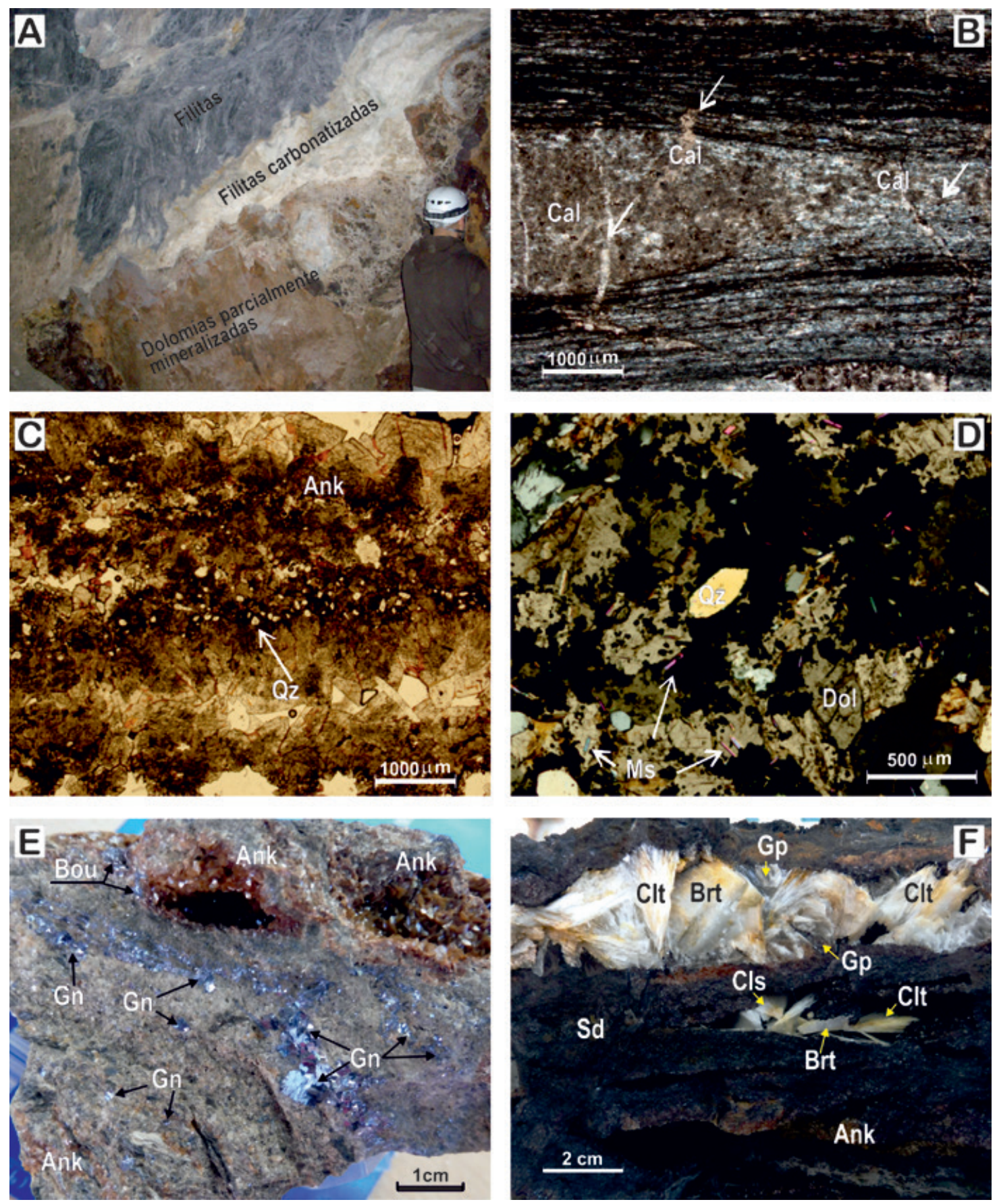

Figura 22. A: Banda de alteración blanquecina en el contacto entre la cizalla que limita la unidad de filitas grises y la mineralización de carbonatos de hierro de color marrón. Cámara de explotación QTP-1. B: Aspecto al microscopio de la zona de alteración de la foto anterior. Se aprecia un progresivo aumento de carbonatos en las filitas, así como una disminución de moscovitas y opacos. NC. C: Estructura bipolar de la mineralización carbonatada formado ritmitas, observese la acumulación en la banda oscura de microcristales euhedrales de cuarzo (Qz, flecha). NP; D: Mayor detalle de una banda oscura, con cristales euhedrales de cuarzo (Qz) y moscovita (Ms). El mineral opaco es galena. NC. E: Agregados microcristalinos de galena y bournonita incluidos entre carbonatos de hierro en uno de los cuerpos de reemplazamiento del 'Tajo Rico', $2^{\text {a }}$ planta, Sector PSA. F: Ritmita de ankerita con oquedades parcialmente ocupadas por cristales de barita (Brt), celestina (Clt) y yeso (Gp). 'Tajo Rico', $2^{\mathrm{a}}$ planta, Sector PSA.

Figure 22. A: A band of whitish alteration in the contact between the shear fault that limits the unit of grey phyllites and the mineralization of brown-coloured iron carbonates. QTP-1 stope. B: Alteration band of the previous photo under microscope. Note a progressive increase in carbonates of the phyllites, as well as a decrease in muscovites and opaques. NC. C: Bipolar structure of the carbonate mineralization forming rhythmites. Observe the accumulation in the dark band of euhedral quartz microcrystals (Oz, arrow). NP. D: More detail of the dark band with euhedral quartz crystals (Oz) and muscovite (Ms). The opaque mineral is galena. NC. E: Micocrystaline aggregates of galena and bournonite included among iron carbonates in one of the replacement bodies in the 'Tajo Rico', $2^{\text {nd }}$ level, PSA sector. F: Rhythmite of ankerite with vugs partially filled by barite (Brt), celestine (Clt) and gypsum (Gp) crystals. $2^{\text {nd }}$ level, 'Tajo Rico', PSA Sector. 
En el interior de los cuerpos mineralizados de carbonato de hierro el característico bandeado centimétrico (ritmita) es coincidente con la estratificación y está formado por crecimientos bipolares de cristales de ankerita, dejando abundantes oquedades (Fig. 21B). Estos minerales no presentan señales de deformación, indicando que su formación tiene lugar en condiciones tectónicamente tranquilas. Al microscopio, las ritmitas presentan acumulación en las bandas centrales de microcristales euhedrales de cuarzo y moscovita de algunos centenares de micras (Fig. 22C y 22D). La mayor parte de los sulfuros aparecen en estas bandas en forma de agregados granulares o microgranulares entremezclados con los carbonatos de hierro (Fig. 22E). En las bandas de carbonatos aparecen oquedades que pueden estar parcialmente rellenas con cristales de barita, celestina y ocasionalmente yeso selenítico (Fig. 22F). Los sulfuros son escasos en esos huecos, habiéndose encontrado en ellos algunos cristales de bournonita en el 'Tajo del Sapo'. Localmente hay brechas de fragmentos angulosos cementados por los carbonatos de hierro, galena y sulfosales microcristalinas creciendo en escarapela alrededor de los fragmentos de roca. Sobre ellos se disponen la ankerita con crecimientos bipolares, dejando también algunas pequeñas oquedades tapizadas de cristales romboedricos de ankerita (Fig. 23A).

Además de la mineralización estratoligada, en los paquetes de rocas carbonatados competentes hay otros cuerpos, algunos brechosos, con halos centimétricos de alteración ferruginosa y escasa continuidad lateral. Estos cuerpos se relacionan con fracturas tensionales y si presentan oquedades estas están tapizadas por romboedros de ankerita/siderita y con reIlenos parciales o totales de barita, (Fig. 23B). En el 'Tajo del Sapo' es frecuente la presencia de cristales de bournonita, normalmente englobada por la barita, aunque en ocasiones puede aparecer aislada.

Por último, es relevante señalar que a nivel microscópico se han encontrado entre los agregados de ankerita pequeños cristales tabulares de sulfato cálcico, que por su hábito cristalino debían ser en origen anhidrita posteriormente transformada a yeso (Fig. 24A).

\section{Cuerpos filonianos de barita y celestina}

En relación con fracturas de rumbo NNE-SSW y NESW, con un marcado carácter tensional y formadas durante o con señales de rejuegos tortonienses o messinienses, aparecen estructuras vetiformes con barita y celestina. Aunque a veces coinciden espacialmente con las estructuras discordantes de reemplazamiento ferruginoso, ambas mineralizaciones son claramente independientes (Fig. 23C). Presentan un trazado arrosariado (ver Fig. 15B), aunque la forma general responde a cuerpos tabulares estrechos, con espesores entre unos centímetros y $1 \mathrm{~m}$, y con corridas máximas de unas decenas de metros. Las más importantes son filones en fallas reactivadas después de la mineralización de los carbonatos de hierro a la que afectan de forma frágil. Entre ellas, las más llamativas son las que aparecen a muro del 'Tajo Rico', la que se sitúa en el contacto de techo de la "dolomía ocre", y la que sirve de límite suroriental a buena parte del macizo explotado en QTP-2. Otros cuerpos de menores dimensiones aparecen repartidos por toda la mina, desarrollándose principalmente en las litologías más competentes.

La estructura interna de estos filones es tanto brechoide como bandeada. Los fragmentos de las brechas son de mineralización ferruginosa y de otras rocas carbonatadas, pudiendo presentar estos últimos pequeños halos de ankeritización, seguramente relacionado con la mineralización precedente. Las salbandas son netas y sobre ellas cristalizan barita de hábito tabular en primer lugar y celestina fibrosa a continuación (Fig. 23D). Es frecuente que los rellenos sean parciales quedando huecos geódicos (en general de escala milimétrica a decímétrica, pero ocasionalmente superando el metro) que aparecen rellenados por yeso selenítico.

Aunque en el yacimiento suelen aparecer asociados barita y celestina, hay estructuras donde predomina ampliamente uno de estos dos sulfatos. Cuando el predominante es la barita, corresponde a la reactivación de las estructuras discordantes de reemplazamiento ferruginoso comentadas anteriormente (Fig. 23B). En estas vetas los cristales de barita son de hábito tabular y crecen sobre los romboedros de ankerita que tapizan las salbandas de los huecos, pero también suelen tener sobre ellos otros cristales milimétricos del carbonato de hierro, crecidos en una recristalización posterior. En algunos lugares, especialmente en el 'Tajo del Sapo', hay vetas pequeñas con galena y bournonita en las salbandas, y barita y ankerita sobre ellos (Fig. 23E). Estas vetas no presentan alteración ferruginosa en la dolomía encajante, por lo que parecen haber sido formadas exclusivamente en este proceso mineralizador. Entre la barita aparecen granos más o menos idiomorfos de bournonita y galena, siendo el primero el más común. Al microscopio se reconoce un crecimiento de la sulfosal a expensas de la galena (Fig. 24B), englobando ésta diminutos cristales de moscovita.

En las estructuras donde predomina la celestina, este mineral forma haces de agujas y bandas fibrosas que rellenan parcialmente espacios, tanto en estructuras tapizadas de ankerita como en otras sin carbonatos de hierro. Si hay barita, la celestina frecuentemente 

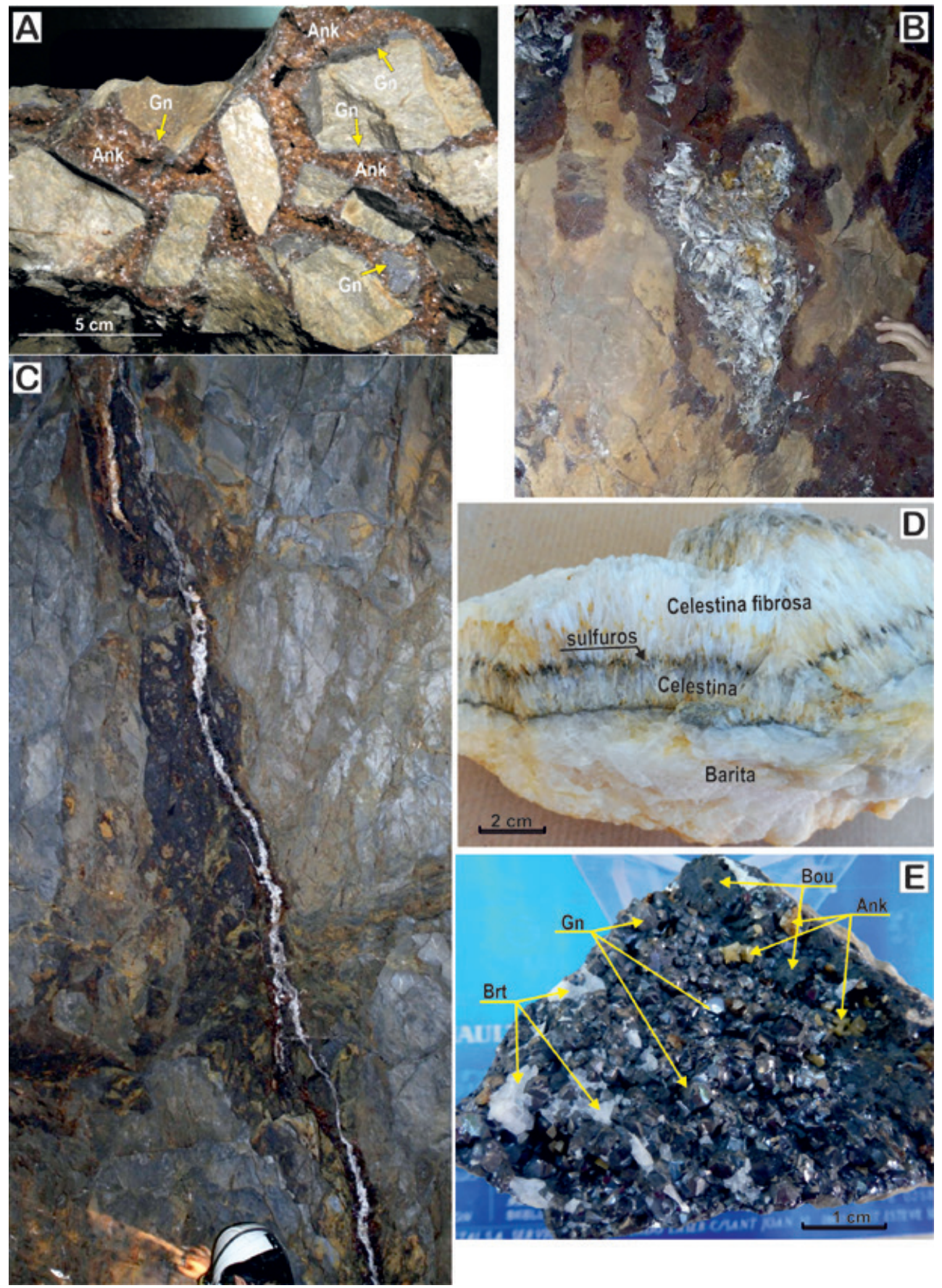

Figura 23. A: Brecha mineralizada con ankerita y sulfuros en el 'Tajo Piritas', $4^{a}$ planta sector PSA. Esta brecha se sitúa en la falla de techo que limita la dolomía ocre con los cuerpos de carbonatos de hierro. Nótese la banda continua de galena y sulfosales microcristalinas (Gn) rodeando los clastos de margofilitas y creciendo sobre ellos la ankerita (Ank). B: Bolsada de barita de forma irregular ocupando un espacio tapizado de siderita. Cámara QTP-1 sector QTP. C: Veta de barita y celestina rellenado una fractura de rumbo NW-SE reactivada con mineralización previa de siderita-ankerita. Cámara principal QTP-2 en el sector de QTP. D: Fragmento de la mineralización de relleno del filón situado a muro del 'Tajo Rico' en la $3^{\text {a }}$ planta del sector PSA. Se reconoce una banda de barita sobre la que crece otra de celestina fibrosa. La parte basal de la celestina presenta un fino lecho formado por sulfuros intercrecidos con las fibras. E: Mineralización de galena, bournonita, barita y ankerita en una pequeña veta encajada en las dolomías masivas craqueladas del 'Tajo del Sapo', $3^{\mathrm{a}}$ planta, sector PSA.

Figure 23. A: Mineralized breccia with ankerite and sulphides in the 'Tajo Piritas', 4th level, PSA sector. This breccia is located in the hanging wall fault that limits the ochre dolostone with bodies of iron carbonates. Note the continuous band of microcrystalline galena and sulphosalts (Gn) surrounding the clasts of marl-phyllites and the ankerite (Ank) growing on them. B: Barite pocket of irregular-shaped occupying a space lined with siderite. OTP-1 stope, OTP sector. C: Barite and celestine vein filling a NW-SE fault reactivated including previous mineralization of siderite-ankerite. Main stope QTP-2 in the QTP sector. D: Fragment of the infilling mineralization in a vein located on the wall

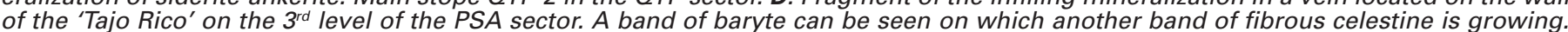
The basal part of the celestine presents a fine line formed by sulphides intergrown with the celestine fibres. E: Mineralization of galena, bournonite, barite and ankerite in a small veins within the massive craquelated dolostones of the 'Tajo del Sapo', $3^{\text {rd }}$ level, PSA sector. 

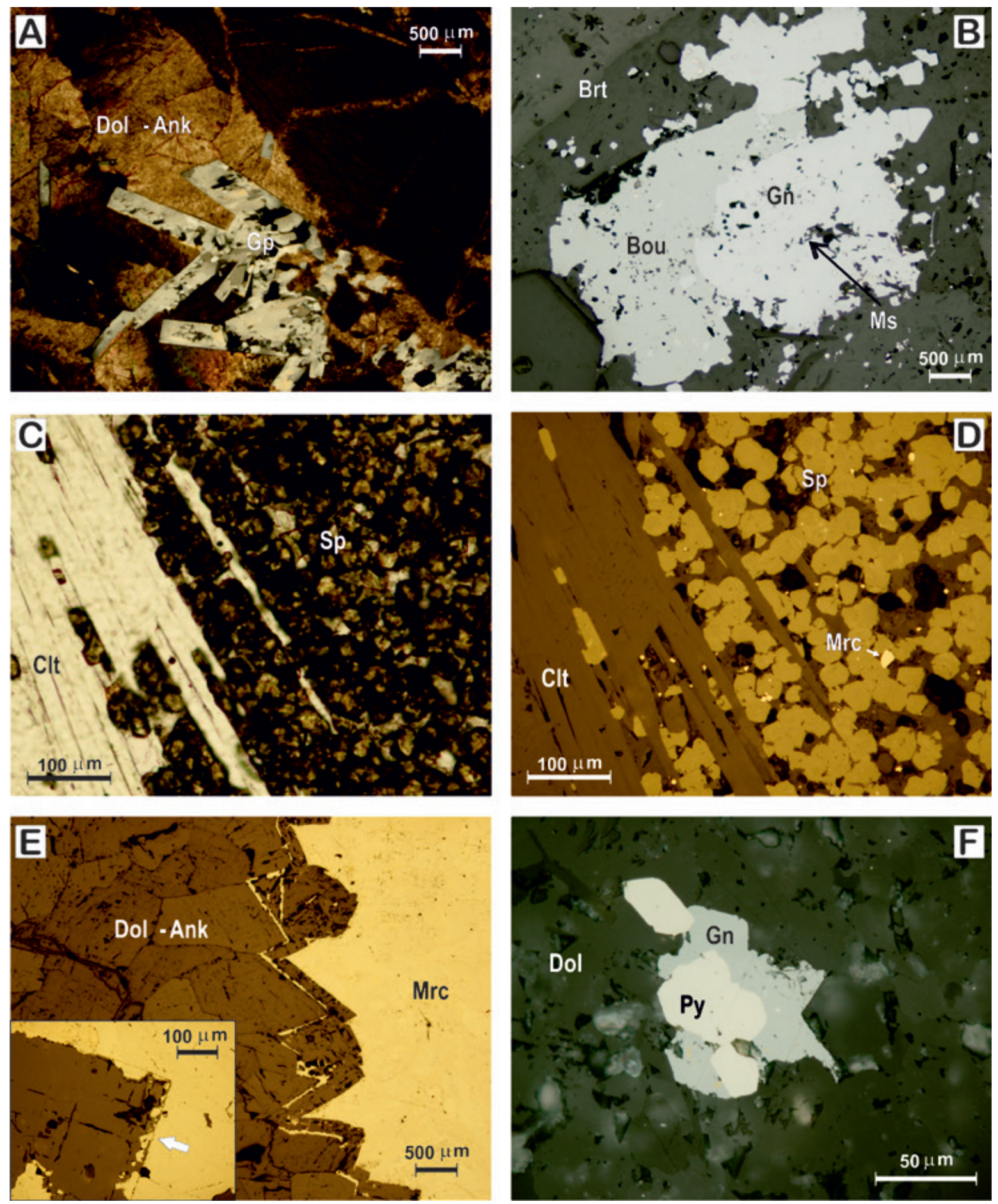

Figura 24. A: Yeso microcristalino pseudomorfizando cristales euhedrales de anhidrita en una vena de carbonato (Dol-Ank). NC. B: Bournonita (Bou) y galena (Gn) entre barita (Brt). La flecha señala algunos cristales de muscovita (Ms) englobados por la galena. Luz reflejada NP.

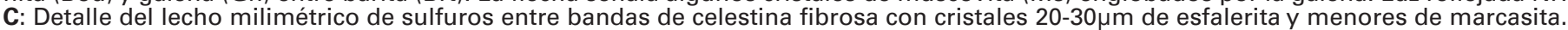
Luz transmitida NP. D: La misma zona que E en luz reflejada. NP. E: Ejemplos de bordes de reacción de marcasita (Mrc) en contacto con ankerita. La flecha señala el límite del cristal de carbonato ahora reemplazado por sulfuro; luz reflejada NP; F: Granos de sulfuros diseminados en las zonas de alteración terrosa de la unidad de "dolomita ocre" con pirita (Py) y galena (Gn). Luz reflejada NP.

Figure 24. A: Microcrystalline gypsum of euhedral crystals of anhydrite in a vein of carbonates (Dol-Ank). NC. B: Bournonite (Bou) and galena (Gn) with barite (Brt). The arrow shows some muscovite (Ms) crystals surrounded by galena. Reflected light NP. C: Detail of the millimetric line of sulphides between bands of fibrous celestine, formed by 20-30 $\mu \mathrm{m}$ crystals size of sphalerite and smaller ones of marcasite. Transmitted light NP. D: The same zone as E in reflected light. NP. E: Examples of reaction edges of marcasite (Mrc) in contact with ankerite. The arrow indicates the limit of the carbonate crystal now replaced by sulphur: reflected light. NP. F: Grains of sulphur disseminated in the zones of earthy alteration of the unit of "ochre dolostone" with pyrite (Py) and galena (Gn). Reflected light NP. 
crece sobre ella o la reemplaza, pudiendo ser a veces este proceso muy intenso. En estructuras brechoides engloba romboedros y agregados de carbonatos de hierro, así como fragmentos tabulares del sulfato de bario a los que puede reemplazar parcialmente. Son frecuentes los crecimientos fibrosos en bandas paralelas simétricas sintaxiales de celestina (Fig. 25A) así como en escarapela en el caso de las brechas. Las fibras de celestina tienen habitualmente longitudes de 3 y $5 \mathrm{~cm}$, pero ocasionalmente pueden llegar a los $15 \mathrm{~cm}$. En los agregados fibrosos es muy común distinguir 2 bandas, siendo la basal más oscura debido probablemente al reemplazamiento de barita (ver Fig. 23D). EI bandeado coincide con un ligero cambios en el contenido en bario y en el límite entre bandas aparecen un lecho milimétrico continuo con sulfuros (esfalerita, marcasita y en menor proporción galena) que crecen entre los cristales de celestina (Fig. 24C y 24D).

Los fragmentos de la mineralización anterior de carbonatos de hierro incorporados en las brechas, o en las salbandas de estas vetas, aparentemente no presentan alteración, pero los reconocimientos al microscopio reflejan claros bordes de reacción especialmente entre la marcasita y la ankerita (Fig. 24E). Esto está reflejando una inestabilidad química entre ambos procesos de mineralización. Sin embargo, las principales evidencias de desestabilización y reemplazamientos en estos cuerpos son los mencionados entre los propios sulfatos, con el crecimiento de celestina a expensas de la barita, que va desde simples crecimientos epitaxiales de fibras sobre los cristales tabulares de barita, a la formación de la banda de celestina que ha reemplazado totalmente a los agregados tabulares de barita.

\section{Cuerpos de reemplazamiento de celestina.}

La mineralización de celestina también aparece reemplazando a las rocas carbonatadas en los extremos de ciertos cuerpos de carbonatos de hierro. Forma cuerpos no muy extensos que presentan una estructura bandeada que parece "fosilizar" la estratificación. EI mineral principal es la celestina que sustituye a la ankerita y dolomita en los frentes de metasomatismo ferroso y se interdigita entre las "ritmitas" a las que reemplaza, mientras que con la roca encajante forma un contacto bastante neto (Fig. 25B, 26A y 26B). El resultado es una roca cebrada con un cierto patrón geométrico resultado de la intersección de los planos de estratificación y de microfisuración, sustituyendo la celestina fibrosa y blanquecina a las capas de carbonatos y dejando relictos lineales de grosor milimétrico y longitud centimétrica de carbonatos grisáceos más refractarios al proceso de reemplazamiento.

\section{Cuerpos irregulares de aspecto terroso con sulfuros diseminados}

Los cuerpos irregulares de aspecto terroso con sulfuros diseminados son abundantes en el 'Tajo Piritas' y en el 'Tajo Clemente'. También son visibles de forma puntual en el lado oeste del 'Tajo Rico' y en la cámara QTP-2. Se trata de bolsadas irregulares brechoides, con abundante matriz terrosa de color gris verdoso, con tamaños que van desde unos decímetros a varios metros. Los más voluminosos aparecen en la unidad de "brechas y dedolomías tableadas", (Fig. 25C).

Además de estos cuerpos brechoides hay algunas cavidades de disolución rellenas parcialmente con material terroso que recuerda al de la matriz de las brechas. Se trata de masas de escasa consistencia con restos de roca carbonatada y cristales aislados de yeso. Si bien estos cristales de yeso son de gran transparencia, frecuentemente presentan bandas de crecimiento marcadas por inclusiones sólidas de carbonato (Fig. 26C y 26D). Estas cavidades también aparecen en la unidad de "dolomías ocres" donde las masas terrosas con sulfuros diseminados tienen tanto brechas como un fino laminado similar al varvado sedimentario (Fig. 25D). La mineralogía, identificada mediante difracción de rayos $X$, consiste en dolomita, calcita, moscovita-fengita, cuarzo, galena, yeso y celestina. Al microscopio también se ha reconocido pirita (Fig. 24F). Los restos de celestina inalterados a modo de pequeños fragmentos sugieren que su incorporación a este relleno es posterior a su formación. Los sulfuros son escasos y son de grano fino.

\section{Geodas y rellenos de yeso selenítico}

La presencia de cristales y placas de yeso selenítico es una constante en la Mina Rica. Aparecen en todo tipo de oquedades, siendo el último mineral en cristalizar. Además de los huecos en las ritmitas de los carbonatos de hierro, o los rellenos en brechas tectónicas, existen otras cavidades que han permitido la formación de excepcionales geodas como la que ha atraído la atención de investigadores y curiosos desde su descubrimiento en 1999 (Palero et al., 2000). Son tres los contextos en los que se han encontrado las estructuras con cristales de gran tamaño de selenita:

- Grietas y fracturas tensionales de buzamiento tendido.

- Vetas en fracturas de fuerte inclinación.

- Rellenos de huecos de disolución.

Las primeras son estructuras que aparecen normalmente abiertas, con espacios submétricos en anchura y métricos en extensión, donde se encuentran alojados cristales centimétricos de yeso de hasta 30 $\mathrm{cm}$ de tamaño. En ellas son comunes también las ma- 

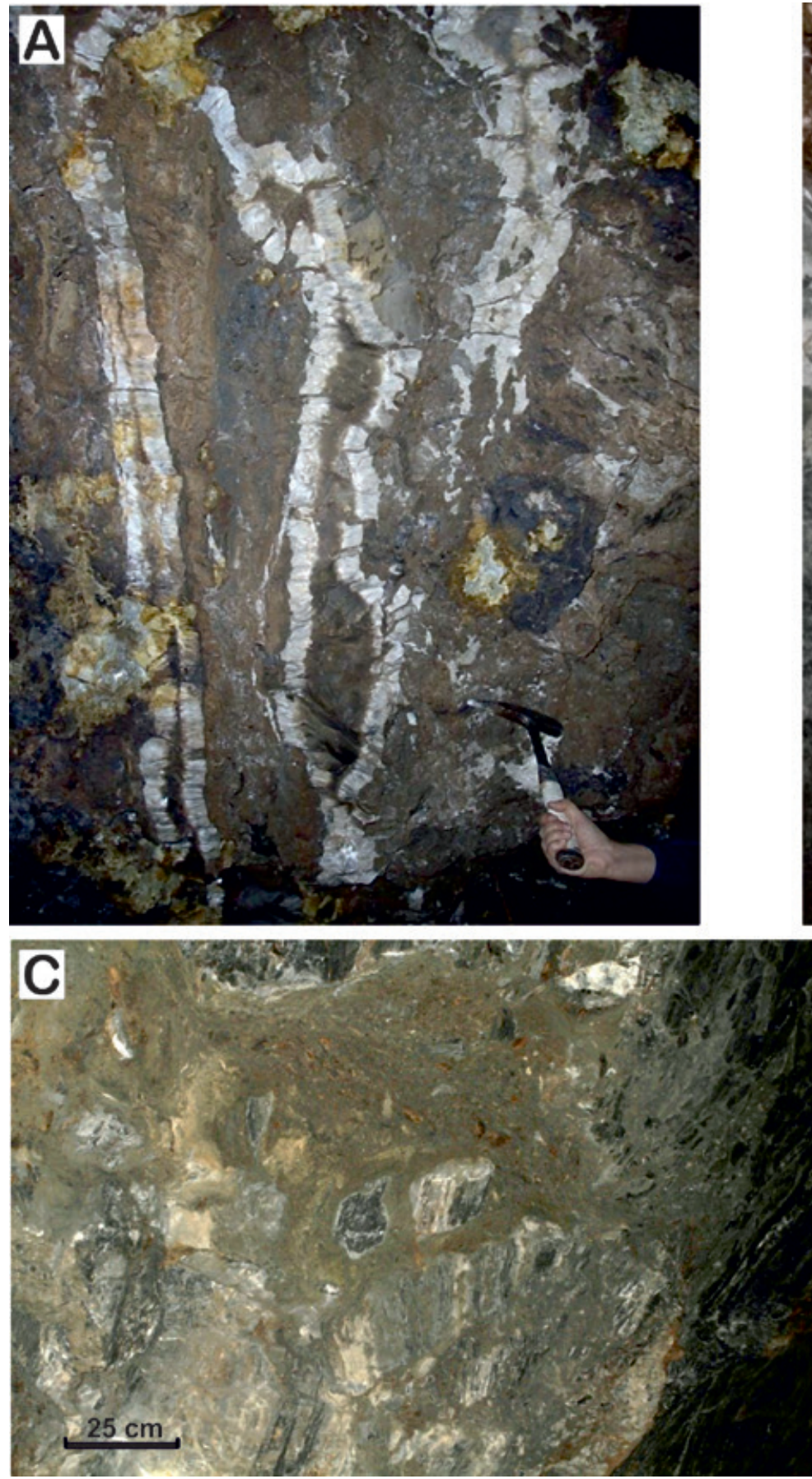
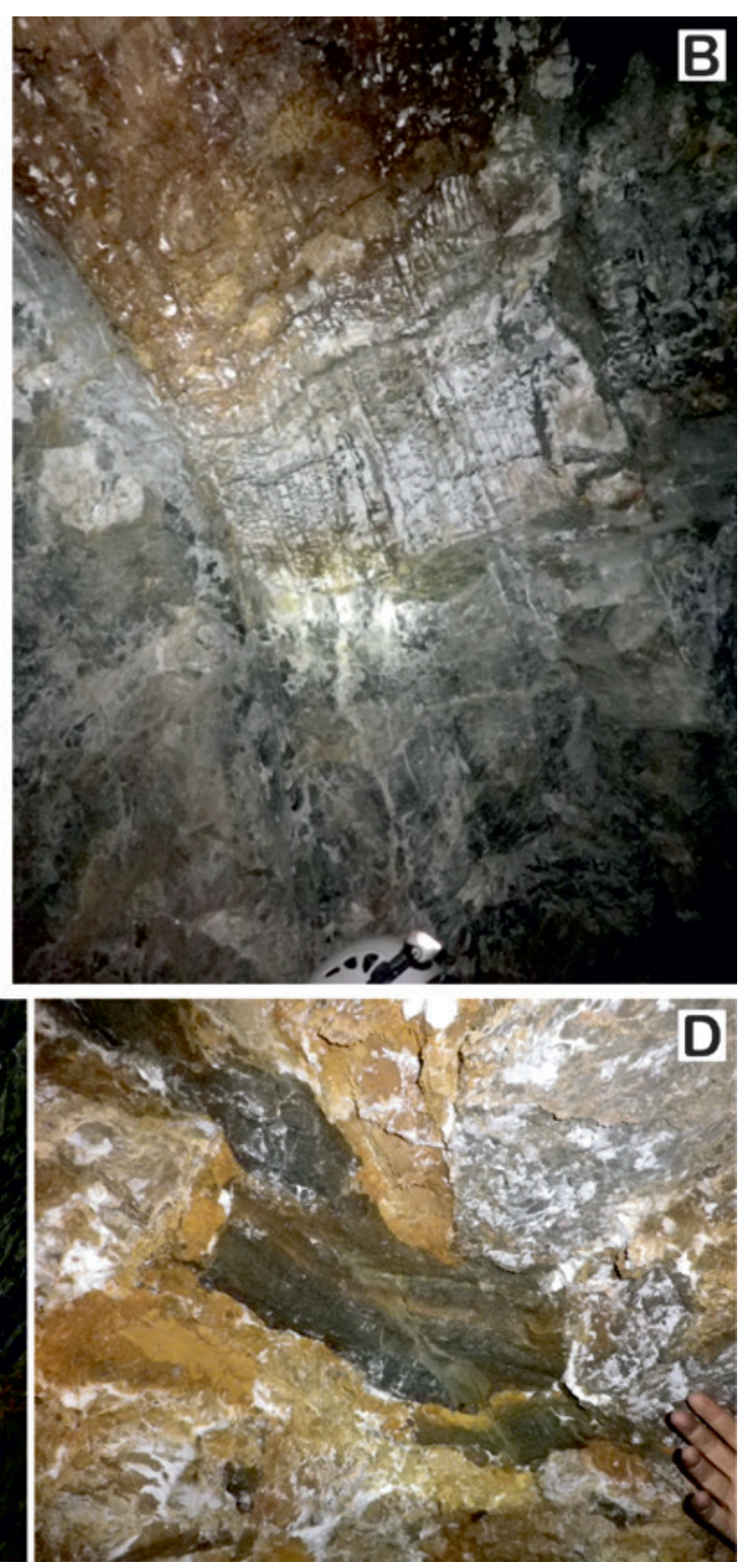

Figura 25. A: Crecimientos simétricos sintaxiales de celestina fibrosa en una fractura de rumbo NE-SW en el borde de la mineralización de la cámara QTP-2 sector QTP. B: Celestina reemplazando a rocas carbonatadas en el frente de un cuerpo de carbonatos de hierro. Obsérvese como el mineral sulfatado se introduce entre los carbonatos de hierro, mientras que con la roca encajante da un frente bastante neto. 'Tajo Rico', $3^{a}$ Planta sector PSA. C: Cuerpo brechoide de aspecto terroso con sulfuros diseminados. 'Tajo Clemente', $3^{\mathrm{a}}$ Planta sector PSA. D: Brecha con matriz de aspecto terroso y estructura "varvada" en las dolomías ocres. $2^{\mathrm{a}}$ Planta sector PSA.

Figure 25. A: Syntaxial symmetrical growths of fibrous celestine in a NE-SW vein at the edge of the mineralization of the QTP-2 stope, QTP sector. B: Celestine replacing carbonate rocks on the boundry of a body of iron carbonates. Observe how the sulphate mineral has got in between the iron carbonates, whilst with the barren host rock it makes quite a net front. 'Tajo Rico', 3rd level PSA sector. C: Breccioid body of earthy appearance with scattered sulphurs. 'Tajo Clemente', $3^{\text {rd }}$ level PSA sector. D: Breccia with matrix of earthy appearance and varved structure in the ochre dolostones. $2^{\text {nd }}$ level, PSA sector. 
sas terrosas de óxidos de hierro, costras y pátinas que recubren los cristales de yeso, o que son englobados en ellos como inclusiones sólidas siguiendo planos de crecimiento. Sirva de ejemplo las grandes grietas con cristales de la pared occidental de la cámara principal QTP-2 (ver Fig. 15D). Otra estructura reseñable de este tipo es la que hay en la galería de acceso a otras cámaras de la $1^{\text {a }}$ planta (Fig. 27A) en QTP, que también presenta costras de óxidos de hierro. Estas oquedades no están rellenas en su totalidad, encontrándose los cristales idiomorfos de yeso bien tapizando las paredes de la cavidad por cristales de menos de $10 \mathrm{~cm}$, o bien como cristales grandes aislados de distribución errática. Las estructuras más pequeñas de este tipo no suelen tener óxidos de hierro siendo los cristales de gran transparencia pero tamaño pequeño. Algunas de estas grietas menores aparecen rellenas de yeso fibroso, con las fibras en la dirección de extensión, indicando en este caso un relleno contemporáneo a su apertura (Fig. 27B).

En las fracturas de fuerte buzamiento aparece el yeso como relleno central sobre la mineralización de barita y celestina. Las grandes placas cristalinas de yeso transparente crecen sobre los bandeados simétricos de celestina, incluyendo dentro de ellos las fibras (Fig. 27C y 27D). Lo normal es que estos rellenos sean completos pero cuando no es así se forman grandes cristales que pueden alcanzar varios decímetros en cavidades con formas oblatas (Fig. 27E y 27F).

Las geodas en huecos de disolución van asociadas a los cuerpos brechoides terrosos con sulfuros. Tienen formas irregulares y tamaños entre unos decímetros y varios metros. Los rellenos suelen ser parciales con cristales de yeso de gran transparencia, algunos con bandas de crecimiento marcadas por inclusiones sólidas. La celestina, limitada a ciertas partes de las paredes del hueco geódico, está presente en algunas cavidades y, como en los casos anteriores, el yeso cristaliza sobre ella.

Entre todas las geodas destaca la del 'Tajo Clemente', en la pared occidental de la explotación del subnivel -59 , que ha sido la que ha dado fama a la Mina Rica. Se trata de un relleno parcial en una cavidad de disolución de unos $25 \mathrm{~m}^{3}$, de forma elipsoidal, alargada en sentido norte, con unos $9 \mathrm{~m}$ de largo, $4 \mathrm{~m}$ ancho y $2 \mathrm{~m}$ de alto (medidas de la cavidad). Se encontró prácticamente completa, ya que solo su extremo suroccidental era el que aparecía expuesto en la pared de la cámara de explotación (Fig. 28A). El relleno de yeso selenítico ocupa menos del $50 \%$ del hueco original, dejando las paredes cubiertas casi completamente de grandes cristales. Se halla en el límite meridional de la banda de "dolomía ocre", donde también está presente la brecha de falla con rellenos de celestina de su contacto de techo. Muy probablemente por debajo de la geoda se encuentre una brecha heterolítica, ya que fuera de ella aparece ésta bajo una banda de carbonato de hierro de unos decímetros de anchura (Fig. 28A). El extremo meridional de la geoda se encuentra a poco más de 1 metro de la falla que limita el lentejón tectónico de 'Por Si Acaso' por el Sur (ver Fig. 20).

En la geoda se puede reconocer la roca de caja en paredes y techo, tanto en algunos espacios sin cubrir por cristales como a través de ellos por su gran transparencia. Ello permite ver que su crecimiento se da mayoritariamente de forma directa sobre una dolomía que muestra superficies rugosas deleznables (Fig. 28B). No obstante hay una parte de la pared oeste que estaba previamente cubierta de celestina fibrosa sobre la que han crecido algunos cristales de yeso (Fig. 28C). Dentro de la geoda hay también evidencias de caída de fragmentos de roca caja que han quedado atrapados por los cristales del suelo de la geoda.

El hueco inicial de la geoda debió formarse por disolución a favor de una zona de fracturación. La existencia en la pared oeste de cristales de celestina sobre los que crecen los de yeso, indica que la formación de la cavidad y la cristalización de la selenita son dos episodios completamente distintos y separados en el tiempo. La densidad de nucleación fue muy baja, puesto que los cristales crecen durante bastante tiempo sin competir por el espacio, colisionando entre ellos a una distancia de varios centímetros de la pared sobre la que nuclearon. El crecimiento de los cristales se produjo mientras que la fractura estaba abierta, pero el flujo de agua debió de ser lento, en régimen laminar o difusivo, de modo que impidiera arrastrar grandes partículas sólidas en suspensión, ya que los cristales son extremadamente transparentes y en su mayoría carecen de inclusiones sólidas. Cuando las tienen, suelen ser de carbonatos y/u óxidos, y de un tamaño por debajo de la centena de micras. Por lo tanto, el transporte debió realizarse a través de la porosidad de la roca caja y de pequeñas fracturas que se irían cerrando a medida que se iban cristalizando. Ese transporte de disolución permitió mantener una pequeñísima pero constante sobresaturación en el interior de la geoda, suficiente para que en un tiempo aun por delimitar con mayor precisión, pudieran cristalizar los casi once metros cúbicos de yeso que contiene la cavidad.

Evidencias de disolución se observan en otros puntos de la unidad "dolomías ocres" (Fig. 26E y 26F), sobre todo en el contacto de techo fallado y brechificado que se extiende desde la zona de la gran geoda hacia el NE hasta el otro extremo del lentejón tectónico. La fractura que delimita este contacto presenta otros reIlenos de yeso selenítico espectaculares (Fig. 27F). La 

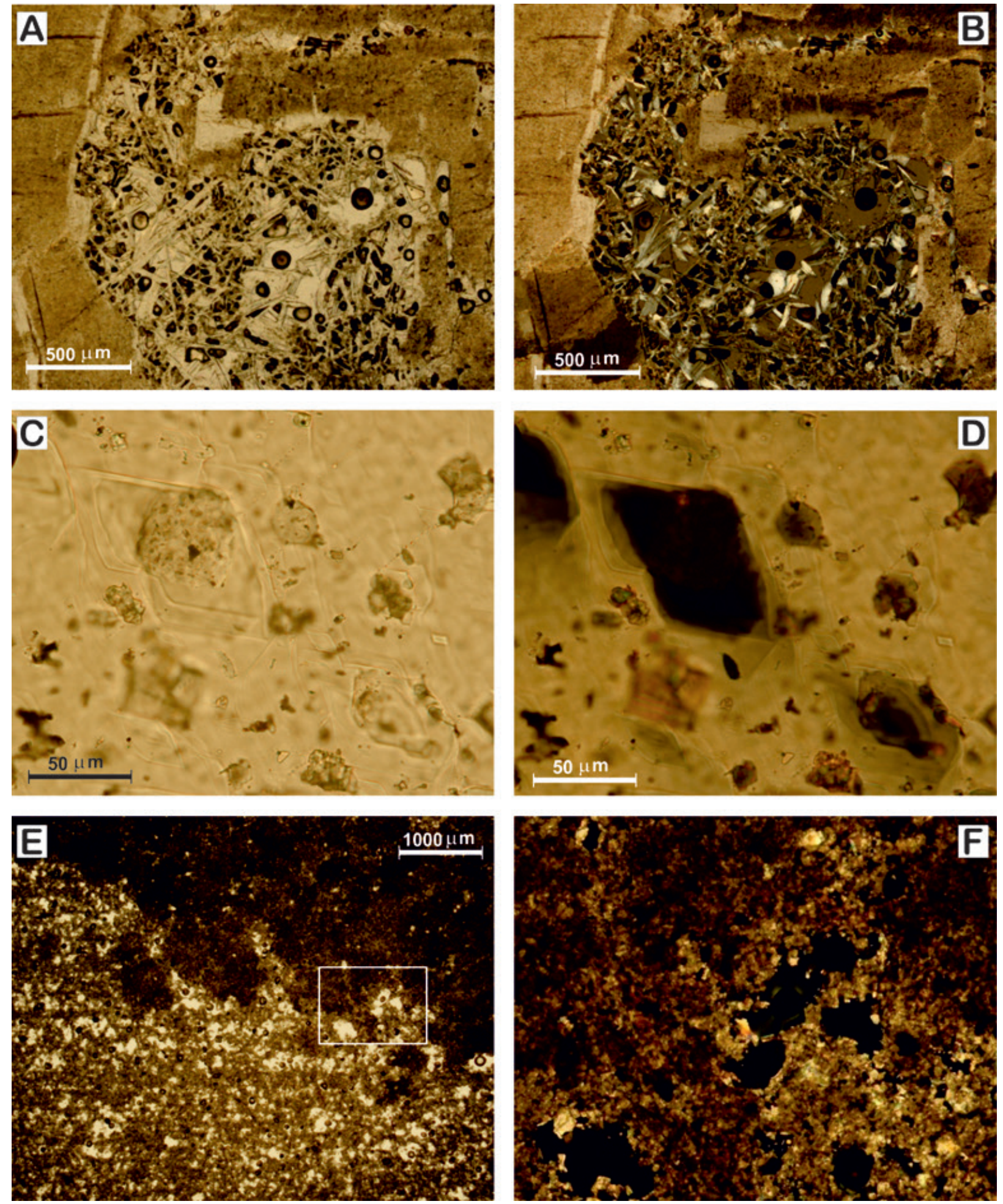

Figura 26. A: Cristales aciculares de celestina (Cls) de algunos centenares de micras reemplazando cristales zonados de ankerita (Ank) de varios milimetros. Entre los cristales de celestina hay porosidad NP. B: La misma zona que A en NC. C: Detalle de las inclusiones sólidas de carbonato en una banda de crecimiento de un cristal de yeso selenítico. NP. D: La misma zona que C en NC. E: Porosidad en la unidad de dolomías ocres debido a la disolución. NP. F: Detalle de la imagen E en NC.

Figure 26. A: Acicular celestine crystals (Cls) of some hundreds of microns replacing zoned ankerite crystals of several millimetres. Among the celestine crystals there is porosity NP. B: The same zone as A in NC. C: Detail of the solid inclusions of carbonate in a growth band of a selenite gypsum crystal. NP. D: The same zone as C in NC. E: Porosity in the unit of ochre dolostones due to dissolution. NP. F: Detail of image $E$ in NC. 

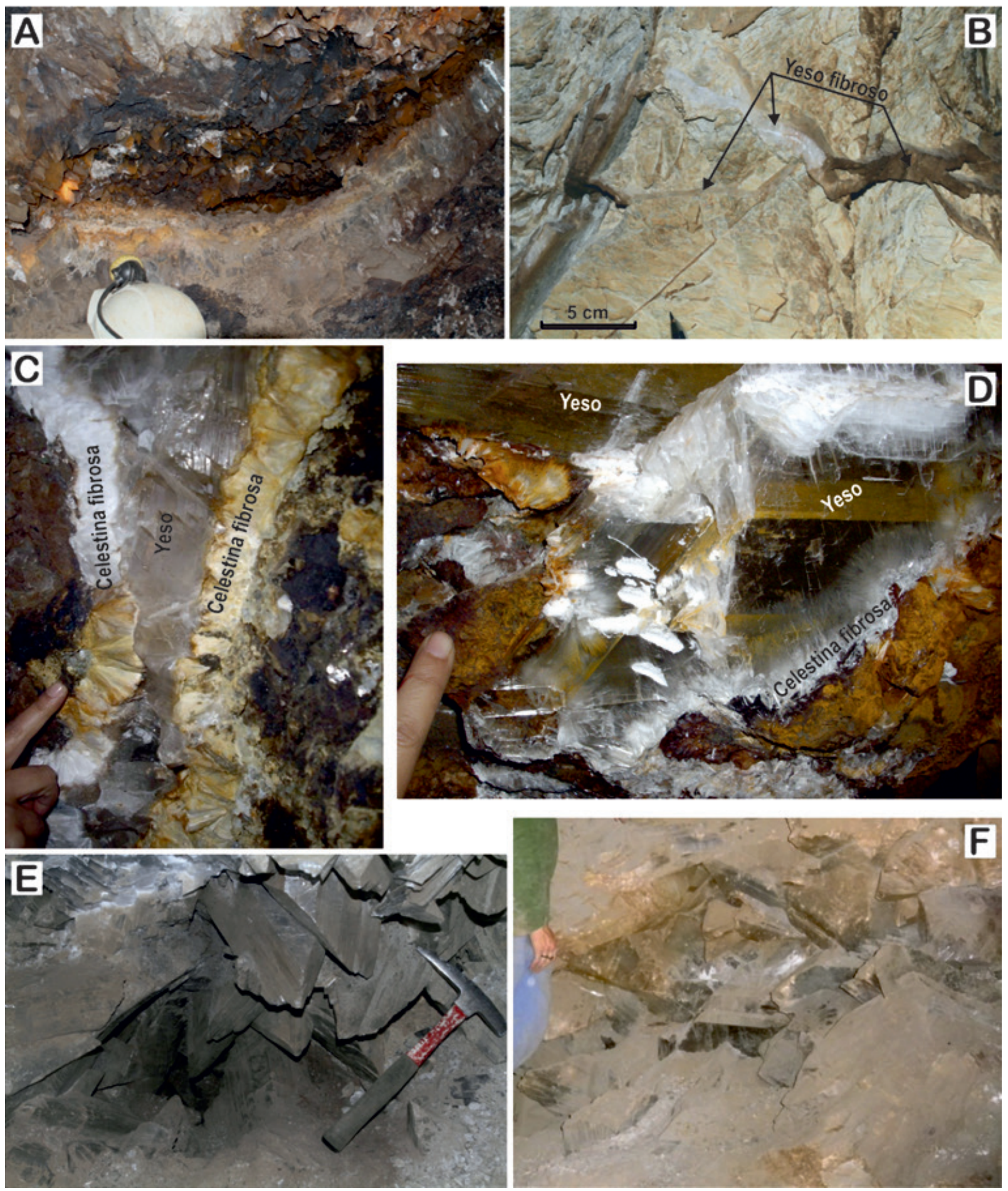

Figura 27. A: Geoda de cristales de selenita en una fractura tensional de buzamiento tendido. Galería de acceso a la $1^{\mathrm{a}}$ cámara desde el socavón general de transporte de $1^{\text {a }}$ Planta, sector de PSA. B: Grieta tensional con yeso fibroso en las margofilitas del socavón general de transporte de $1^{\text {a }}$ planta. Sector QTP. C: Relleno filoniano de celestina y yeso selenítico en una fractura subvertical en el hastial suroriental de la cámara QTP-2. D: Cristales de yeso selenítico englobando cristales aciculares de celestina en una fractura con estructura brechoide en la cámara QTP-2, sector QTP. E: Hueco geódico con grandes cristales de selenita en la falla del borde oriental del 'Tajo Rico', Planta $3^{\mathrm{a}}$ sector de PSA. F: Hueco geódico con grandes cristales de selenita en la falla límite de techo de la dolomía ocre, Planta $2^{\mathrm{a}}$, sector PSA.

Figure 2. A: Geode of selenite crystals in a low dip tensional fracture. Cross-cut tunnel to access the first stope in the PSA sector from the general transport adit, (level-15). B: Tensional crack with fibrous gypsum infilling hosted in the marl-phyllites, general transport adit (level-15), QTP sector. C: Celestine and selenite gypsum filling a subvertical fracture in the south-eastern side wall of the QTP-2 stope. D: Selenite gypsum crystals including acicular celestine crystals in a fracture with brecciated structure in the QTP-2 stope, QTP sector. E: Geodic cavity with large selenite crystals in the fault of the eastern edge of the 'Tajo Rico', $3^{\text {rd }}$ Level, PSA sector. F: Geodic cavity with large selenite crystals in the hanging wall fault of the ochre dolostone, $2^{\text {nd }}$ Level, PSA sector. 
estructura es de carácter tensional y las brechas que alberga y los rellenos parciales por la fase sulfatada, reflejan que ha sido una zona de elevada permeabilidad.

A partir de datos texturales, de inclusiones fluidas e isotópicos, Canals et al. (2019) proponen un doble mecanismo para explicar la formación de los rellenos de yeso selenítico. Así, el reemplazamiento isovolumétrico de anhidrita por yeso aportaría calcio y sulfato a la solución, de manera constante. Además, un proceso de recristalización (maduración de Ostwald) aumentado/mejorado por fluctuaciones térmicas climáticas, facilitaría la disolución de los cristales de yeso más pequeños, también aportando calcio y sulfato a la disolución. Todo ello permitiría el crecimiento constante de los cristales de yeso a temperaturas de $20 \pm$ $5^{\circ} \mathrm{C}$ a una baja tasa de saturación. Respecto a la edad de los grandes cristales, si la calcita sobre cristales de yeso tiene una edad de 60.000 años (Canals et al, 2019), estos se habrían formado entre los $3,5 \mathrm{Ma}$ y los 60.000 años. Como los cristales de yeso no muestran señales deformativas, ni varios pulsos de crecimiento, su formación muy probablemente debió ocurrir después de los últimos pulsos de elevación, en el límite Terciario-Cuaternario hace unos $2 \mathrm{Ma}$.

En el yacimiento existen otros huecos de disolución de grandes dimensiones como son los formados en los yesos microcristalinos, pero estos aparecen ocupados por las brechas heterolíticas de colapso dejando apenas espacio abierto para permitir el crecimiento de cristales. A pesar de ello hay algunas evidencias de cristalización en algunos espacios que han quedado, como los agregados de cristales de yeso selenítico que hay junto al Pozo Carrasco en la primera planta de la mina (ver Fig. 11D).

\section{Secuencia paragenética}

Establecer la secuencia temporal de las fases minerales presentes en la Mina Rica es complejo, no tanto por el número de fases sino por la superposición de eventos que entremezclan los distintos tipos de mineralización. Además, algunos sulfuros precipitan repetidamente en distintos eventos y se hace difícil establecer, a visu y al microscopio, a cuál de ellos pertenecen. La secuencia paragenética general que se presenta en la Figura 29 se ha realizado a partir de los trabajos en la mina, la cartografía geológica de las labores mineras, el estudio estructural, la petrografía y mineralogía de los materiales. En conjunto se definen 5 episodios de mineralización caracterizados por los carbonatos de hierro el primero, por el sulfato de bario el segundo, el sulfato de estroncio el tercero, el sulfato de calcio el cuarto, y la mineralización supergénica el quinto. Junto a ellos aparecen diversos sulfuros que, aunque suponen una mínima cantidad respecto al resto, tuvieron un indudable interés económico.

La etapa de mineralización de hierro y de las baritas comparten similitudes con las mineralizaciones de Sierra de Almagrera y Herrerías (Martínez Frías, 1993; Morales Ruano et al., 1993; Dyja et al., 2015). A partir de la composición isotópica del plomo de las galenas de la Sierra del Aguilón y de Sierra de Almagrera, Arribas y Tosdal (1994) vincularon estos depósitos a la actividad volcánica del Mioceno. De acuerdo con Canals et al. (2019) los datos isotópicos de la baritina son compatibles con una fuente mixta de sulfato procedente de las evaporitas del Triásico y del sulfato marino Terciario o de evaporitas Terciarias. Estos mismos autores indican que la distribución multimodal de la temperatura de homogenización en las baritas de Mina Rica no permite establecer con precisión la temperatura de formación de este mineral, si bien esta se estima que fue por encima de los $100^{\circ} \mathrm{C}$. El dominio de inclusiones monofásicas en las celestinas, indican condiciones de formación de menor temperatura $\left(<70^{\circ} \mathrm{C}\right)$ para esta etapa de mineralización y un predominio de la fuente del sulfato Terciario.

En la secuencia paragenética de la Mina Rica, la primera mineralización estratoligada con carbonatos de hierro fosiliza la deformación Serravaliense. Es muy probable que el metasomatismo ferroso se produjera principalmente a favor de los rejuegos ya en el Tortoniense de las fracturas longitudinales a la estratificación dentro de los lentejones tectónicos. Junto con los carbonatos de hierro existe una mineralización de galena y sulfosales que se formó en los primeros estadios, y que aparece también entremezclada entre los carbonatos de hierro. En esta etapa también se ha encontrado anhidrita, pero la escasez de ejemplares impide una concreta situación temporal.

La mineralización de barita se asocia claramente a los rejuegos Tortonienses de la zona, con la re-apertura de fracturas ya existentes y la formación de algunas nuevas en rocas competentes. Junto con el sulfato de bario se formó una mineralización rica en bournonita y algo de galena. Probablemente con los rejuegos Messinienses se formó la celestina. Este sulfato sustituye al de bario e incluso lo reemplaza en gran medida. Con esta mineralización aparecen la marcasita, como sulfuro más importante, y la esfalerita.

El yeso, que cristalizó en condiciones de baja temperatura, es la última fase sulfatada en formarse y lo hace con posterioridad a los rejuegos verticales Pliocenos. En la secuencia también se distingue una alteración supergénica sobre la mineralización de carbonatos de hierro, que fue objeto de explotación a cielo 

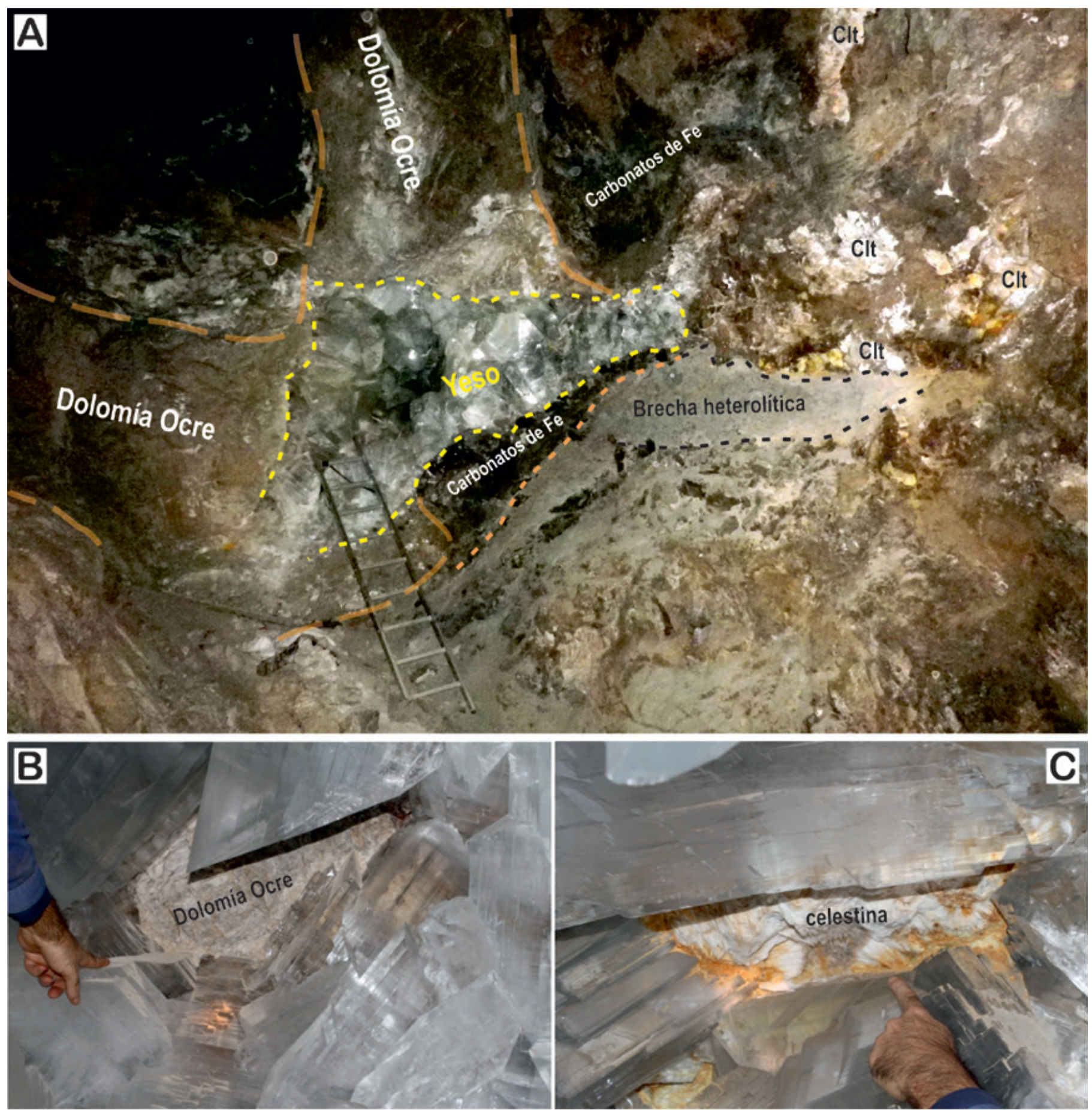

Figura 28. A: Parte exterior y entrada a la 'Gran Geoda' de yeso selenitico de la Mina Rica. Esta exposición corresponde al extremo SW de la cavidad que alberga a la geoda, la cual se extiende hacia la izquierda dentro de la dolomía ocre. El contacto de techo de esta unidad litológica viene indicado por el trazo naranja en la foto y queda cortado al bies por la pared de la cámara de explotación del nivel-59 de la mina. B: Hastial este de la gran geoda formado por una superficie rugosa de la dolomía ocre. C: Hastial oeste de la gran geoda con agregados fibrosos de celestina sobre los que crecen grandes cristales de yeso selenítico.

Figure 28. A: External part and entrance to the geode of selenite of the "Mina Rica". This exposure corresponds to the SW end of the cavity that contains the geode, which extends to the left inside the ochre dolostone. The hanging wall contact of this lithological unit is marked by an ochre line in the photo and is cut on the bias by the wall of the stope at level -59 of the mine. B: East side wall of the large geode formed by a rough surface of the orange dolostone. C: West side wall of the large geode with fibrous celestine aggregates on which big crystals of selenite gypsum have grown. 


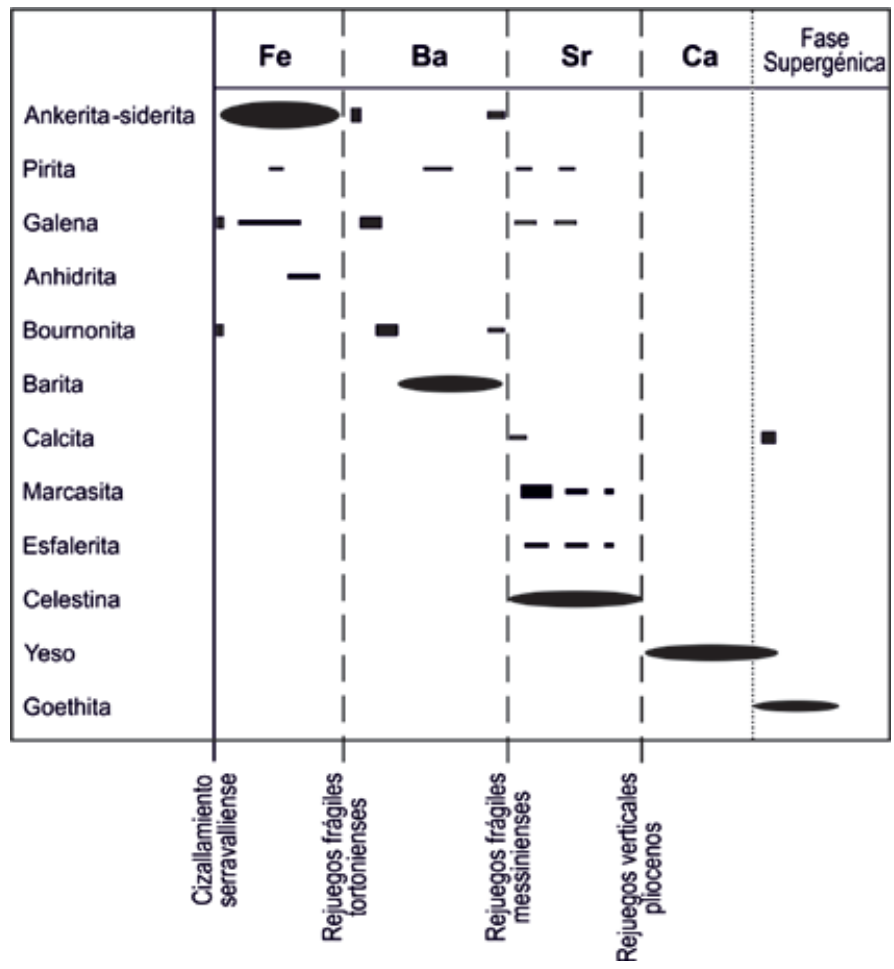

Figura 29. Secuencia paragenética del yacimiento de la Mina Rica. Figure 29. Paragenetic sequence of the "Mina Rica" deposit.

abierto. Se trata de una mineralización de oxi-hidróxidos de hierro, que se desarrolló junto al crecimiento de los últimos cristales de yeso.

\section{Conclusiones}

El yacimiento de la Mina Rica de Pulpí es un excelente ejemplo de la metalogenia del SE peninsular en especial del tipo mantos y filones de $\mathrm{Pb}-\mathrm{Zn}-\mathrm{Fe}-\mathrm{Ag}$ (Ba-Cu-Sn-Sb) encajados en rocas triásicas diferenciados por Arribas y Tosdal (1994). La paragénesis del yacimiento es compleja con superposición espacial de procesos mineralizantes. La mineralización volumétricamente más importante es la de reemplazamientos estratoligados de carbonatos de hierro, (ankerita principalmente) formada en condiciones post-cinemáticas. Este conjunto mineral encajaría en el grupo de yacimientos filonianos de $\mathrm{Fe}-\mathrm{Ba}-\mathrm{Pb}-\mathrm{Zn}$-Ag que aparecen en la parte oriental del complejo Nevado-Filabride (Molina y Ruiz-Montes, 1993), con la salvedad de que se trata de cuerpos estratoides, a la que hay que añadir las mineralizaciones de estroncio y yeso, propias del complejo Alpujárride y de las cuencas post-mantos.

Las óptimas condiciones de observación en las galerías de la Mina Rica, que ponen a la vista excelentes exposiciones de las estructuras geológicas, nos han permitido realizar un detallado estudio estructural sobre su formación. Su compleja paragénesis es el resultado de al menos cinco eventos de mineralización superpuestos, que se encuentran en otros yacimientos de las Cordilleras Béticas de forma individualizada o superpuestas en no más de un par de tipos de mineralizaciones. El caso más parecido sería el de Las Herrerías en Cuevas de Almanzora (Almería), donde se encuentran las mineralizaciones de hierro, barita y sulfuros argéntíferos, pero donde falta la de celestina.

Los resultados de nuestra investigación permiten concluir que la mineralización de hierro carbonatada de la Mina Rica de Pulpí se formó con posterioridad al evento principal de deformación de la zona, el que dio lugar a la banda de cizalla dextral atribuible a la tectónica Serravalliense (Sanz de Galdeano, 1990). La presencia de fallas NW-SE con rejuegos, que contienen brechas mineralizadas de carbonatos de hierro, así como la tendencia a mantener esa orientación los espacios abiertos en ellos, sugiere que la mineralización ferruginosa pudo darse a favor de la reactivación Tortoniense.

La mineralización sulfatada de barita parece controlada por la misma estructura que la carbonatada, por lo que podría haberse formado en momentos tardíos de la reactivación Tortoniense. Como se ha indicado en el contexto geológico regional, durante ese periodo ocurrió un cambio progresivo del campo de esfuerzos de NW-SE a NNE-SSW (Sanz de Galdeano, 1990; Huibregtse et al., 1998; Coppier et al., 1989), con una componente extensional sobre las estructuras de rumbo entre NW-SE y N-S. La reactivación Messiniense, sin embargo, también haría jugar las mismas fracturas como tensionales controlando la mineralización de celestina. Finalmente, hay evidencias de un episodio extensional de edad tardi-Messiniense, Plioceno o incluso Pleistoceno, al que debe asociarse la formación del yeso de las geodas. Todo ello es coincidente con lo encontrado en el análisis estructural del yacimiento, donde la fracturación responde a un régimen compresivo generado por un acortamiento ENE-WSW propio del Serravaliense. No obstante, las mineralizaciones aparecen controladas espacialmente por los sistemas que han tenido reactivaciones tensionales en los acortamientos más norteados del Tortoniense y Messiniense. La fracturación tardía en forma de estructuras de buzamiento tendido encaja con los movimientos verticales ocurridos en el Plioceno y ya en el cuaternario. La geoda se habría formado entre los 60.000 y dos millones de años, que sería la edad de los últimos movimientos de elevación.

Nuestro estudio también pone de manifiesto que la Mina Rica ofrece una inusual riqueza didáctica que debiera ser aprovechada para convertirla en un centro 
de interpretación geológica y minera en el ámbito de la enseñanza secundaria y universitaria. La reciente rehabilitación de la Mina Rica-basada en gran medida en la cartografía y la geología aportada en este trabajo-y su apertura al público para visitar la 'Gran Geoda', facilita el aprovechamiento de esta instalación para un uso didáctico más allá del propiamente turístico. De esta manera, esperamos que este estudio de la Mina Rica contribuya a mejorar la puesta en valor del patrimonio geológico y minero de nuestro pais.

\section{Agradecimientos}

Este trabajo ha recibido financiación del Ministerio de Educación y Ciencia [MEC] a través de los proyectos CGL2010-16882; CGL2010-12099-E, y CGL201678971-P. Agradecemos el apoyo logístico y técnico de Francisca Espinosa Pérez, Raquel Fernández Penas y Magí Baselga, así como al Dr. Cristóbal Verdugo-Escamilla por su ayuda con los análisis de difracción de Rayos X. Los autores agradecen las sugerencias y cometarios de dos de los revisores del trabajo, el Dr. Francisco Velasco y el Dr. Gabriel Ruiz de Almodóvar. Agradecemos igualmente las facilidades concedidas por el ayuntamiento de Pulpí para la realización de este estudio y la Junta de Andalucía por su ayuda en el marco del Proyecto de Excelencia RNM 5384.

\section{Referencias}

Aguirre, J. 1998. El Plioceno del SE de la Península Ibérica (provincia de Almería). Síntesis estratigráfica, sedimentaria, bioestratigráfica y paleogeográfica. Revista de Sociedad Geológica de España, 11 (3), 297-315.

Álvarez, F. 1987, La Tectónica de la Zona Bética en la región de Águilas. Tesis Doctotal, Universidad de Salamanca, 371 págs.

Álvarez, F. and Aldaya, F. 1985. Las unidades de la Zona Bética en la región de Águilas-Mazarrón (Prov. de Murcia). Estudios geológicos, 41 (3-4), 139-146.

Álvarez, F., Aldaya, F. and Navarro-Vilá, F. 1989. Miocene extensional deformations in the región of Águilas-Mazarrón (Eastern Betic Cordilleras). Estudios geológicos, 45 (5-6), 369-374.

Arribas, A. and Tosdal, R.M. 1994. Isotopic Composition of $\mathrm{Pb}$ in Ore Deposits of the Betic Cordillera, Spain: Origin and Relationship to Other European Deposits. Economic Geology, 89, 1074-1093.

Banda, E. and Ansorge, J. 1980. Crustal structure under the central and eastern part of the Betic Cordillera. Geophysical Journal International, 63 (2), 515-532.

Bellido Mulas, Fy Brändle Matesanz, J.L. 2008. Vulcanismo Ultrapotásico Neogeno. En Contextos Geológicos Espa- ñoles, García-Cortes, A. ed. Instituto Geológico y Minero de España. Madrid. 139-145.

Boccaletti, M., Gelati, R., López Garrido, A.C., Papani, G., Rodríguez Femández, J. and Sanz de Galdeano, C. 1987. Neogene-Quaternary sedimentary-tectonic evolution of the Betic Cordillera. Acta-Naturalia de "L'Ateneo Parmense" , 23 (4), 179-205.

Canals, A., Van Driessche, A.E.S., Palero, F. and García-Ruiz J.M. (2019). The origin of large gypsum crystals in the Geode of Pulpí (Almería, Spain). Geology, 47 (12), 1161-1165.

Coppier, G., Griveaud, P., de Larouziere, F.D., Montenat, C. and Ott d'Estevou, P. 1989. Example of Neogene tectonic indentation in the Eastern Betic Cordilleras: The Arc of Aguilas (Southeastern Spain). Geodinamica Acta, 3 (1), 37-51.

Dyja, V., Hibsch, C., Tarantola, A., Cathelineau, M., Boiron, M. C., Marignac, C., Bartier, D., Carrillo-Rosúa, J., Morales-Ruano, S. and Boulvais, P. 2015. From deep to shallow fluid reservoirs: evolution of fluid sources during exhumation of the Sierra Almagrera, Betic Cordillera, Spain. Geofluids, 16 (1), 103-128.

Espinosa Godoy, J.S., Martín Vivaldi, J.R., Martín Alafont, J.M. and Pereda, M. 1974. Mapa Geológico de España E.1:50.000, $2^{a}$ serie. Hoja ${ }^{\circ} 997$ (Águilas). Instituto Geológico y Minero de España. Madrid.

Fernández-Leyva, C., Ruiz-Montes, M. y Molina, A.L. 2011. Descripción de las mineralizaciones de las Zonas Internas Béticas. En Cartografía de recursos minerales de Andalucía (A.García-Cortés, Ed. Ppal.). IGME-Consejería de Economía, Innovación y Ciencia de la Junta de Andalucía. Madrid. 190-212.

García-Guinea, J., Morales, S., Delgado, A., Recio, C. and Calaforra, J.M. 2002. Formation of gigantic gypsum crystals. Journal of the Geological Society, 159 (4), 347-350.

Garcia-Ruiz, J.M., Villasuso, R., Ayora, C., Canals, A., and Otarola, F. 2007. Formation of natural gypsum megacrystals in Naica. Geology, 35 (4), 327-330.

García-Ruiz, J.M. (2006). Corazón de cristal. Bajo el desierto mexicano de Chihuahua. National Geographic España, (Noviembre 2006), 64-83.

García-Ruiz, J.M. Canals, A. and Ayora, C. (2008). Gypsum Megacrystals. Mcgraw-HillYearbook of Science andTechnology, 154-156.

Giménez, J., Suriñach, E. and Goula, X. 2000. Quantification of vertical movements in the Eastern Betics (Spain) by comparing levellin data. Tectonophysics, 317 (3-4), 237-258.

Harding, T.P. 1974. Petroleum traps associated with wrench faults. American Association of Petroleum Geologists Bulletin, 58 (7), 1290-1304.

Huibregtse, P. van Alebeek, H. Zaal, M. and Biermann, C. 1998. Palaeostress analysis of the northern Nijar and southern Vera basins: constraints for the Neogene displacement history of major strike-slip faults in the Betic Cordilleras, SE Spain. Tectonophysics, 300 (1-4), 79-101. 
Logan, J.M. Friedman, M. Higgs, N. Dengo, C. and Shimamoto, T. 1979. Experimental studies of simulated gouge and their application to studies of natural fault zones. In: Proceedings of Conference VIII-analysis of actual fault zones in bedrock. 305-343.

Lustrino, M., Duggen, S. and Rosenberg, C.L. 2011. The central-western Mediterranean: anomalous igneous activity in an anomalous collisional setting. Earth-Sciences Review, 104 (1-3), 1-40.

Manteca Martínez, J.I., Pérez de Perceval, M. A. López-Morell, M.A. 2005. La Industria Minera en Murcia durante la época contemporánea. Bocamina. Patrimonio Minero de la Región de Murcia. Edit. Ayuntamiento de Murcia. Museo de la Ciencia y el Agua. Murcia. 119-129.

Martín, J. M. Braga, J. C. and Betzler, C. 2003. Late Neogene-Recent uplift of the Cabo de Gata volcanic province, Almería, SE Spain. Geomorphology, 50 (1), 27-42.

Martin-Rojas, I., Somma, R., Estévez, A., Delgado, F., and Zamparelli, V., 2014, La plataforma Triásica Alpujárride (Zonas internas de la cordillera Bética, España). Revista de la Sociedad Geológica de España, 27, 63-78.

Martínez Frías, J. 1993. The Fe-Mn-Ag deposist of Las Herrerias. Proceedings Second Biennial SGA Meeting, Granada, Field Trip guide, 45-48.

Molina-Molina, A. y Ruiz-Montes, M. 1993. Las mineralizaciones filonianas del Complejo Nevado-Filábride (Cordilleras Béticas, España). Boletín Geológico y Minero, 104-(6), 621-639.

Montenat, C. Ott d'Estevou, P. and Masse, P. 1987. Tectonic-sedimentary characters of the Betic Neogene basins evolving in a crustal transcurrent shear zone (SE Spain). Bulletin des centres de recherches exploration-Production Elf-Aquitaine, 11 (1), 1-22.

Morales Ruano, S., Both, R. A. and Fenoll Hach-Ali, P. 1993. Paragenesis and regional zoning of the polymetallic ore deposits in the Aguilas and Sierra Almagrera-Herrerias areas, Southeastern Spain. Proceedings Second Biennial SGA Meeting, Granada, 171-174.

Morales Ruano, S., Both, R. A. and Fenoll Hach-Ali, P. 1995. Fluid evolution and mineral deposition in the Aguilas-Sierra Almagrera base metal ores, southeastern Spain. Third Biennial SGA Meeting: Mineral Deposits: from Their Origin to Their Environmental Impacts, Prague, 365-368.
Otalora, F. and Garcia-Ruiz J.M. 2014. Nucleation and growth of the Naica giant gypsum crystals. Chemical Society Reviews, 43 (7), 2013-2026.

Palero, F.J. Gómez, F. and Cuesta, J.M. 2000. Pilar de Jaravía. La Geoda Gigante de la Mina Rica. Bocamina, 6, 54-67.

Sánchez Valverde, J., Feixas, C., García-Cortés, A. y Boixereu, E. 2011. Descripción de las mineralizaciones de las Zonas Externas Béticas y de las Cuencas Neógenas. En Cartografía de recursos minerales de Andalucía (A.García-Cortés, Ed. Ppal.). IGME-Consejería de Economía, Innovación y Ciencia de la Junta de Andalucía. Madrid. 212-235.

Sanz de Galdeano, C. 1983. Los accidentes y fracturas principales de las Cordilleras Béticas. Estudios Geológicos, 39 (3-4), 157-165.

Sanz de Galdeano, C. 1987. Strike-slip faults in the southern border of the Vera basin (Almería, Betic Cordilleras). Estudios Geológicos, 43 (5-6), 434-443.

Sanz de Galdeano, C. 1990. Geologic evolution of the Betic Cordilleras in the Western Mediterranean, Miocene to the present. Tectonophysics, 172 (1-2), 107-119.

Silva, P.G. Goy, J.L. Somoza, L. Zazo, C. and Bardají, T. 1993. Landscape response to strike-slip faulting linked to coIlisional settings: Quaternary tectonics and basin formation in the Eastern Betics, southeastern Spain. Tectonophysics, 224 (4), 289-303.

Torres Roldán, R.L. 1979. The tectonic subdivision of the Betic Zone (Southern Spain): Its significance and one possible geotectonic scenario for the Westernmost Alpine Belt. American Journal Science 279 (1) 19-51.

Torres Ruiz, J. 2006. Geochemical Constraints on the Genesis of the Marquesado Iron Ore Deposits, Betic Cordillera, Spain: REE, C, O, and Sr Isotope Data. Economic Geology, 101, 667-677.

Van Driessche, A.E., García-Ruiz, J.M., Tsukamoto, K., Patiño, L.D., and Satoh, H. 2011. Ultra slow growth rates of giant gypsum crystals. Proceedings of the National Academy of Sciences USA, 108, 15723-15728.

Whitney, D. L. and Evans, B. W. 2010. Abbreviations for names of rock-forming minerals. American mineralogist, 95 (1), 185-187.

Recibido: julio 2020

Revisado: noviembre 2020

Aceptado: diciembre 2020

Publicado: marzo 2021 